\title{
SAME SEX RELATIONS, STATE CRIME AND RESISTANCE
}

\author{
By \\ Cara Fleur Stone Gledhill
}

A thesis submitted in fulfilment of the requirements for the degree of Master of Arts in Criminology

School of Social and Cultural Studies

Victoria University of Wellington

July, 2013 


\begin{abstract}
This thesis explores the criminalisation of same sex relations in a global context, using a framework which centres the state as criminal. It argues that criminalising laws serve as hegemonic dictates, which condone and encourage violence perpetrated by state officials, as well as private individuals. The form of these laws, the punishments they mandate and the harms that lesbian and gay individuals suffer due to the existence of criminalisation is critically examined. The thesis shows that international legal progress in the area of 'sexual rights' has been painstakingly slow and that civil society organisations (CSOs) have been the driving force behind much of the change that has occurred. States have also been able to deny, minimise and neutralise challenges by the UN concerning criminalisation. Jamaica, a state which criminalises consensual sex between men, is provided as a case study in order to examine the ways in which criminalisation laws emerge, and the contemporary social and cultural context which supports their continued existence. Despite the climate of heterosexism in Jamaica, the continued work of CSOs means that information about human rights violations can be dispersed through a number of networks, allowing challenges to take place in the international arena. The thesis concludes by arguing that, while the work of CSOs offers great potential for change in the area, international pressure to repeal criminalising laws and address related human rights violations must continue.
\end{abstract}




\section{Acknowledgements}

First, I would like to thank Boris Dittrich, Jan Logie and the New Zealand Human Rights Commission. Late last year, I was lucky enough to be invited to a meeting in honour of Boris, who is one of the foremost human rights campaigners in this area as an advocacy director for Human Rights Watch. Thank you for sharing your wisdom and passion for the area, thank you Jan Logie for inviting me to the meeting, and thank you to the Human Rights Commission for making me feel so welcome.

Thank you to the ANZSOC conference committee who allowed me to present a chapter of this thesis at the conference in Auckland last year. It was terrifying, but ultimately rewarding.

This thesis would not have been possible without the assistance of an amazing group of people (and cats) around me who somehow managed to keep me on track despite numerous distractions.

I was extremely lucky to have two amazing supervisors. Thanks to Lizzy Stanley for allowing me to do something that is definitely outside the realm of 'mainstream' criminology. Your wide knowledge of state crime research has been very useful. Thank you also for putting up with my chronic self-doubt throughout the course of the last year. Thanks also to my secondary supervisor, Jan Jordan. I saw Jan on a current affairs show many years ago and decided I wanted to do Criminology and wanted her to be my supervisor. Somehow, that ended up happening. Thank you for providing me with much needed reassurance throughout the last year, and for your invaluable feedback.

More generally, it is also great to be in a department where critical thinking is encouraged. In particular, thank you to Charles Sedgwick, perhaps the most well-read person I know, for providing me with advice on some of the more theoretical aspects of this piece of work and for engaging in many political rants with me along the way. I was lucky to have a dedicated team of proofreaders. Thank you to Kellie Hoy, Samantha Keene and Jared Walton for finding all those niggly areas that needed work and providing encouraging feedback.

Finally, thank you to my friends and family for being there for me over the last year, and in many cases longer. In particular, thank you to the three proof-readers named above, as well as Ana, Anna, Bronwyn, Caleb, Jen, Katy, Kirsten, Lara, Laura, Merrin, Toni and Vita. Thank you also to Zoë; not a day goes by that I don't think about you and a photo of you has hung above my desk for the last year. To my parents and my two sisters, thank you for bearing with me on this strange journey, and for putting up with (and for dad, at times encouraging) my political rants. Last, but not least, thanks to my cats for reminding me that life is for relaxing, being alarm clocks and for providing cuddles when I needed them. 


\section{Abbreviations}

AI - Amnesty International

CAT - Convention Against Torture

CEDAW - Convention on the Elimination of all forms of Discrimination Against Women CommEDAW - Committee on the Elimination of Discrimination Against Women

CESCR - Committee on Economic, Social and Cultural Rights

CFRF - Charter of Fundamental Rights and Freedoms

CRC - Convention on the Rights of the Child

CommRC - Committee on the Rights of the Child

CSO - Civil society organisation

DoM - Declaration of Montreal

DSOGI - Declaration on Sexual Orientation and Gender Identity

ECOSOC - Economic and Social Council

HIV/AIDS - Human Immunodeficiency Virus/Acquired Immune Deficiency Syndrome

HRComm - Human Rights Committee (monitors the ICCPR)

HRCoun - Human Rights Council (organ of the OHCHR)

HRW - Human Rights Watch

ICCPR - International Covenant on Civil and Political Rights

ICESCR - International Covenant on Economic, Social and Cultural Rights

ICHRP - International Council on Human Rights Policy

IGLHRC - International Gay and Lesbian Human Rights Commission

ILGA - International Lesbian and Gay Association

J-FLAG - Jamaican Forum for Lesbians, All-Sexuals and Gays

LGBT - Lesbian, Gay, Bisexual and Transgender

OAPA - (Jamaican) Offences Against the Person Act

UDHR - Universal Declaration of Human Rights

UN - United Nations

UNGA - United Nations General Assembly

UNOHCHR - Office of the High Commissioner for Human Rights

UPR - Universal Periodic Review 


\section{CONTENTS}

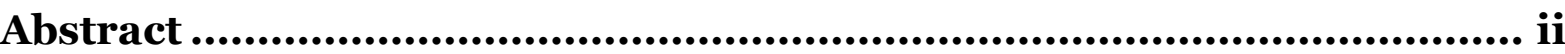

Acknowledgements .................................................................................... iii

Abbreviations .........................................................................................

Chapter One: A critical approach to sexual orientation and state power.. 1

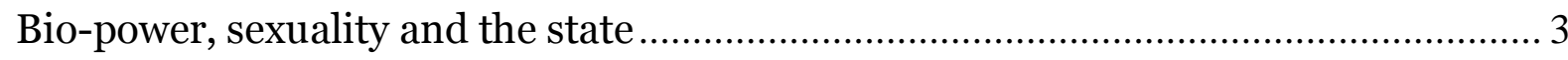

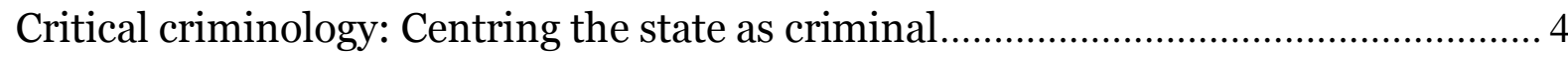

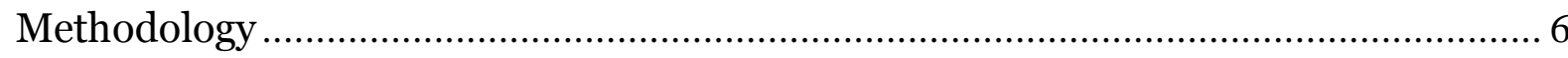

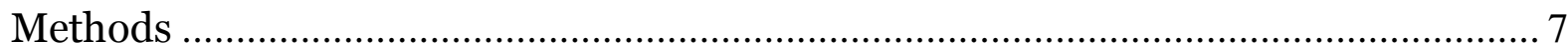

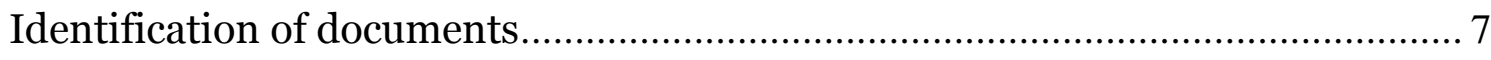

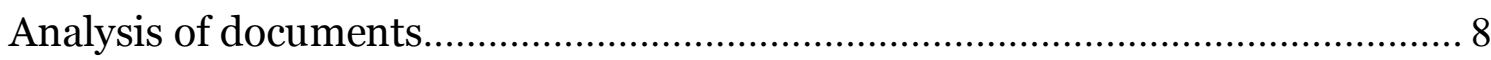

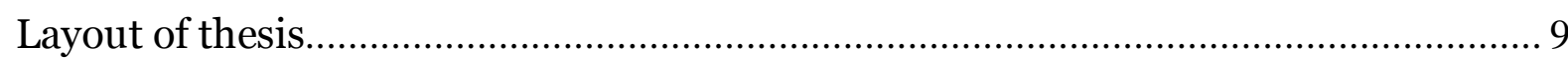

Chapter Two: Locating criminalisation and the power of law..................11

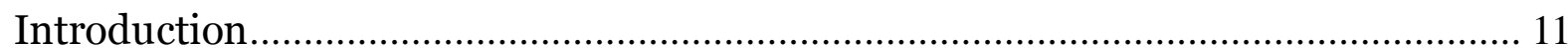

The criminalisation of same sex relations around the world...................................... 12

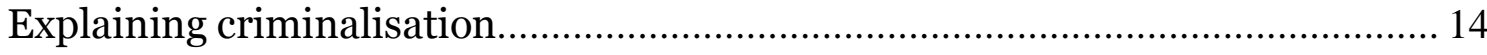

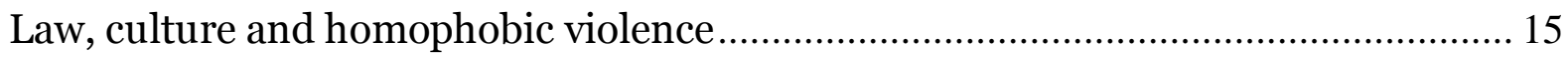

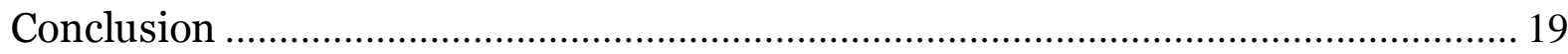

Chapter Three: Criminalisation and state crime................................ 21

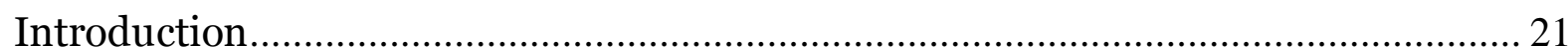

Sexuality in the international arena: Constructing criminalisation as state crime …2 21

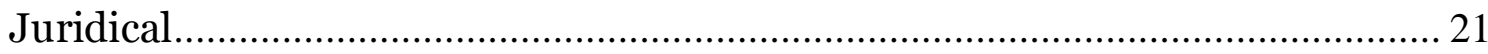

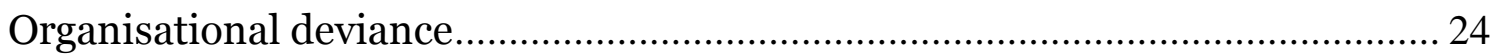

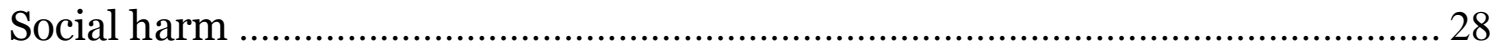

Chapter Four: Civil society and challenges to criminalisation ................34

The normalisation and institutionalisation of human rights norms ......................... 34

Challenges to states through the Universal Periodic Review process........................... 37

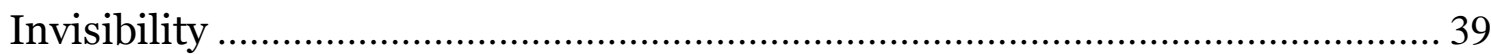

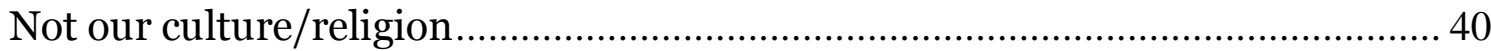

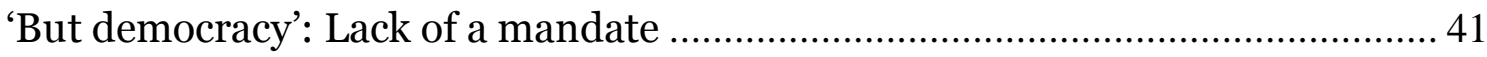

No evidence of discrimination and no prosecutions ............................................. 42

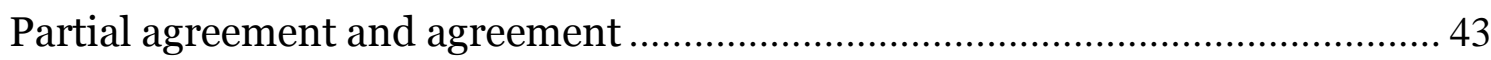

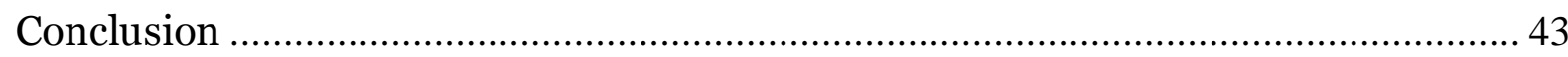

Chapter Five - 'The most homophobic place on Earth?': Jamaica, sexual

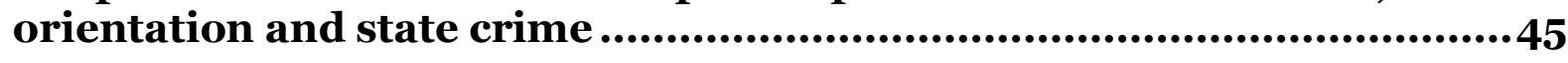

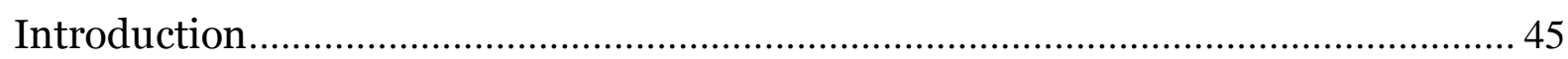

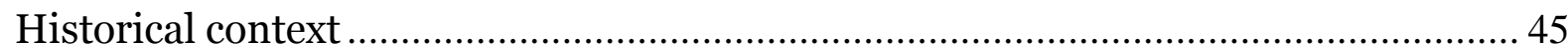

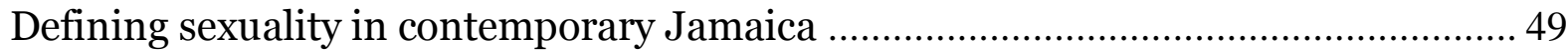


State-sanctioned discrimination and violence .................................................... 54

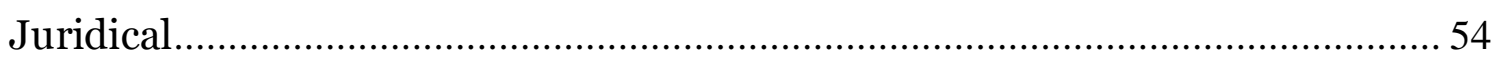

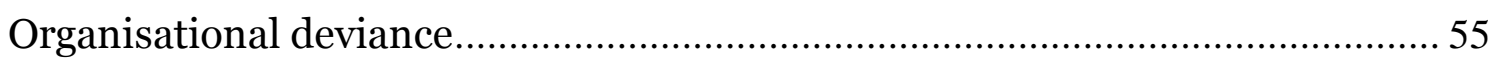

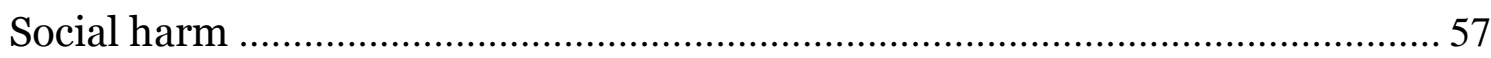

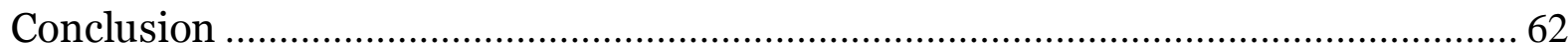

Chapter Six: Resisting criminalisation - the role of civil society and the UN

The role of civil society in challenging Jamaica on human rights............................. 64

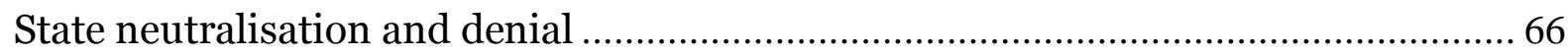

Jamaica and the UN on criminalisation and related phenomena............................ 68

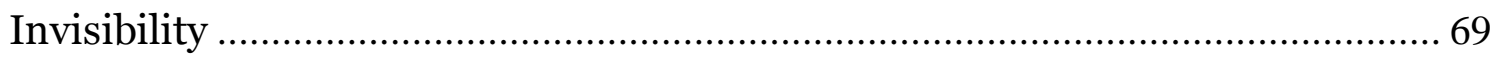

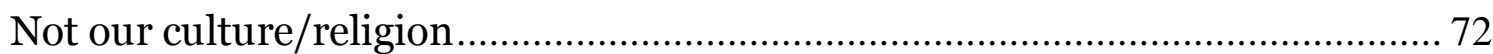

'But democracy' - Lack of a mandate ...................................................................... 73

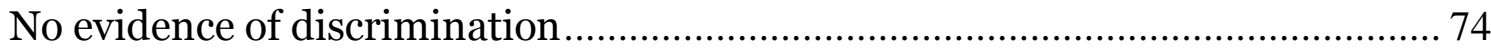

Cases of discrimination are being investigated ............................................. 75

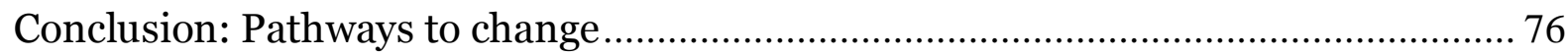

Chapter Seven: Conclusion................................................................78

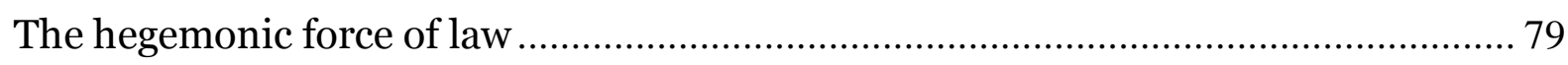

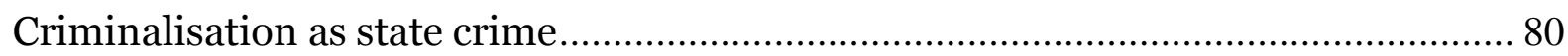

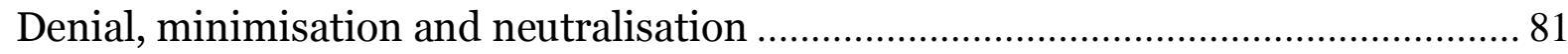

The importance of civil society in resisting state crime ...................................... 82

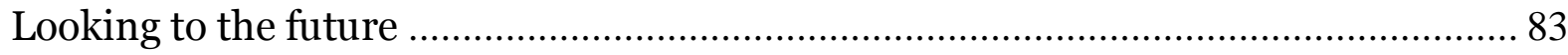

Appendix One: Criminalisation of same sex relations around the world85

References ....................................................................................92 


\section{Chapter One: A critical approach to sexual orientation and state power}

\section{Introduction}

Consensual same sex activities are criminalised in $74^{1}$ states around the world (see Appendix One). In over half of these states, criminalisation processes apply to men and women, but for many the laws apply only to men. Penalties for those found guilty of these offences range from fines, to long prison terms, corporal punishment and, in at least eight states, the death penalty. This thesis aims to unravel the context of sexualitybased discrimination, with regards to the domestic laws of criminalising states, as well as how these laws serve as a backdrop to state-tolerated violence towards homosexual people. The thesis argues that the failure of states to enshrine sexual rights in law constitutes a human rights violation. Furthermore, the failure by states to investigate discrimination and violence towards those suspected of being homosexual is also a failure by states to protect its citizens. This will be explained not just through the frame of international human rights violations, but also with regard to state-led social harm or injury. To this end, Jamaica is used as a case study to examine in more depth the contemporary context of criminalisation and how it is challenged.

Critically, for this research, the definition of 'sexuality' should be clarified. It is a term which is notoriously difficult to define and one which has an incredibly wide scope. For the purposes of this research, sexuality will be used to refer to the inexhaustible range of sexual orientations, usually explained in the binary of 'homo' and 'hetero' (Butler, 2004). Sexuality, as it is to be understood in this research fits well with Foucault's (1976:105-106) definition:

...the name that can be given to a historical construct: not a furtive reality that is difficult to grasp, but a surface network in which the stimulation of bodies, the intensification of pleasures, the incitement to discourse, the formation of special knowledges, the strengthening of controls and resistances, are linked to one another in accordance with a few major strategies of knowledge and power.

In Foucault's (1976) view, modern sexuality has evolved to designate not just who one has sex with, but a whole host of other factors that make up a person's very identity. For example, laws criminalise particular sex acts, but in practice are used to target and

\footnotetext{
${ }_{1}^{1}$ A further six or seven countries arrest, and sometimes prosecute, people for consensual same sex relations under different laws, but because of the complexity of these situations, only states where consensual same sex relations are directly criminalised in legal codes will be covered in this thesis.
} 
devalue a particular 'type' of person, whether or not they engage in these acts. With this in mind, Rubin (1984:285) has argued that "sex acts become burdened with an excess of significance". This idea will be explored further in later chapters.

Sexuality has an uncertain place in international law and human rights frameworks. The fight for international sexual rights has been a long one and it encompasses not only rights to sexual orientation, but also rights to equal employment, custody of children, education and health (Marks \& Clapham, 2005). The founding document of the United Nations (UN), the Universal Declaration of Human Rights (UDHR), does not mention sexuality as a ground of discrimination, but the inclusivity of its wording suggests that sexuality could fit within its scope (UDHR, 1948). Progress towards the recognition of sexuality as a human right has been slow and painstaking. However, the Special Rapporteur on the Right to Health (SRRTH) recently spoke of the criminalisation of same sex relations as producing violence and stigmatisation towards sexual minorities, and as inhibiting their rights to health (Grover, 2010). Despite this commentary, the UN appears reticent to widely acknowledge sexual rights. Introducing sexuality into an international human rights instrument, which would cement its status as a human right, is considered a culturally divisive move with intense resistance coming from several states, as well as transnational religious organisations ${ }^{2}$ (Saiz, 2004). Typically, while states are challenged on criminalisation and violence through a number of UN mechanisms, they have been able to neutralise these complaints in a number of ways.

With these arguments in mind, this thesis aims to explore the following themes:

(1) How the criminalisation of same sex relations can be connected with both state and private violence;

(2) How criminalisation feeds, and is fed by, culture;

(3) How sexuality as a human right has been constructed and contested within the $\mathrm{UN}$; and

(4) How individual states have responded to challenges by the UN

The impetus for this research comes from a long-term interest in the area of human rights and surprise at the lack of attention paid to sexuality-based human rights abuses. Given the unclear status of sexual minorities around the world, this research aims to

\footnotetext{
2 The resistance to enshrining sexuality as a human right has primarily come from the Vatican, Islamic states, and fundamentalist Christian groups in the USA (Saiz, 2004).
} 
unpack why this takes places and the way in which state criminalisation and a lack of UN enforcement contribute to breaches of human rights. The case study of Jamaica is also given to expand and elaborate on the ideas presented above. The area of sexuality and human rights has been neglected by all but a few key authors (such as Murray \& Viljoen, 2007; Richardson, 1998; Saiz, 2004; Sanders, 1996; Tahmindjis, 2005; Waaldijk, 1994). It is hoped that this research will fill a longstanding gap in the literature. This thesis critiques the criminalisation of same sex relations using state crime analyses and frameworks. In particular it employs Michalowski's (2010) tripartite framework of state crime to show how international legal mechanisms have failed to protect sexual minorities globally and much of the progress made in the area can be largely attributed to civil society organisations (CSOs). Moreover, it analyses the way in which states are able to neutralise and deny human rights breaches based on sexual orientation that are raised at the international level, employing Cohen's (1993, 1996, 2001) framework of denial and Sykes and Matza's (1957) techniques of neutralisation.

\section{Bio-power, sexuality and the state}

Sexuality is tied in with power relations. This power is not just exercised by the state, but is also infiltrated into populations and sub-state organisations through what has been termed 'bio-power' (Foucault, 1976). Bio-power can be defined as "an explosion of numerous and diverse techniques for achieving the subjugation of bodies and the control of populations" (Foucault, 1976:140). Heterosexuality relies on the binary of male/female and "[d]issident sexual acts which either undermine and/or transcend" this binary are seen as disruptive (Beckmann, 2009:14). Sexuality as it is widely understood includes not only a person's sexual orientation, but also something intrinsically linked with a person's entire identity (Cooper, 1995; Foucault, 1978). Heterosexuality then becomes the most desired form of being in the majority of contexts (Cooper, 1995). Connected to this, deviance from heterosexual norms is viewed as threatening to the female/male binary (Bibbings, 2009).

Rubin (1984) argues that a sexual hierarchy is evident in Western societies, where 'good' sex acts (heterosexual, married, procreative and so on) are valued and 'bad' sex acts (homosexual, unmarried, gender non-conforming, sadomasochistic and so on) are denigrated. Butler (1993:23) likens the refusal by societies to accept 'bad' sex as an ontological panic:

What might happen if a masculine penetration of the masculine were authorized 
or a feminine penetration of the feminine, or a feminine penetration of the masculine or a reversibility of these positions - not to mention a full-scale confusion over what qualifies as penetration anyway. Would the words "masculine" and "feminine" still signify in stable ways, or would the relaxing of the taboos against stray penetration destabilize these gendered positions in serious ways?

This panic has increased in connection with the shift from top-down, feudal forms of power to the post-industrialisation bio-power, when the formation of 'expert' knowledge on sexuality began to increase (Foucault, 1976). The hierarchy of sex acts lends itself to a heteronormative and heterosexist society. In such a setting, harms are disproportionately experienced by those who do not fit with heteronorms; this leads to a 'heterosexual hegemony', in which the dominant (heterosexual-abiding) group imposes cultural definitions, norms and laws (Bibbings, 2004, 2009). Those who do not fit, or abide with these norms will find themselves alienated from society and left outside of the protection of the law. With this in mind, a critical framework is needed to challenge this hegemony.

\section{Critical criminology: Centring the state as criminal}

Criminology as a discipline has traditionally neglected the idea that states can, through action or inaction, be criminal (Stanley, 2007). One of the reasons for this is that criminology has typically focused on crime as an individual action with individual motivations (Cohen, 1993; Michalowski, 2010). Theorists of state crime argue that, while individual agency is important, states also need to be held to account for wrongdoing (Stanley, 2007). It is clear that although these 'crimes' may not fit within a legal framework, they constitute grave harm to countless individuals (Stanley, 2007).

With this understanding, this thesis takes a critical approach, to acknowledge the ongoing and widespread abuses of human rights against those who do not fit into the hegemonic heterosexual norm. The overarching framework of state crime used in this thesis is Michalowski's (2010) model. Drawing upon key scholars such as Green and Ward (2004), Michalowski establishes a tripartite analysis of state crime incorporating three levels: juridical, organisational deviance and social harm/injury (Michalowski, 2010). In relation to the criminalisation of same sex relations, this thesis demonstrates how states commit crimes at each of these levels. Firstly, legal frameworks show that criminalisation runs contrary to international human rights law, as well as domestic laws in most states. This fits with the juridical level, where criminalisation can be viewed 
as breaking these laws. However, there are many actions or inactions that cause harm to a large number of people which are missed by this definition (Michalowski, 2010). The organisational deviance approach thus focuses on

analyses of harms that have not risen to the level of law violations, but which have attracted the approbation of significant audiences who would define these acts as deviant, and would be willing to impose sanctions on the offenders if they were able (Michalowski, 2010:20-21).

Here, and as shown in this thesis, CSOs become an important arbiter of how deviant actions by states contravene human rights that are contained in international human rights law, but may not be specifically criminalised. For example, in the context of criminalisation, CSOs often lead the way in labelling the failure to decriminalise as 'criminal' before international human rights law has caught up. Thus, using an organisational deviance framework enables negotiation of the political labelling of what constitutes a 'crime'.

Finally, the social harm approach focuses on actions or inactions by states that cause harm to people throughout their lives - these can be single incidents or the result of structural harms experienced over a number of years (Hillyard \& Tombs, 2007). While criminalisation may not cause direct violence, the culture of fear and structural discrimination accorded to those not fitting heterosexual norms causes harm throughout the life course (Bibbings, 2009). 'Harm' is a difficult term to define and, in this thesis, it will be used primarily to describe the failure of states to decriminalise same sex relations. This has culminated in an increased societal tolerance of violence towards the criminalised group. Furthermore, harm can be defined in this context as the failure by states to sanction community violence against those suspected of being homosexual (cf. Bibbings, 2004; 2009). More broadly, harm can be extended to the failure of the UN to enshrine sexuality in international human rights instruments (ICHRP, 2009). This failure means that lesbian and gay individuals face a struggle to have their rights to autonomy, self-determination and freedom from discriminatory violence recognised at an international level.

All of the above levels of state crime link into ideas about how law and society interact to produce and reproduce social harms to marginalised groups. Michalowski (2010:29) notes that "[e]xamining the crimes and social injuries committed by governmental leaders...has the potential of calling attention to, and stimulating action against, such 
governmental wrongdoing". Critical research which takes all three levels into consideration can thus further the cause of, for example CSOs, and in turn, international bodies, in an effort to stimulate change. Moreover, a critical approach allows examination of the ways in which states can manoeuvre challenges on human rights breaches through techniques of denial, neutralisation and minimisation. The critical theoretical approach to this thesis centres the state as responsible for criminalising laws, which interact with populations and bodies to cause immeasurable harms.

\section{Methodology}

The methodology that underlines this research is that of Critical Discourse Analysis (CDA). CDA is an extension of discourse analysis, which has its roots in sociolinguistics. This approach allows research to take the context and power relations of a given text into account (Crotty, 1998). Such a focus has an emphasis on the intersection of words and texts with their surrounding environment (Gubrium \& Holstein, 2003). CDA extends this to explore:

...often opaque relationships of causality and determination between (a) discursive practices, events and texts, and (b) wider social and cultural structures, relations and processes; to investigate how such practices, events and texts arise out of and are ideologically shaped by relations of power and struggles over power (Fairclough, 1995:132).

The critical element of CDA thus takes on the role of uncovering connections between language and power structures (Fairclough, 1989). It does this by deconstructing and contextualising the use of specific language, how it is used and by whom (Wodak, 2004). Moreover, as with much critical research, there is a focus on challenging competing structures of power in order to bring about change (Wodak, 2004). While this may seem a lofty aim and perhaps an unrealistic one, the current discourse of human rights - both in the mainstream media and in political circles - is one which obscures those issues seen to be irrelevant or politically dangerous (Cohen, 2001). Therefore, critical research revolves around "ensuring the voices and experiences of those marginalised by institutionalised state practices are heard and represented" (Scraton, 2007:10). With this in mind, this thesis will attempt to uncover state practices by exposing what Cohen (2001) terms a 'culture of denial', a denial which has been a central barrier towards gaining rights for sexual minorities.

A degree of reflexivity is also vital to the practice of critical research. In the practice of $\mathrm{CDA}$, the researcher acknowledges their own subjective interpretations of texts 
(Chouliaraki \& Fairclough, 1999). As a white, upper-middle class, cisgender woman in a country where, within reason, I am free to express my sexuality without persecution from the state3, I come from a position of privilege relative to those whose ill treatment and degradation I seek to expose. It is worth noting too that the UN documents I will analyse, while in the public domain, are unavailable to many of those whose lack of rights are being addressed and may well be structurally blocked from accessing such documents. Furthermore, many are written in language which is dense and phrased in 'expert' terms (Tonkiss, 1998).

Within this critical framework and with the tenets of CDA in mind, this thesis uses the qualitative method of documentary analysis. This method involves drawing together relevant documents, in this case from the UN, stakeholders and civil society groups and exposing themes (Bowen, 2009; Prior, 2003). These themes reflect how states demonise, deny and construct homosexuality, as well as how international legal forums have dealt with ideas around sexuality and human rights. Bowen (2009: 27) points out that documentary analysis centres around data "be[ing] examined and interpreted in order to elicit meaning, gain understanding, and develop empirical knowledge”. The UN is a highly complex and rule-bound institution, and documentary analysis can allow some insight into the way states and CSOs negotiate its various rules to their advantage.

\section{Methods}

In an organisational setting, such as that of the UN, it should be noted that in many cases, documents serve a dominant purpose - that of illustrating organisational competence (Atkinson \& Hammersley, 2007). In this vein, it is important to look at what documents do contain, as well as what is obscured (Prior, 2003). The data collection processes carried out for this research are outlined here.

\section{Identification of documents}

To identify the relevant UN documents, an online database (UNBIS) 4 was searched. Documents of relevance to this research were those connected with specific UN mechanisms, as well as any other sessions specifically related to sexual orientation. Search terms included a variety of words related to the subject including 'sex',

\footnotetext{
3 While New Zealand has its own problems in regard to discrimination on the basis of sexuality, particularly in relation to marriage and adoption rights, my position is privileged relative to the abuses that go on in the states which this thesis focuses on.

4 The UN Bibliographic Information System
} 
'sexuality', 'sexual orientation', 'homosexuality' and 'LGBT'. All relevant documents were downloaded and relevant sections were highlighted. Critical to the methodology of CDA, it is also important to examine what is left unmentioned (Bowen, 2009). With this in mind, special note has been taken both of mechanisms which do not raise these issues as well as challenges in UN forums which are not responded to, and what this demonstrates.

Documents such as human rights reports, letters of allegation and UN shadow reports from CSOs were also collected and analysed. Unlike UN session reports, these are typically written in more understandable language, which makes locating the relevant information much easier. Further, standards such as the Yogyakarta Principles and the Declaration of Montreal were collected for analysis.

\section{Analysis of documents}

While the data collection for this research had a wide scope, the bulk of the analysis was focused on documents pertaining to specific mechanisms. For example, once the importance of the Universal Periodic Review (UPR) in challenging states on sexual orientation grounds was recognised 5 , analysis for Chapter Four was confined to the UPR. Likewise, documents from CSOs for Chapter Four were those submitted during the UPR process. Themes relating to how states responded to challenges in this process were constructed in the process of analysis, resulting in the following: 1) invisibility 2) lack of a mandate; 3) not our culture/religion; 4) no evidence of discrimination and no prosecutions under the relevant laws; and 5) partial agreement. These categories are further explained in Chapter Four. In analysis for Chapter Six, which included documents from several UN bodies specifically pertaining to Jamaica, the same categories were also found to be useful in illustrating how states respond.

A more in-depth analysis of how states responded to CSOs was not possible due to the word limits of an MA thesis. However, it is worth noting that a number of states (including Jamaica) pay little attention to evidence from CSOs about breaches of human rights $^{6}$. With this in mind, this thesis examines how CSOs present evidence of human rights violations, and explores the extent to which UN bodies and state representation to

\footnotetext{
5 After initial analysis of various UN processes, the uniqueness of the UPR in terms of both CSO involvement and mandatory reporting was realised. This is discussed further in Chapter Four.

${ }^{6}$ For a detailed examination of how states neutralise and deny recommendations and/or evidence from human rights reports, see Cohen (1996).
} 
the UN rely on these accounts when presenting challenges.

\section{Layout of thesis}

This thesis critically analyses the criminalisation of same sex relations in states around the world (with a specific examination of Jamaica) and adopts an approach which critiques, in particular, the UN for its lack of action on sexual orientation-based human rights. It consists of six chapters.

The following Chapter Two sets out the background and context of the criminalisation of same sex relations, including an overview of how and why states criminalise. Consequently, it examines the complex relationship between top-down laws and grassroots culture. Law as a normative force is analysed, and the chapter shows how criminalisation laws not only condone, but at times encourage, violence against marginalised groups - in this case those not conforming with heterosexual norms.

Using Michalowski's (2010) framework, Chapter Three outlines how criminalisation can be understood as a 'state crime' and analyses how international human rights norms can become incorporated into the norms of a state.

Chapter Four posits that institutionalising human rights standards and normalising them into a state allows increasing awareness of the human rights implications for states with criminalising laws, and in this way, allows criticism of states in the international arena. The chapter concludes by analysing how the Universal Periodic Review (UPR) has become one of the main forums to challenge criminalising states.

Subsequently, Chapter Five introduces the case study of Jamaica to provide an understanding of why states criminalise. Jamaica's historical, social and cultural context for its laws, which criminalise sexual relations between men, is examined. The chapter then looks at how sexualities are understood and negotiated in contemporary Jamaican society. Connected with this, the retention of criminalising laws in Jamaica is shown to be a 'state crime' through Michalowski's lens of juridical, organisational deviance and social harm categories.

Continuing with the case study of Jamaica, Chapter Six provides a detailed analysis of how local and international CSOs challenge its government on criminalising laws, and 
related discrimination and violence. Following this, it explores the response of UN bodies to criminalisation in Jamaica, and analyses how they have variously confronted and ignored human rights breaches. As will be seen, the Jamaican government have been able to deny and neutralise challenges by the UN and CSOs using a variety of techniques. The chapter concludes by examining how change could be envisioned in Jamaica through the continuing work of both CSOs and bodies like the UN.

The conclusion in Chapter Seven argues that, while there has been significant progress in explaining the phenomenon of criminalisation as a criminal act by the state, there is much work to be done in furthering the cause of those who are continually placed outside the protection of the law. Attached to this, the responsibility of the state in protecting minorities from violence is emphasised. 


\section{Chapter Two: Locating criminalisation and the power of law}

\section{Introduction}

Homosexuality as an orientation has never been criminalised, but the criminalisation of consensual same sex relations is evident in many states historically. As discussed in Chapter One, this has the effect of criminalising orientation because of the way that the use of the body has become linked with one's entire identity (Foucault, 1976). Criminalisation has been related to the perceived danger of homosexual individuals who have been connected to other deviant sexual 'fetishes' such as paedophilia (Kohler, 1986). Sanctions on same sex relations have been gradually removed within numerous states including England and Wales in 1967 (which provided criminalising laws through colonisation to a number of the states discussed in this thesis), as well as New Zealand, Australia, and eventually the USA in 2003 (HRW, 2008). There are 76 states where consensual same sex relations are still criminalised and the penalties for those found guilty of offences are wide-ranging (see Appendix One). This chapter will examine these criminalising states and detail three primary factors that influence the retention of their laws: religion, embedded cultural homophobia and a colonial legacy. Recent examples will be given of states that have engaged in decriminalisation processes, as well as those states that are expected to decriminalise in the near future.

This chapter argues that criminalisation has many consequences outside of legal penalties, including tacitly condoning the occurrence of homophobic violence from both state and private actors, which often benefits from an environment of impunity. The norm-setting power of law will be discussed and connected to the symbiotic relationship between state laws and grassroots culture. The capability of the law to encourage or, conversely, sanction incidents of discriminatory violence is important in this context. Furthermore, the concept of hegemonic heterosexuality is applied to criminalising states and the role that laws play in producing and reproducing this hegemony will be discussed. The scant literature relating to the existence of criminalising laws has resulted in original research that was collated specifically for this thesis. This provides an important springboard from which to analyse the effects of such legislation. The consequences of labelling a certain group as 'criminal' and consequently not worthy of the law's protection is vital in understanding the occurrence of homophobic violence, and responses to it in these states. 


\section{The criminalisation of same sex relations around the world}

Appendix One contains data collated specifically for this thesis in an original way and shows that there are currently 74 states $^{7}$ where same sex relations are criminalised ${ }^{8}$. These laws enforce and punish acts of consensual sex in a variety of ways. While an indepth analysis of the source of the laws in each of these states and the reasoning behind them is not feasible, this section aims to set out a model of how and why criminalisation occurs. In 47 of the states with criminalisation still in place, the laws apply to both men and women, but in 27 states, criminalisation only applies to same sex activity between men (see Appendix One). The reason for the lack of legal attention to women in these countries relates to the invisibility of lesbianism in general, a point explored further in later chapters (Amnesty International [AI], 2008; Rich, 1996). Many states also inherited adaptations of laws from colonial powers - particularly the United Kingdom (UK), Spain and Portugal (Ottosson, 2010; Human Rights Council [HRCoun], 2011). For example, almost half of the states which retain criminalisation are in the Commonwealth, stemming from Victorian era law-making in the UK and continue to be in force, despite the repeal of the English law in 1967 and in the rest of the UK shortly after (Baudh, 2008).

Laws criminalising same sex acts do so using a range of terminologies including: 'homosexual acts', 'acts against the order of nature', unnatural offences', 'carnal knowledge of any person or animal', 'buggery', 'sodomy', 'voluntary sodomy', 'lewd acts', 'outrage on public decency', 'pederasty'9, 'unnatural sex' and 'gross indecency' (Ottosson, 2010; HRCoun, 2011d). Such laws are variously referred to as 'sodomy laws' or 'buggery laws'10 (e.g. Baudh, 2006; Fradella, 2002; Goodman, 2001; Leslie, 2000; Thomas, 1992). The language used in codified laws often links into medicalised views of non-normative sexual orientations or activities (AI, 2008; Narrain, 2004). For example, in Zimbabwe where the law criminalises 'sodomy' as an 'indecent act', homosexuality is

\footnotetext{
7 It is also worth pointing out that three of the 'states' noted in this thesis do not meet the technical definition of states. The Cook Islands is an 'associate' of New Zealand, Gaza is part of the disputed Palestinian Occupied Territories and Somaliland only qualifies as a 'partial state'. As a result, none of these territories have full membership of the UN.

${ }^{8}$ There are some states which do not feature in this thesis. This is because, while people are arrested for same sex activity in these states, there is no express law prohibiting it. See Ottosson (2010) for more detail.

9 According to Ottosson (2010), in Afghani legal definitions, pederasty can equate to any sex acts between males regardless of age.

10 I have chosen not to use either of these terms in this thesis, as they have an explicit focus on the sexual act while I intend to show that criminalisation in these states is aimed more towards the elimination of anything which does not fit a heterosexual norm.
} 
thought to be a 'white man's disease' which one parliamentarian in 1995 likened to a festering finger that needed to be cut off so it would not infect others (Phillips, 2009). Likewise, in the United Arab Emirates (UAE) in 2005, men arrested at what was thought to be a 'gay wedding ceremony' were forced to have hormone treatments as a 'cure' (AI, 2008). The UAE combines both Shari'a and civil law advocating for punishment (including the death penalty) or medical treatment for those convicted. Consensual sex between same sex couples is framed by many states as morally similar to bestiality, rape or child abuse. For example, in several states, acts are criminalised under the rubric of 'acts against the order of nature' or 'unnatural acts' (e.g. Ottosson, 2010:13). Similarly, some states criminalise bestiality and same sex relations together, aligning them in the eyes of the law (e.g. Ottosson, 2010:14). In this way, states set apart men who have sex with men and women who have sex with women as criminal and, in many cases, as sick (Chan, 2006; Gutzmore, 2004).

Punishments for those convicted of same sex activities are wide-ranging and are listed in the third column of Appendix One. Twenty-three states have penalties of either fines or prison terms of up to five years. The majority of these states are in Africa with another seven in the Middle East, Comoros in the Caribbean, and Singapore in Asia. Forty-six states have penalties loosely grouped as long prison terms with the majority of these states in Africa (18) and the Caribbean (11). A further eight states are Oceanic, with an additional five in the Middle East and five in Asia. In addition to prison terms, seven states mandate punishments directly on the body: hard labour or corporal punishment ${ }^{11}$. In nine states, homosexual acts can be punishable with the death penalty (Appendix One) ${ }^{12}$.

Criminalising laws are variably applied and enforced in different states. In many, laws criminalising same sex conduct are regularly enforced (see Appendix One). For example, in Iran, there have been 153 known executions for homosexuality, which is likely to be an underestimate (Boroumand Foundation, 2013). Similarly CSOs have recorded routine arrests in many other states (see HRW, 2013). In some states, rates of enforcement are not recorded publicly, or laws are rarely enforced throughout the criminal justice system (HRCoun, 2011d). For these states, gay (and in many cases

\footnotetext{
${ }_{11}$ These are Iran, Jamaica, Malawi, Malaysia, Nauru, Somalia, Somaliland and Yemen

12 These are Afghanistan Iran, Mauritania, Saudi Arabia, Somalia, Somaliland, Sudan, the UAE and Yemen. In Iran, the death penalty can only be given to the 'passive' party in consensual sex.
} 
lesbian) individuals face a constant fear of arrest and in many states, arrests that are not followed through to conviction invite attacks by members of the public (these are listed in Appendix One as 'sporadically enforced'). Thus, as will be argued in the next section, the non-enforcement of these laws does not render them harmless. Finally, there are some states that still have laws on their books, but do not enforce them, even for arrests. These laws are often still in place because they are entrenched in a Constitution, thus difficult to overturn, or governments have not sought to repeal them ${ }^{13}$.

\section{Explaining criminalisation}

The various reasons for criminalisation can be loosely grouped as religious/moral, cultural or colonial. These descriptions overlap in a variety of ways, and the aim here is to designate the primary reason for criminalisation where possible; a full list can be found in Appendix One. In reading this list, it is worth noting that most criminalising countries have a primary religion and many religions at least in part condemn homosexual activity; however, religion has only been noted as a reason for criminalisation where it appears to be the driving force. Seven states with religiousbased criminalisation have Shari'a law ${ }^{14}$ in place, while a number of other states have a mixture of Shari'a law and civil or common law systems (Appendix One). Shari'a law views male-male sexual activity as sinful, following the example of the Qur'an which condemns the 'people of Sodom' and recommends an array of punishments (Hidayatullah, 2003) ${ }^{15}$.

In addition, there are many states that, while secular in name, have criminalisation laws based in Christian values, which have developed a cultural life of their own. A large number of these countries derive their laws primarily from Judeo-Christian traditions (AI, 2008). In many African states, non-heteronormative behaviour is labelled 'unAfrican' and assumed to be an immoral behaviour picked up from European colonisers (Murray \& Viljoen, 2007). This is despite the fact that a large number of criminalisation laws in Africa came in when Christian moral values were imposed by colonial powers (Murray \& Viljoen, 2007). Likewise, in much of the Caribbean, where Christianity is now the primary religion, same sex activity is considered to be an extravagance of liberal Western origin (LaFont, 2001).

\footnotetext{
${ }_{13}$ States like this include Samoa, Seychelles and Tuvalu.

14 Shari'a law is a form of Islamic law.

15 A number of Muslim scholars have disputed this interpretation of the Qur'an and argue that dialogue needs to address more diverse readings (for example Kugle, 2003).
} 
The link between colonial laws and embedded cultural norms can be seen as existing on a continuum. At one end, many states have retained colonial criminalisation laws and have grassroots cultures supportive of homophobia. States which could fall into this category include Cameroon, Ghana, Jamaica, the Solomon Islands and St Lucia. At the other extreme, while retaining colonial criminalisation laws, some states have little grassroots support for the laws and many are signatory to the UN Declaration on Sexual Orientation and Gender Identity (DSOGI, explained further in Chapter Three), despite still having criminalising laws on their books. Relevant states here include: Dominica, Nauru, Seychelles and Tuvalu (see Appendix One; United Nations General Assembly [UNGA], 2008).

Only two states have expressed a commitment to decriminalisation in the near future. Nauru agreed to review its criminal code and explicitly noted that one of the aims of this process was to decriminalise sex between consenting adults (HRCoun, 2011a). Additionally, in its most recent response to the Universal Periodic Review (UPR) process, the Seychelles agreed to decriminalise same sex relations (HRCoun, 2011b). Other states, including Samoa and the Solomon Islands agreed to overturn criminalisation laws, before reneging on this due to public criticism (Chand, 2010; Samoa Law Reform Commission, 2011). Since 2007, eight states have overturned criminalisation laws, with the most recent being Fiji in 2010 (Chand, 2010).

What this data collection and analysis shows is the relatively widespread nature of laws that criminalise consensual same sex relations, and the way in which these behaviours are enforced and punished. Homophobia is embedded in the cultural context of many of these states, despite the colonial origins of the laws, and this is manifest in cultural supports including religion, media and political support (discussed in later chapters). While this section has mapped out the extent to which criminalisation is in place around the world, the next section aims to set out the link between state laws, culture and homophobic violence.

\section{Law, culture and homophobic violence}

The legal system is one of many institutions that creates and reproduces social norms and inequalities (Madsen \& Dezalay, 2002; Moore, 1978; Sunstein, 1996; Weisberg, 1992). The relationship between law, culture and other discourses is a symbiotic one - 
they interact to create and contest different identities, boundaries and ways of being (Coombe, 1995; Madsen \& Dezalay, 2002; Merry, 2006; Mezey, 2001; Moore, 1978; Sunstein, 1996). In this way, law and culture are intertwined; law can be a product or an object of culture (Mezey, 2001; Riles, 2009). Consequently, law is able to "produce and reaffirm the existing social order" (Hunt, 1993:17). In this vein, while changing the law cannot change behaviour, it can alter the meanings derived from particular practices (Goodman, 2001; Mezey, 2001; Sunstein, 1996). This means that changes in law have the potential to change "background normative signals" in society (Goodman, 2001:644) and, ultimately, legal changes can change the social meanings of particular practices (Mezey, 2001; Riles, 2009). Mezey (2001) argues that culture can often be influenced in ways not necessarily intended by lawmakers; this 'slippage' between the aims of law and their social consequences animates law's discursive power.

Within state structures, the legal system is fundamental to the maintenance of the monopoly on violence, as it includes an ability to inflict, excuse or condemn violence in a variety of circumstances (Black, 1984; Bourdieu, 2000; Madsen \& Dezalay, 2002). In this way the law acts as a boundary between what violence is perceived as legitimate or illegitimate (Abrahams, 1996; Weisberg, 1992). Law can often provide meaning to violence, particularly if the law supports the condemnation of a particular 'class' or 'type' of person (Black, 1984; Madsen \& Dezalay, 2002; Romany, 1994; Thomas, 1992; Weisberg, 1992) ${ }^{16}$. Violence by a perpetrator who is not acting on behalf of the state, but sees that they are acting with the state, has been termed 'violent self-help'. Those who commit violence and see themselves acting for the law can be led to "feel like the state itself" (Weisberg, 1992:185). Such exercise of force is symbolic of the hegemonic power which law provides to violence (Bourdieu, 2000).

For example, consider the use of violence against women by non-state actors and the state's failure to protect women from these acts (see Charlesworth, Chinkin \& Wright, 1991; Romany, 1994). States are typically seen to have failed to protect women and children from private actors or to punish all kinds of violence with equal commitment; the complicity of the state in private violence also means that structures of power are maintained (Romany, 1994). Roth (1994) refers to the state's failure to prevent private

\footnotetext{
16 For example, Kennedy (1993, cited in Mezey, 2001) notes that laws which, until recently, condoned marital rape and violence led credence to societal rules which allowed for patriarchal dominance in relationships. In this case, women were seen for many years as needing discipline from their husbands and handing over ownership of their bodies on marriage and the law supported this.
} 
violence as 'state liability by omission'. This can be extended to the area of homophobic violence, where crimes rooted in heterosexism are committed with the power of social customs, religion and law behind them (Herek, 1992).

As detailed previously, the 'heterosexual hegemony' propagated by state powers in which heterosexuality is centred as the norm, casts anything outside the heterosexual matrix as unnatural and abnormal (Baudh, 2006). In this environment, anything outside the norms of heterosexuality is viewed as being contrary to the moral consensus and "tends to be denied, rejected and repressed by the state apparatus" (Bibbings, 2009:36). Consequently, while human rights laws promise non-discrimination, in practice, sexual minorities are afforded fewer rights than others and face constant battles to have their rights recognised all over the world (Richardson, 1998). In this context, the binaries of heterosexual or homosexual have been entrenched in the nature and practice of state laws - normative and illicit sexual identities are constantly monitored and reproduced by the state and by its citizens (Baudh, 2006; Bibbings, 2009; Mason, 2002). This hegemonic heterosexuality has the potential to cause numerous harms for those who do not fit the narrowly defined norm.

As detailed above, laws which criminalise consensual same sex relations justify the view of gay people as deviant or even subhuman (AI, 2008; Berrill \& Herek, 1992). For instance, up until 2003, many US states had laws in place which criminalised sexual activities between men ${ }^{17}$. A small number of legal scholars wrote about these 'sodomy laws' and the way in which they criminalised a 'deviant' class of people (see Fradella, 2002; Kogan, 1994; Leslie, 2000; Thomas, 1992). Thomas (1992) argues that the laws set the context for the occurrence of homophobic violence committed by both public officials and private citizens. Violence by private citizens can be seen as working with criminalisation by inflicting punishment upon those who belong to a 'criminal class' (Thomas, 1992). By legitimising violence and instituting social control, criminalisation acts as:

[t]he site of a 'constellation' of practices [which] is intended to capture the essential inseparability of these laws from the actual methods - public and private, official and unofficial, sanctioned or unsanctioned, act-based or identitybased, instrumental or symbolic - by which the social control of those to whom

\footnotetext{
${ }_{17}$ In 2003, a decision by the Supreme Court in Lawrence $v$ Texas overturned criminalisation laws - thus federally, criminalisation laws no longer exist in the US. However, some states have not repealed these laws and still use them to arrest individuals they deem guilty of same sex relations.
} 
they are directed is undertaken and achieved (Thomas, 1992:1440-1441). Jamieson and McEvoy (2005) note that states exercise power by 'othering' those who do not fit with the norms of the state. Along these lines, the non-enforcement of laws is not harmless, but sends a message to society that homosexuality is not normal or acceptable, thus 'othering' those who self-define as homosexual (AI, 2008; Leslie, 2000; UNGA, 2010). In doing so, those who commit homophobic violence can classify themselves as vigilante enforcers of state laws and see themselves as being in the 'normal' and 'legitimate' group (Leslie, 2000). Amnesty International (2008) argues that criminalisation provides a perceived justification for private violence yet, in many instances, those targeted by such violence are not provided with access to legal support or police protection.

As a case in point, Goodman (2001) assessed the situation in South Africa before and after decriminalisation, which occurred in 1998. He argues that criminalisation laws interact with methods of control and public surveillance. Those targeted by the law in South Africa were visible through the 'social gaze' with private citizens performing policing roles in controlling gay and lesbian lives, which he terms 'social panoptics' (Goodman, 2001). While there is still an alarmingly high level of homophobic violence (and violence in general) in South Africa (Msibi, 2009), sexual minorities interviewed in Goodman's (2001) research spoke of feeling safer being openly homosexual in public, as well as being able to go to the police for any discrimination or harm perpetrated against them. Vitally, they saw decriminalisation as a first step to attaining further freedoms in expressing their sexuality (Goodman, 2001) ${ }^{18}$.

The relationship between the existence of laws which discriminate against sexual minorities and private violence towards those minorities is a difficult one to prove. It is indisputable that laws which punish same sex relations criminalise an identity, rather than just an act, in the eyes of society (Donnelly, 1999; Kogan, 1994; Nussbaum, 1999; Wilets, 1997). The dehumanisation afforded to gay and lesbian people both in the legal system and by discrimination and violence from private citizens paints them as subhuman, alien subjects of the law (Donnelly, 1999; Leslie, 2000). This is the case whether or not such laws are enforced through the criminal justice system (Fradella, 2002;

\footnotetext{
${ }^{18}$ It is worth noting that South Africa's legal progress after this was significant. South Africa is now one of the only states worldwide to have gay marriage and partnership rights, adoption rights for gay couples, and strong anti-discrimination laws in place (Reddy, 2006).
} 
Kogan, 1994; Leslie, 2000; Thomas, 1992). Arguably, "homophobic violence punishes what homosexual sodomy statutes prohibit" (Kogan, 1994:213) and this is an argument supported by many authors (see Donnelly, 1999; Goodman, 2001; Thomas, 1992; Wilets, 1996; UNGA, 2010). Much work has emphasised the way in which individuals targeted by homophobic attacks are not the only victims, as attacks also serve as warnings to all people who may not fit the gender or heteronorm (Leslie, 2000; Mason, 2008; Wilets, 1996; Tomsen, 2009). Critically, the labelling of a particular 'type' of person as criminal places them outside the protection of legal authorities (Donnelly, 1999; Goodman, 2001). In this context, it is useful to see criminalisation as condoning or even encouraging such violence by excluding those not conforming to heterosexuality from law's protection (Goodman, 2001; Wilets, 1996). Decriminalising consensual same sex activities can thus be seen as a first step in the direction of the elimination of discrimination towards sexual minorities (Donnelly, 1999; UNGA, 2010).

Waaldijk (1994) provides a useful framework for the way in which states adapt their laws to provide for sexual minorities. While not all states follow this model, it is valuable to view decriminalisation as one identifiable step towards providing recognition and protection of homosexuality and for sexual minorities more generally. He begins with systems with a total ban on homo-sex, followed by: (1) the decriminalisation of consensual sexual activities between adults of the same sex; (2) equalising ages of consent; (3) anti-discrimination legislation; and, (4) legal partnership (Waaldijk, 1994:51-52). Further, Donnelly (1999) argues that decriminalisation, while not eliminating the loss of civil rights, general social prejudice or non-discrimination, is still a useful resource in the wider struggle for human rights, and is often the first and most obvious step to take in such a struggle.

\section{Conclusion}

The focus of this chapter has been the criminalisation of consensual same sex relations, which currently occurs in 74 states around the world. The terminology used in these laws is connected to wider medical and moral discourses that demonise lesbian and gay individuals in these states. Punishments for those found guilty of these laws include fines, imprisonment, hard labour, corporal punishment, chemical castration, and in nine states, the death penalty. While in many cases, the level of enforcement of criminalising laws is unclear, in others the law is regularly enforced. In this environment, states criminalise same sex relations and, more widely, denigrate 
homosexuality for a variety of reasons. The vast majority of states listed in Appendix One originally inherited criminalising laws from colonial powers. However, some countries retain the laws primarily for embedded religious or cultural reasons, extending beyond colonial reasoning. This chapter has set out three main reasons for criminalisation, although it should be noted that these often overlap and are by no means exhaustive.

The criminalisation of same sex relations is connected with the occurrence of homophobic violence globally. While homophobic violence occurs in virtually every country regardless of criminalisation, laws prohibiting homosexual conduct go some way towards legitimising and encouraging acts of violence from the highest level. The second part of this chapter has reflected on how the law acts as a normative framework by which the discourses of law and culture interact. The law acts alongside a number of other discourses; it acts as a hegemonic dictate of appropriate and acceptable practice according to the state. Connected to this, violence by private citizens against those designated as 'criminal' by the law can be seen as people acting with, and for, the state's interests. Literature drawn from the US and South Africa shows the connection between law, violence and impunity in an environment of criminalisation. Decriminalisation will not eliminate the occurrence of violence, but can make it less legitimate in the eyes of the state and society in general. The next chapter will explore how criminalisation itself can be understood as a 'crime'. 


\section{Chapter Three: Criminalisation and state crime}

\section{Introduction}

The criminalisation of homosexuality has faced concentrated challenges in the last decade. Civil society organisations (CSOs) have exerted significant pressure on governments and the UN to effect change through binding international human rights law. Yet, the way in which states are able to neutralise and deny lesbian and gay human rights makes legal change incredibly difficult. Sexuality as a ground of nondiscrimination is still at an uncertain juncture. In this context, it is useful to look at how non-legal standards can provide a framework with which to explore criminalisation.

This chapter explores how criminalisation can be understood as a 'criminal' act by states. It will do this by applying Michalowski's (2010) definitional framework of 'crime' which includes: juridical definitions, state organisational deviance and a social harm approach. This framework is particularly useful as it acknowledges the ways in which actions or inactions which do not fit the typical definition of 'crime' still cause harm and social inequality.

\section{Sexuality in the international arena: Constructing criminalisation as state crime}

The struggle for 'sexual rights' around the world has been fraught. This section, using Michalowski's (2010) framework, argues that the criminalisation of same sex relations can be defined as a form of state crime in terms of legal violations, organisational deviance and social harm.

\section{Juridical}

Both domestic and international laws make up the juridical definition of crime. In the case of criminalisation, domestic laws offer little use in determining discrimination. International law, however, offers a means to construct state actions/inactions in relation to sexuality as criminal. The UN's founding document, the UDHR, affirms protection for all people regardless of "race, colour, sex, language, religion, political or other opinion, national or social origin, property, birth or other status" (UNGA, 1948:Art. 2). The universal wording of this document suggests that protection should be afforded to sexual minorities. However, the exclusion of the word 'sexuality' as a ground of discrimination in the UDHR and subsequent human rights instruments is 
noteworthy, particularly when one considers that sexual minorities were among those sent to death camps during the Nazi Holocaust (Tahmindjis, 2005).

Instead of affirming sexuality as a key focus for human rights protections, the UN has sought to apply existing rights instruments to cases involving sexual rights (Tahmindjis, 2005). One early example is an Australian case, Toonen $v$ Australia, in which criminalisation was held by the Human Rights Committee (HRComm) to be in breach of the International Covenant on Civil and Political Rights (ICCPR; Tahmindjis, 2005) ${ }^{19}$. Since this decision, the HRComm has urged other states to decriminalise consensual sexual acts, often citing the ICCPR's right to privacy (UN Office of the High Commissioner for Human Rights [UNOHCHR], 2012). Several other UN committees have also - although only nominally - supported universal rights contained in their provisions as being applicable to sexual minorities (Corrêa et al., 2008) ${ }^{20}$. The current situation on sexual rights in the UN has relied on the use of existing conventions and rights including privacy, freedom from torture, and rights to life and freedom from discrimination (Saiz, 2004; UNOHCHR, 2012). The UN's stance, which avoids affirming sexuality as grounds for non-discrimination, can be viewed as one that neutralises the harms experienced by sexual minorities.

In particular, the exclusion of 'sexual orientation' in major UN instruments and the lack of progress by the UN on sexuality-based rights can be understood as neutralisation through denial of responsibility. This involves an individual or group indicating that they have been pushed into actions by forces outside of their control (Sykes \& Matza, 1957). In the push for sexual rights, states often argue that the lack of progress is connected to widespread social, cultural and religious opposition. Putting sexual orientation rights into international instruments is perceived as controversial on cultural and religious grounds and better left uncodified (Saiz, 2004). In this context, the UN, as the primary arbiter of 'human rights' will accept states' reasoning and will similarly avoid arguments that rights should be enforced. In not taking a position, the UN perpetuates human rights abuses on the basis of sexuality, which occur in an environment of impunity.

\footnotetext{
19 The HRComm held that Australia breached Article 17 (the right to privacy) and Article 2(1) (the right to non-discrimination on the basis of 'sex') (Tahmindjis, 2005).

${ }_{20}$ This includes the monitoring committees of: The Convention on the Rights of the Child (CRC), the Convention on the Elimination of all forms of Discrimination Against Women (CEDAW), and the Convention Against Torture (CAT).
} 
Neutralisation through denial of injury is another way that the lack of progress by the UN can be explained. Denial of injury can be defined as "...minimising any resultant hurt or injury" from actions or inactions (Cohen, 2001:60). Typically, states are not brought to the attention of the UN unless CSOs or individuals directly affected by criminalisation laws raise awareness (Corrêa et al., 2008; Narayan, 2006). Moreover, CSOs can only be officially involved in UN discussions through what is called 'consultative status'21 and while the number of LGBT rights organisations with this status has grown, there are still only ten of these organisations with it (Economic and Social Council [ECOSOC], 2011). This makes it more difficult for such issues to be raised and debated at the international level, unless it is linked to other human rights arguments, as discussed above (Narayan, 2006) ${ }^{22}$. With the exclusion of 'sexual orientation' in any convention, and the lack of UN initiative in exposing sexual orientation discrimination, the global persecution and alienation of sexual minorities is largely ignored, except through the work of CSOs (Shiell, 2009). In this way, CSOs have the job of taking up the "battle against silent silencing" - that is, unmasking the truth of the level of injury inflicted on sexual minorities (Mathiesen, 2004:35).

The UN can be seen to pacify states which do not believe that people have the right to express their sexuality. Moreover, they respond to CSOs, but do so in a way that does not fully recognise their arguments as credible. Bibbings (2009) argues that 'hegemonic heterosexuality' is still centrally placed in the context of state power. The expectation is that populations will adhere to heterosexual norms (Bibbings, 2009). This argument can also be used to apply to the failure by the UN to create any documents with binding status.

In summary, while UN human rights instruments are universal in nature, and would be expected to cover discrimination on the grounds of sexual orientation, their application

\footnotetext{
${ }^{21}$ Consultative status is held by around 3000 organisations giving them direct participation in discussions around particular issues within the $\mathrm{UN}$, as well as greater participation (Narayan, 2006).

22 Criminalisation is often constructed as a breach of rights to health (e.g. Grover, 2010), which has the effect of cementing the linkage of HIV/AIDS with homosexuality, contributing to the still widespread belief that gay men and sex workers are entirely responsible for the spread of HIV/AIDS, a situation that causes further discrimination on grounds of sexuality (AI, 2008; Corrêa et al. 2008). The reframing language used to refer to sexual orientation rights as 'rights to health', rather than to sexual autonomy (including rights to freedom of movement, life and expression among others), amounts to an official UN denial of actual rights to express sexual orientation (cf. Cohen, 1996).
} 
is still uncertain. This makes defining states as criminal in a juridical framework very difficult, as "...the distinction between violations of conduct norms that are designated as crimes and those that are not is the outcome of political processes" (Michalowski, 2010:15). Moreover, legal frameworks - both domestic and international - often serve the interests of only those with the privilege to be heard, which has the effect of emphasising extant inequalities (Mathiesen, 2004; Stanley, 2007). In this context, until there is a more defined basis for sexuality-based discrimination and violence, the construction of criminalisation as a breach of international law cannot be given sure status. This chapter will next turn to organisational deviance, the breach of 'conduct norms', as another level of state crime (Michalowski, 2010).

\section{Organisational deviance}

While the juridical definition of crime is a straightforward and useful framework, it can play a part in "directing us away from broad structural arrangements" that cause some of the most pertinent harms (Michalowski, 2010:19). Organisational deviance refers to acts that, while not technically illegal, may be viewed as similar to illegal acts by an audience (Green \& Ward, 2004). Approaching legal actions by a state as wrongful enables those harms that do not fall within the ambit of criminal law to be analysed (Green \& Ward, 2004; Michalowski, 2010). This section analyses the ways in which criminalisation - and its resulting phenomena - may be viewed as deviant. It will explore transnational human rights frameworks, as well as more recent UN documents, which, while not binding as international law, contain a framework which allows states to be challenged on sexuality-related human rights abuses.

The first openly homosexual person to address a UN human rights forum on lesbian, gay bisexual and transgender (LGBT) issues did so in 1992 (Sanders, 1996). Since then, the political struggle for rights through the work of NGOs has intensified (Kollman \& Waites, 2009). The first attempt to create a framework for sexual orientation rights was the 2006 Declaration of Montreal (DoM). This document, compiled at the 2006 Outgames International Conference on lesbian, gay, bisexual and transgender (LGBT) Human Rights, summarises LGBT human rights including protection from state and private violence, and freedom of expression, assembly and association (DoM, 2006). It declares that governments need to take action immediately to ensure human rights for LGBT people, and demands "the repeal of all laws criminalizing private, consensual, adult, same-sex sexual activity" (DoM, 2006:s1(c), emphasis in original). The document 
is imbued with such imperatives including: "we demand...that LGBT organisations be granted the place they deserve" (s2), "[we] urge the international community to put pressure on governments" (s1(c)), and so on (DoM, 2006). The aim of the DoM was to lobby the UN, as well as state governments, to effect global change in tackling violence and discrimination (Swiebel, 2008). Critically, it also calls for a 'Declaration on the Elimination of all forms of Sexual Orientation and Gender Identity Discrimination', in effect asking the UN to cement sexual orientation and gender identity rights in binding human rights law (Kollman \& Waites, 2009). The DoM has set the groundwork for continued discussions of human rights issues related to LGBT people at an international level (Swiebel, 2008).

Following the Declaration of Montreal, a more influential document was drafted by a group of human rights experts brought together through a coalition of CSOs in Yogyakarta, Indonesia (O’Flaherty \& Fisher, 2008). The Yogyakarta Principles ('the principles'), as they came to be known, consist of 29 statements. Unlike the DoM, these principles apply existing human rights law to LGBT rights (Brown, 2010). Moreover, this document aims to set out "a comprehensive set of legal standards related to sexual orientation and gender identity" (Dittrich, 2008:32). The rights reflected in these principles all relate to existing binding human rights law (O'Flaherty \& Fisher, 2008). The text is drawn from several conventions, but a large part is based on the wording of the ICCPR (Brown, 2010). Moreover, the content of this document reflects four general obligations on states including that:

(i) all necessary legislative, administrative and other measures [be taken] to eradicate impugned practices; (ii) protection measures for those at risk [are put in place]; (iii) [there is] accountability of perpetrators and redress for victims; and, (iv) [there is] promotion of a human rights culture by means of education, training and public awareness-raising (O’Flaherty \& Fisher, 2008:137).

The Yogyakarta Principles can be seen as part of the process towards recognition of sexuality-based human rights (Brown, 2010). This is reinforced by the fact that the principles have been positively endorsed, several times, by UN treaty bodies (Corrêa et al., 2008).

In 2008, following pressure from LGBT activists and CSOs around the world, France and the Netherlands sponsored the Declaration on Sexual Orientation and Gender Identity (DSOGI), drafted by a number of CSOs. This document affirmed the human rights of LGBT individuals worldwide (UNGA, 2008a). The initial statement was 
endorsed by 66 states, with the notable exception of the United States 23 (Waites, 2009). Drawing upon the universal rights in Article Two of the UDHR, the right to equality under the law in the ICCPR and rights to non-discrimination on any basis in the IESCR, the statement is unequivocal in its support of human rights for all, regardless of sexual orientation or gender identity (UNGA, 2008a). However, it should be noted that since the statement remains open for signature and has not been adopted by the UNGA, it is not binding on states (UN, 2012). This is made clear by the fact that eight states who signed up to the 2008 statement, or later versions of it, still have criminalisation laws in place $^{24}$ (UNGA, 2008a; see Appendix One). However, this document remains important, given the fact that any statement before the UNGA can be applied in future sessions, arguably setting the scene for further debate (Sheill, 2009). Despite its nonbinding status, this statement of rights serves as a guide for states that undeniably breach a number of human rights, but are not included in current definitions of the juridical notion of 'crime' (Green \& Ward, 2000; Michalowski, 2010).

Despite the above document's influence, there is still difficulty in establishing decriminalisation as one of the initial steps to end human rights violations. A statement was submitted in opposition to the DSOGI by Syria, with the endorsement of 57 other states (UNGA, 2008b). The statement argues that the use of the term 'sexual orientation' could be used to refer to child sexual abuse and other criminal offences. Furthermore, it proclaims that there are no legal grounds for the proposed declaration, and that these matters should be left to individual states' jurisdictions (UNGA, 2008b). Perhaps surprisingly, the opposing statement also reaffirms the universality of human rights pertaining to non-discrimination based on whatever ground (Sheill, 2009). This fits with Cohen's (2001) concept of 'interpretive denial', where although states support the concepts of universality and non-discrimination, they appear to brush aside the occurrence of sexuality-based discrimination and violence. This is made clear in the concluding part of the statement, which argues that the UN's focus should prioritise efforts to "eliminate all forms of racism, racial intolerance, xenophobia and other forms of discrimination and to avoid giving priority to the rights of certain individuals" (UNGA, 2008b:Syrian general statement, author's emphasis). This appears to suggest that only racial discrimination is worthy of recognition. Both the DSOGI and the opposing statement show that the area of sexual minority rights remains "a

23 The US endorsed a later version of the statement in 2011.

24 These states are: Dominica, Mauritius, Nauru, Palau, Samoa, Seychelles, Sierra Leone and Tuvalu. 
battleground within the UN human rights system" (Saiz, 2004:50).

Following the DSOGI, a 2011 resolution at the Human Rights Council25 (HRCoun) allowed research to be conducted into laws and practices which discriminate against LGBT people, as well as violence directed towards them on the basis of their sexuality or gender identity (HRCoun, 2011c). The preliminary report, released in November 2011, details acts of violence and discrimination (expanded upon further below) and makes a number of recommendations, including the decriminalisation of consensual same sex relations (HRCoun, 2011d). Through the lens of organisational deviance, the HRCoun condemns criminalisation and related phenomena which, while not legally enforceable, can be understood as a normative framework (Green \& Ward, 2004). More succinctly, criminalising consensual same sex behaviour can be seen to breach the 'conduct norms' of the UN (Green \& Ward, 2004).

A further recent development is a $2012 \mathrm{UN}$ document, which sets forth the place of sexuality and gender identity in international human rights law (UNOHCHR, 2012). This establishes five key obligations of states under international human rights law. The third of these is to decriminalise homosexuality, with the argument that:

Laws that criminalize homosexuality give rise to a number of interrelated violations. Such laws violate an individual's right to be free from discrimination, which is enshrined in article 2 of the [UDHR]...as well as the rights to be protected against unreasonable interference with privacy and arbitrary detention, protected by articles 12 and 9 of the [UDHR] and articles 17 and 9 of the [ICCPR]. (UNOHCHR, 2012:28).

The reference to existing human rights instruments here is telling, considering that their application is uncertain and has only been ruled on in rare instances (Saiz, 2004). Moreover, as argued above, this amounts to neutralisation of any complaints that sexual orientation is not covered in human rights law. While it is argued that "the obligation on [s]tates is immediate" (UNOHCHR, 2012:11), this document illustrates how international law has been applied and may be applied in the future. By doing so, it sets out organisational norms which elaborate on the criminalisation of same sex relations as deviance by states. In this way, it fits within the framework of organisational deviance, as criminalisation and related phenomena are viewed as harmful by an audience - in this case the HRCoun and the UNOHCHR.

25 This is a separate entity to the Human Rights Committee (HRComm), which is the monitoring committee of the ICCPR. The Human Rights Council is a body attached to the UNGA. 
Organisational deviance is a useful framework to apply to acts which are not legally designated as crimes, but are (1) breaches of accepted standards of behaviours; (2) acts which are seen as breaking a social rule; and (3) acts to which an audience would apply sanctions if they could (Green \& Ward, 2004; Michalowski, 2010). This section has argued that a number of actions by CSOs and more recent UN documents show that criminalisation violates the norms which underlie human rights law. However, some criminologists have argued that wrongful actions resulting in penalty should be "determined by the substantive outcome of actions rather than their legal status" (Michalowski, 2010:16). The next section will explore this 'social harm' approach as a third level of analysis.

\section{Social harm}

A social harm approach is one that acknowledges the shortcomings of legal frameworks of crime, and looks to the outcomes of actions or inactions to determine wrongdoing (Hillyard \& Tombs, 2007; Michalowski, 2010; Pemberton, 2007). Moreover, as Hillyard and Tombs (2007:12) point out, "the undue attention given to events which are defined as crimes distracts attention from more serious harms". This section will set out the harms caused to individuals by discriminatory laws and the failure to protect LGBT individuals from state and private violence. These can be broadly separated into direct harms (those inflicted by criminalising laws in and of themselves) and indirect harms (harms caused through the state-endorsed construction of sexuality as deviant, abnormal and threatening to the moral order).

\section{Direct harms}

Lesbian and gay individuals have long been subject to a variety of harms based on their sexuality, the most obvious being the penalties for those convicted. Nine states, named in Chapter One, still have the death penalty for same sex crimes under their criminal laws (see Appendix One). While such laws are differentially enforced, they do give state officials the power to detain and punish those engaging in illegal acts.

As outlined in Chapter Two, penalties are variable and unpredictably enforced, however even in cases which do not progress to the sentencing stage, arbitrary arrest, detention and ill treatment, including torture, are not unusual. The International Gay and Lesbian Human Rights Commission (IGLHRC) regularly publishes 'country reports', produced 
by CSOs, to present evidence of human rights abuses at universal periodic reviews (UPRs) and monitoring committees. While there is not space to detail results from all states with criminalising laws, some examples include: arbitrary arrest, either in homes or on the street in suspected 'gay hang outs' (Gays and Lesbians of Zimbabwe [GALZ], 2011; Guyana Rainbow Foundation [GRF] et al., 2012; IGLHRC \& Iranian Queer Organisation [IRQO], 2011); unlawful detention for extended periods of time, often accompanied with verbal abuse and extortion (GRF et al., 2012; Thoreson \& Cook, 2011); systemic discrimination and harassment by law officials (IGLHRC \& IRQO, 2011); the use of torture to extract confessions (IGLHRC \& IRQO, 2011; Thoreson \& Cook, 2011); and, sexual assaults on men in the attempt to 'prove' their homosexuality through evidence of anal sex (Thoreson \& Cook, 2011). Michalowski (2010) notes that social harm models must account for alternatives to the status quo; it is clear from the evidence above that criminalisation provides the justification for arrests and the need for proof further justifies the injurious methods to obtain convictions.

Moreover, attempts to 'cure' homosexuality are not unusual. In many states, those who 'out' themselves to family or friends are sent to get psychiatric treatment, which may result in institutional detention under mental health laws (AI, 2001). More rarely, gay men can be subject to forms of castration (HRCoun., 2011d). There is no doubt that these practices constitute a form of harm, and that in many instances they appear to be sanctioned, or encouraged, by state officials.

Amnesty International (2008:5) state that "[b]y institutionali[s]ing discrimination, laws criminali[s]ing homosexuality reinforce systemic disadvantage of lesbians, gay men and bisexual people....and act as an official incitement to or justification for violence against them". Their annual reports also consistently note that harms are inflicted by state agents, deriving from their power to arrest those suspected of homosexual activity. The 2012 report includes: cases of men being imprisoned for homosexuality, often lured and trapped by security forces posing as gay men; orders by security forces to arrest all gay men and lesbians and to encourage landlords to report those they suspected; three men executed for 'sodomy' in Iran; punishments of flogging and imprisonment in Iran and Nigeria for alleged homosexuality; the enactment of a law criminalising lesbian sex in Malawi; and arbitrary arrests in a number of states (AI, 2012). This mirrors previous reports, with the 2011 report documenting that in Uganda "LGBT individuals and rights activists continued to face arbitrary arrests, unlawful detention, torture and other ill- 
treatment by the police and other security personnel". This is also the case in many states with criminalising laws (AI, 2011:335). There is no doubt that these harms constitute "...acts whose consequences, rather than intentions, are as bad as crime regardless of the juridical or public approval" (Michalowski, 2010:21). While these harms can be directly connected to criminalising laws and their enforcement, this section will now turn to more indirect, but nonetheless pertinent, harms.

\section{Indirect harms}

An alarmingly high number of people face daily danger from the general public, as well as state officials, due to their sexual orientation (AI, 2008). These indirect harms emerge from state-sanctioned discrimination and bias, which leads to high levels of violence against this group. This section explores some of the indirect harms that occur in connection with criminalisation. Such harms occur in states without criminalising laws, but in criminalising states, these harms are often committed in an environment of total impunity, or are publicly endorsed by the state.

While stigma is related to homosexuality in most - if not all - countries, criminalisation entrenches and sanctions discrimination and violence against those presumed to be outside the heteronorm (AI, 2008). Social attitudes towards those suspected of homosexuality have led many lesbian and gay individuals to seek asylum on the basis that they fear persecution from the public, and do not trust their home state to protect them from violence (AI, 2008; IGLHRC \& IRQO, 2011). Public figures regularly denounce the perceived immorality of same sex relations; the Iranian Prime Minister described homosexual sex as a 'despicable act' (IGLHRC \& IRQO, 2011), in Cameroon, homosexuality was denounced as 'un-African' (Human Rights Watch [HRW], 2010), and in Malawi and Zimbabwe the respective Presidents described gay men as 'worse than dogs' (AI, 2012; Mittelstaedt, 2008). In Uganda, recent proposed legislation seeks to punish homosexuality with the death penalty and up to seven years in prison for anyone offering support to the idea of homosexuality (Dicklitch, Yost \& Dougan, 2012). Furthermore, media sources in criminalising states also take part in inciting violence by publishing the names of those alleged to be gay or lesbian (AI, 2008).

This leads to a climate in many of these states where violence on the basis of perceived homosexuality is a routine occurrence. For example, in the Philippines, 28 killings on the basis of sexuality were recorded in the first half of 2011 (AI, 2012). Moreover, human 
rights activists who reproach their states on LGBT issues have been killed or forced to seek asylum elsewhere in fear of their safety (HRW, 2007; AI, 2012). Harassment and extreme violence are often perpetrated in purposefully degrading and demoralising ways. Men are forced to strip before being beaten by members of the public in a moblike mentality (e.g. HRW, 2004; 2010). The HRCoun's (2011d:9) recent report states that "homophobic hate crimes and incidents often show a high degree of cruelty and brutality and include beatings, torture, mutilation, castration and sexual assault". Such violence is encouraged by demands that the public engage in surveillance of those under suspicion (AI, 2012), which leads to an environment of vigilantism (AI, 2008).

Sexual violence or the threat of sexual violence against lesbians is also reported in many of these states (HRCoun, 2011d; UNOHCHR, 2012). Some gay men have also been victims of sexual violence due to their sexual orientation (HRCoun, 2011d), but the general pattern indicates that women are sexually victimised far more often on these grounds (AI, 2001). Amnesty International (2001) explains that lesbians are often targeted for forced pregnancy, which is seen as a way of enforcing heterosexuality upon them. Many men:

...use rape as a form of therapy. The term 'corrective rape' has been coined to describe this particular type of hate crime, because the rapists claim that they are acting in the lesbian's interest, by 'teaching her to behave like a woman' (Reddy, Potgieter \& Mkhize, 2007:10).

This form of sexual victimisation has been reported in a number of states, typically used as a method to 'cure' women of their lesbian desires (AI, 2011; Dicklitch et al., 2012; HRCoun, 2011d; HRW, 2004).

Yet, these crimes regularly occur in an environment of impunity, where public officials turn a blind eye to such acts or ignore reports of violence from victims (AI, 2008; GRF et al., 2012). Further, victims usually do not come forward when victimised, given the chance of self-incrimination (AI, 2001). This enables states to deny knowledge that violence has occurred and also to deny their responsibility in protecting citizens through what Cohen (2001:80) calls "the 'twilight between knowing and not-knowing': alleged perpetrators and collusive bystanders caught in the web of denial that is 'part and parcel' of the act", a point further explored in the next section.

Many states with criminalisation laws in place also have high rates of HIV/AIDS. 
Moreover, many states continue to perpetuate the false assumption that gay men and sex workers are entirely responsible for its spread (AI, 2008). This can result in public health programmes being labelled as services for homosexuals, meaning that many 'at risk' groups avoid them for fear of being identified (Grenada Caribbean HIV/AIDS Partnership et al., 2007) In accordance with this, AI (2008:21) states that these assumptions make it more difficult to "access information on HIV prevention, condoms and health services and [this] results in the targeting of individuals and organi[s]ations that provide HIV/AIDS education and services". There are documented cases of doctors and other health professionals refusing to treat HIV-positive patients, stemming from the belief that they are engaging in 'high risk' behaviours and, for that reason, deserve to be sick (AI, 2008; HRW, 2004).

It is clear from the above evidence that both direct and indirect harms are inflicted by states who maintain criminalisation laws, even where these laws are unenforced. Critically, a social harm approach can focus on what can be done to reduce levels of harm (Hillyard \& Tombs, 2007). While a number of different social institutions have a role in perpetuating homophobia and heterosexist violence, changing the law so that all citizens are truly under the protection of the state would be a step in the right direction. This mirrors the sequence of changes (discussed in Chapter Two) that states can make towards recognition of same sex relationships and sexual rights (Waaldijk, 1994).

This chapter has provided a multi-level analysis of how state actions or inactions pertaining to the criminalisation of sexuality can be understood as 'criminal'. A juridical understanding of crime is the most straightforward framework, but given the difficulties associated with cementing the sexuality-based discrimination in international instruments, it "poses a potential straitjacket for the study of state crime since states rarely criminalize or prosecute wrongful acts undertaken to facilitate their interests" (Michalowski, 2010:16-17). An organisational deviance approach that centres on adherence to 'conduct norms' allows actions/inactions similar to crimes, but not specifically designated as such, to be exposed as wrongful (Green \& Ward, 2004). A final level is the social harm approach, which looks to the outcomes of actions, rather than their intent or potential fit with a normative framework. Shaping discussions of practice around social harm has the potential to address practices which perpetuate social injustices (Hillyard \& Tombs, 2007), while also proposing potential moves away from these injustices (Michalowski, 2010). The next chapter examines how international 
human rights norms can become institutionalised, primarily through the work of CSOs. 


\section{Chapter Four: Civil society and challenges to criminalisation}

\section{Introduction}

Drawing from the understanding of criminalisation as a state crime in Chapter Three, this chapter examines how these understandings can transfer to state policy and general society. It first analyses how human rights norms become institutionalised in states, emphasising the importance of CSOs in challenging and pressuring states 'from below'. Risse and Sikkink's (1999) spiral model is used here to understand the various processes undertaken by states and citizens before an idea becomes a norm. The second part of this chapter analyses the use of a specific UN mechanism - the UPR - that has a high amount of CSO involvement throughout. How states are challenged within the UPR (by both other states and CSOs) is examined, and how these states are then able to neutralise, minimise or deny responsibility for human rights violations is discussed.

\section{The normalisation and institutionalisation of human rights norms}

States are pressured to adhere to international human rights norms through several processes and structures. Much of the research connected with international human rights has focused on the ability of the UN and international law to guarantee human rights to all (Evans, 2005). Consequently, the role of CSOs in resisting repressive state actions is often ignored (Green \& Ward, 2012). This section outlines how norms become institutionalised; consequently it looks at the way in which the UN adheres to, and enforces norms, through international law. Finally, it details the role of civil society in pushing for change at both domestic and transnational levels.

Finnemore and Sikkink (1999:251) define norms as "standard[s] of appropriate behavio[u]r for actors with a given identity". The evolution of a norm can be understood as a three stage process: emergence, cascade and internalisation. Firstly, norms emerge and this is often through the work of civil society groups who, through moral consciousness raising, attempt to persuade both states and their citizens of the importance of these norms (Finnemore \& Sikkink, 1999). Consequently, norm cascades refer to a state rapidly accepting a set of international norms as legitimate, usually in an effort to maintain its international reputation. Internalisation of norms occurs when norms introduced through cascades are no longer questioned or debated (Finnemore \& Sikkink, 1999). 
The UN is the primary forum through which international law is created and enforced. A host of conventions and principles hold states to standards of appropriate behaviour towards citizens (Narayan, 2006). However, the powers of the UN to act against states that do not adhere to international human rights law are severely limited. States must sign up to treaties and ratify ${ }^{26}$ them before they are legally subject to their provisions; ratification is also by no means a guarantee that human rights norms will be enforced (Cerna, 1994). UN attention is, understandably, aimed only at the worst violations (Saiz, 2004). Thus, even when sanctions have been put into place, they are rarely enforced and while committees play a role in 'shaming' states for breaches of human rights, they cannot mandate domestic change (Narayan, 2006). The extent to which international law is legally binding is uncertain and reservations ${ }^{27}$ to major human rights conventions are incredibly common (Saiz, 2004). This makes the status of international law unclear and largely dependent on compliance by states. As Wilets (1997) notes, it falls largely on those victimised by illicit state actions to request international protection.

In this context, the role that CSOs take in both cementing and challenging the hegemony of the state is vital. Civil society, as Gramsci viewed it, is independent of both the coercive state apparatus and the economy (Kaldor, 2003). Drawing upon work on civil society, Green and Ward (2012) argue that two main versions of civil society are evident. 'Civil Society I' posits that civil society acts with and aids state democratic processes by helping to engage citizens in decision-making, in turn strengthening the legitimacy of the state (Foley \& Edwards, 1996). With this understanding, a state with a strong civil society will have less violence, repression and corruption (Green \& Ward, 2012). Domestic CSOs are able to uphold the state's hegemony through a kind of social contract, where the state makes sacrifices in order to gain consent of the population and thus legitimacy to govern (Ward \& Green, 2000).

Conversely, 'Civil Society II' underlines the importance of civil society as independent from the state, and able to produce resistance to illegitimate state actions (Foley \& Edwards, 1996). As Green and Ward (2012: 30) succinctly explain "the first line of argument sees civil society as strengthening the democratic state, whereas the second

\footnotetext{
${ }^{26}$ Ratifying treaties simply means adopting their provisions into domestic legislation.

27 Reservations can be made by states on signing up to UN conventions. They allow states to opt out of certain provisions (Vienna Convention, 1969).
} 
argument sees it as resisting the authoritarian state". In states where civil society is repressed, domestic groups may go directly to international organisations to pressure states from the outside, allowing networks to be created to more effectively disperse information (Risse \& Sikkink, 1999).

Green and Ward (2012) argue that both versions of civil society described above are required. With this understanding, contemporary civil society can be seen as existing between, on the one hand, militant resistance to state repression and, on the other, the total amalgamation of civil society into the apparatus of the state (Green \& Ward, 2012). Risse and Sikkink (1999) offer a useful five stage 'spiral model' for mapping how CSOs aid in cementing human rights norms in a given state. The five phases of the model are: 1) repression, 2) denial, 3) tactical concessions, 4) prescriptive status, and 5) ruleconsistent behaviour (see Figure 4.1). States move into the first phase when there is weak domestic opposition to state actions and information is gathered by CSOs to publicise breaches of human rights, raising the level of public attention (Risse \& Sikkink, 1999). In the second phase which follows, information is produced, often in the form of human rights reports, by transnational CSOs and states will often react by denying that norms are valid for all states. Consequently, transnational CSOs will become mobilised.

The third phase outlined by Risse and Sikkink (1999:25) is the use of "tactical concessions" by states in order to silence criticism. At this stage, it is assumed that efforts from transnational CSOs have led to domestic CSOs becoming more prominent within the state. Consequently, pressure is put on governments to end human rights abuses from both above (typically through UN challenging) and below (with the work of CSOs) (Green \& Ward, 2012). In this phase, states will no longer deny that international human rights norms exist and 'shaming' by international human rights organisations becomes more effective. This leads on to the fourth phase where human rights norms gain 'prescriptive status', meaning the government acknowledges them, regardless of the audience and institutionalises them through the ratification of conventions and optional protocols (Risse \& Sikkink, 1999). The final phase in this model is the development of 'rule consistent behaviour' by the state. Even when states have subscribed to, and acknowledged the validity of human rights norms, violations may 
continue $^{28}$. At this stage, domestic and transnational civil society networks must keep pressuring governments to comply, as even after norms are nominally implemented, societal implementation is much more difficult (Risse \& Sikkink, 1999).

\begin{tabular}{|c|c|c|c|c|c|}
\hline Phase & Repression & Denial & $\begin{array}{l}\text { Tactical } \\
\text { Concessions }\end{array}$ & $\begin{array}{l}\text { Prescriptive } \\
\text { status }\end{array}$ & $\begin{array}{l}\text { Rule- } \\
\text { consistent } \\
\text { behaviour }\end{array}$ \\
\hline Dominant actors & $\begin{array}{l}\text { Transnational } \\
\text { CSOS }\end{array}$ & $\begin{array}{l}\text { Transnational } \\
\mathrm{CSOs}\end{array}$ & $\begin{array}{l}\text { Transnational } \\
\text { networks and } \\
\text { domestic } \\
\text { opposition }\end{array}$ & $\begin{array}{l}\text { National } \\
\text { governments } \\
\text { and domestic } \\
\text { society }\end{array}$ & \begin{tabular}{|l} 
National \\
governments \\
and domestic \\
society
\end{tabular} \\
\hline
\end{tabular}

Figure 4.1: Spiral model: phases and dominant actors (adapted from Risse \& Sikkink, 1999:32).

This section has outlined the ways in which norms become institutionalised in states, primarily through the work of domestic, and increasingly, transnational, civil society groups. While the UN takes primary responsibility for monitoring the behaviour of states, it is usually only through the work of civil society groups that human rights breaches come to the attention of the UN. Norms are dynamic and the process by which these come to be fully accepted by states can be understood through Risse and Sikkink's (1999) spiral model, including initial opposition, and consequently the mobilisation of civil society groups. The next section will use the example of the UPR, a mechanism with room for significant CSO involvement, to look at how states are challenged and how they respond.

\section{Challenges to states through the Universal Periodic Review process}

Despite the uncertain place of sexual minorities in international law, human rights abuses connected with sexual orientation are increasingly raised within the UN, primarily due to the work of domestic and transnational CSOs. This section draws together the discourses with which states are challenged on human rights abuses, and the resulting dialogues between states and the UN. The UPR is the main means of challenging states on criminalisation due to its mandatory and regular reporting, as well as the fact that it covers all major human rights treaties (Cowell \& Milon, 2012). Moreover, as Rathgeber (2008) points out, states are obligated to go through consultation with CSOs before submitting their report and this high level of CSO

\footnotetext{
28 This is often due to the fact that even where states have embedded norms into their own discourse, representatives of the state, typically police officers and members of the armed forces, may continue to breach human rights (Risse \& Sikkink, 1999).
} 
involvement continues throughout the process, making the UPR a useful mechanism with which to look at challenges. Drawing on strategies used by states to neutralise, ignore or deny challenges from other states, it will be argued that while the UPR process is unique in its capabilities to confront states about abuses, it is limited in terms of gains.

The UPR runs on a four year cycle and every UN member state must account for its actions in each cycle (Cowell \& Milon, 2012). The process of the UPR is comprised of four main phases: (1) the gathering of information and drafting on the initial report; (2) a process of submissions from 'relevant stakeholders' after the submission of the report; (3) an interactive dialogue with the state in question and a number of other rapporteur states, culminating in an 'outcome report'; (4) the adoption of the report and initial follow-up on recommendations; and (5) a further follow-up report (Rathgeber, 2008).

The UPR process is one which emphasises the participation of civil society groups from the beginning. For example, states are expected to consult with CSOs in drafting the initial report on the state of human rights. Further, written submissions are requested from stakeholders (including CSOs) after the release of the original report, allowing criticism of incorrect information about human rights in the state concerned (Rathgeber, 2008). The only part of the process unavailable to CSOs is the interactive dialogue, where only states or special observers (e.g. Palestine, the Holy See) are allowed to speak. However, during the adoption of the report and follow-up on recommendations, CSOs are again allowed to take the floor to express concerns about recommendations not supported or followed up by the state (Rathgeber, 2008). Finally, the follow-up report again encourages participation by CSOs (Rathgeber, 2008).

A recent study examining states' responses to challenges on criminalisation during the 2011 UPR round (Cowell \& Milon, 2012) found that states typically responded in three ways. The most favourable response was a complete repeal of legislation; Sao Tome and Principe responded in this manner by repealing provisions in their penal code. A second response suggests that UPR recommendations have prompted a review of legislation; several states including St Lucia, Kiribati and Samoa have responded in this way (Cowell \& Milon, 2012). Finally, a third response is one of resistance; this includes states who "demonstrated considerable resistance to the recommendation to decriminalise" (Cowell \& Milon, 2012:350). States resist in three main ways: the first response echoes 
the lack of a public mandate for decriminalisation; the second response suggests that societal attitudes are unchangeable, or alternative, that homosexuality does not exist in the state; while the third response denies that any discrimination is present and cites domestic laws, which affirm non-discrimination (Cowell \& Milon, 2012).

While Cowell and Milon's (2012), research offers a useful framework for analysing responses, this thesis uses a different framework to explain responses, as it seeks to examine the ways in which states deny sexual orientation discrimination and a more detailed model is required. First, 'invisibility' refers to situations where criminalisation is rendered invisible either through the non-mention of criminalisation or refusal by states to discuss issues which are raised. Second, 'lack of a mandate' refers to responses where states indicate that they cannot decriminalise due to the perceived lack of a democratic mandate from citizens. Third 'not our culture/religion' refers to states that neutralise challenges by arguing that homosexuality is not something accepted in their culture, or by their religion. Fourth, some states argue when challenged that there is no evidence of discrimination, that there has been no prosecutions and that criminalisation is therefore not an issue. Finally, some states acknowledge that criminalisation and the problems associated with it need to be examined and state either that they will review the laws, or look to overturn them. Each of these five responses is now examined in turn. For this analysis, the most recent UPR documents available for each state have been used.

\section{Invisibility}

A number of states were not challenged on sexual orientation discrimination at all. These were states with major human rights violations; they are often countries in transition or in a near-constant state of conflict. Saudi Arabia, for example, still does not allow extramarital sex under its criminal laws (HRCoun, 2009a), while states such as Afghanistan and Pakistan are challenged on serious gender inequities as well as continued and overt torture by authorities (HRCoun, 2008, 2009b). For these reasons it is clear that other human rights take precedence, and due to the time limits imposed in the UPR process, criminalisation is not considered to be a serious issue.

Four other states simply did not respond to challenges raised during dialogue, or to the subsequent recommendations. Ignoring the UN in the UPR process is easy; recommendations are not binding, and other states and civil society groups can only 
request that recommendations are followed up (Cowell \& Milon, 2012). Thirteen other states listed that they did not support recommendations but did not give any reasons for this. This amounts to what Cohen (2001:98) deems 'moral indifference', where states do not deny troubles associated with criminalisation "because the recognition is not troubling". Although it is difficult to glean anything from a lack of support with no reasoning offered, it can be construed that states simply are not concerned because they do not see the issues raised as legitimate (Cohen, 2001). Through techniques of avoidance, states make it much more difficult for these rights to be continually contested (Mathiesen, 2004). Alternatively, states engage in denial of knowledge, to the extent that they do not want to know anything further about human rights abuses, so they will not engage in dialogue about them (Cohen, 2001).

\section{Not our culture/religion}

A further justification given for criminalisation was that of religion and/or culture. While there were some states that used the high rates of religious belief among the population as a reason for not having a mandate, this category refers to states which maintained that rights to sexual orientation were not universal. Further, many states explained that homosexuality simply did not exist in their country, or that, if it did, it was a Western imposition and something that was not accepted within the culture. A clear example of this is the response from Bangladesh to recommendations: "Bangladesh is a society with strong traditional and cultural values. Same-sex activity is not an acceptable norm to any community in the country. Indeed, sexual orientation is not an issue in Bangladesh...Therefore the recommendation is out of context" (HRCoun, 2009e:5). These arguments draw from the 'righteousness' of compulsory heterosexuality and the apparent non-existence of homosexual identity. In adopting this attitude, Bangladesh (and other countries which come under this category) are advocating the notion that "any society can act according to its own morality" (Cohen, 2001:110). Moreover, by doing so, they also invoke comparison with other apparently less moral (Western) states who, they argue, have imposed their norms onto cultures who do not accept them (Cohen, 1996).

Kenya simply stated that homosexuality was not culturally acceptable, with no response to any of the issues raised in connection with criminalisation (HRCoun, 2010b). In this way, the statement can be made that decriminalisation is contrary to the morals of a society without any regard to unintended legal or social consequences. While they do 
not try to deny that criminalising laws are in place they do deny the slant put on it (that the state is failing to protect its own citizens) by the UPR process, because they deny the very existence of these people. Kenya can be seen to ignore the existence of gay and lesbian people "[b]ecause their very presence is not acknowledged, they cannot be seen as victims" (Cohen, 1996:532).

A final way that states can respond on grounds of culture or religion is by not explicitly denying that discrimination and/or violence is present, but maintaining that this is not directed towards 'victims'. By denying the existence of 'real' victims, states can excuse or legitimise crimes committed against them (Sykes \& Matza, 1957). These people do not meet victim status because they are a "lower form of being with less right to comparison than other humans" (Cohen, 1996:531). Rather, those who are on the receiving end of such actions are only in that position because of their own wrongdoing. For example, Malaysia's report simply states that homosexuality is contrary to Islamic law (HRCoun, 2009f). With this in mind, anyone engaging in such activity is committing a sin, and deserves whatever indignities are perpetrated on them (Cohen, 2001).

\section{'But democracy': Lack of a mandate}

A large number of states with criminalisation laws in place responded to recommendations by saying that they had no mandate to decriminalise and that any legal change would need to be done in consultation with the population. Given that one major UN premise is transitioning to democracy, it would seem that this is a difficult proposition to argue against (UN, 2012). By appealing to civil and political rights, such as the democratic process, "the language of justification is total and self-righteous" (Cohen, 2001:98), and states can argue that they are unable to brush aside democratic rights. This is a form of 'implicatory denial', where states appeal to necessity, arguing they cannot decriminalise because it goes against the will of citizens (Cohen, 1996, 2001).

For example, Barbados, in an addendum to the initial report of the Working Group, stated that the government did not have a mandate for decriminalisation. To emphasise this point, they cited a study which indicated that decriminalisation was not favoured by the majority of the population (HRCoun, 2009c). Such justifications allow states to argue that even if sexual orientation is a human right, other human rights (i.e. democracy) trump it, therefore, making the suggested changes would be contrary to 
these 'higher' human rights (Cohen, 1996). Of added interest was Syria's contribution to the dialogue of this Working Group, where they encouraged Barbados to "continue to exercise its full sovereign right concerning sexual orientation on the basis of its cultural fabric and legal system requirements" (HRCoun, 2009c:15). Such responses argue against the universality of human rights, which are seen to be imposing on local cultures (Cohen, 2001). Additionally, by insisting that a mandate needs to come from the public, rather than from the government, states in this category are able to "isolate [the] offence within a specific situation or place, without seeing [it] as immoral in general" (Cohen, 2001:93).

Of note, Kiribati and Tuvalu were also able to argue their lack of a mandate with the added justification of entrenched laws, which would take a large majority in Parliament to overturn (HRCoun, 2009d, 2010a). This gives impetus to the claim that it is not just difficult but impossible for laws to be changed. Mathiesen (2004:30) explains that in such instances "it is not possible to carry out the suggested demand or alternative goal without threatening or breaking down the general activity [i.e. the entrenched nature of criminal law] which was the point of departure".

\section{No evidence of discrimination and no prosecutions}

Since criminalisation was connected with violence and discrimination in many of the UPR dialogues, several states simply responded, by stating that non-discrimination was already guaranteed under constitutional law, and that no cases of it had been reported. For example, Guyana was adamant in its claim that no discrimination based on sexual orientation had been reported to the police (HRCoun, 2010d). Ignoring any evidence from civil society groups and focusing on official reports and statistics, states in this category are able to deny that there are any problems with human rights, thus there is no need to overturn laws. Interestingly, Togo stated that it was "not prepared to legislate on the question of homosexuality, given that homosexuals were not subject to any form of discrimination. Such legislation might in fact be counterproductive, given the attitude of the population" (HRCoun, 2011e:9). It is unclear what 'attitude' this is in reference to. However, the response shows a clear denial of discrimination faced by sexual minorities, amounting to a denial that victimisation had ever taken place - 'we don't know about the discrimination, therefore there is no discrimination'.

Others in this category may rely on the power of domestic human rights laws to 
illustrate that nothing is happening and that there is no discrimination. For example, Namibia stated that discrimination against sexual minorities did not happen as it went against the rights guaranteed in the Constitution (HRCoun, 2011f). This relates to Cohen's (1996:524) assertion of literal denial where because "the action in question is prohibited by the government...then, by definition, the action could not have occurred".

A final variety of denying discrimination was evident in states where laws were reportedly not enforced. St Kitts and Nevis, Swaziland, and Trinidad and Tobago were all adamant that the laws in place were of no consequence, as there had been no prosecutions (HRCoun, 2011g, 2011h, 2011i). Thus, while the existence of discrimination in legal codes is not denied, the flow-on effects from these are. These states are able to proclaim that unenforced discriminatory laws cause no harm.

\section{Partial agreement and agreement}

Four states agreed to decriminalise or to look seriously into decriminalisation. Burundi had an amendment to change the Penal Code rejected in the upper house. They also stated that the process would be reviewed (HRCoun, 2009g). Grenada indicated that the Cabinet would consider the laws, but there has since been no follow-up (HRCoun, 2010c). This is what Cohen (1996:536) described as 'partial acknowledgement' where states "appear to acknowledge at least some claims and criticisms...they give every appearance of taking the report's allegations seriously".

Overall, this section has aimed to show the way in which the process of the UPR has been used to challenge states on the criminalisation of same sex relations. Drawing on Cohen's (2001) framework, it has illustrated that states contest these allegations in five ways: invisibility, the lack of a mandate, not fitting with culture/religion, denial that discrimination is present and a partial acceptance of recommendations and/or observations.

\section{Conclusion}

In summary, this chapter explores the ways in which the criminalisation of same sex relations can be understood as a 'crime' drawing on Michalowski's (2010) tripartite model encompassing juridical, organisational deviance and social harm approaches. Further, it identifies ways in which human rights norms can become institutionalised, contributing to sexuality-related human rights breaches being recognised as crimes, 
both within and outside states. While the UN is responsible for officially condemning and challenging states, CSOs play a vital role in exposing breaches of human rights and raising awareness about their occurrence. This is exemplified in the UPR process, one which has heavy involvement with CSOs from the beginning. Finally, this chapter demonstrates that, while significant progress has been made in 'shaming' states which still have criminalisation in place, the ideal of sexual orientation as a universal human right is still a lofty one. 


\section{Chapter Five - 'The most homophobic place on Earth?'29: \\ Jamaica, sexual orientation and state crime}

\section{Introduction}

While previous chapters analysed criminalisation globally, this chapter uses the case study of Jamaica to more deeply examine the background to criminalising laws and the environment that supports their continued existence. It will frame the existence of Jamaican criminalising laws using Michalowski's (2010) tripartite model of state crime. This chapter then sets out how Jamaica has come to be known as one of the most homophobic countries in the world and, further, how this homophobia has been shaped and reshaped through cultural relationships and structures. It should be noted that the situation in Jamaica, while particularly extreme in many ways, is one replicated in many of the states discussed in Chapters Two, Three and Four.

This chapter illustrates how both the historical context and contemporary environment in Jamaica continue to support the existence of criminalisation. The chapter first explores the historical context in Jamaica, beginning in the period of colonisation, and specifically examines how this background links to contemporary views of sexuality. The laws which emerged with British colonisation will then be explored. The subsequent section focuses on contemporary Jamaica, explaining the support for culturally embedded homophobia in Jamaica and examining how sexuality is defined. This chapter argues that criminalisation in Jamaica is a form of state crime. In particular, criminalising laws and practices can be viewed as crimes through juridical, organisational deviance and social harm frameworks.

\section{Historical context}

Jamaica, a small island in the Caribbean Sea, was originally 'discovered'3o by Christopher Columbus and settled by the Spanish in the late- $15^{\text {th }}$ century (Hurwitz \& Hurwitz, 1971). The Spanish started the first plantations and took slaves from West Africa as a labour force. The plantations were expanded by the British who gained formal ownership of Jamaica in the $17^{\text {th }}$ century (LaFont, 2001). A large proportion of plantations produced sugar, a much needed colonial commodity, and this meant that a

\footnotetext{
29 Title from Padgett (2006)

30 In fact, the indigenous Arawak people originally inhabited the island from as early as 40ooBC, and were consequently all but eliminated by the disease and destruction wrought by European settlement (LaFont, 2001).
} 
larger seasonal labour force was required. By the late- $18^{\text {th }}$ century, over 600,000 slaves had been brought over from Africa (LaFont, 2001). This represented a component of the 'triangle' of the Atlantic slave trade - British goods going to Africa, Africans being sent to the Americas as slaves, and finally products sent to the European market (Hurwitz \& Hurwitz, 1971; Turner, 1998). The British looked upon African slaves as needing civilisation, which it was thought would help to repress their 'animal' sexuality (LaFont, 2001; Turner, 1998). Closely connected with colonisation was the mid-18 $8^{\text {th }}$ century arrival of missionaries, from a number of denominations (Hurwitz \& Hurwitz, 1971). Christianity was used at first to justify slavery: Christian preaching emphasised that African people were slaves because that is the way that God had intended it, and the only important qualities for any slave to possess were obedience and servitude (Charles, 2001). These existed in contrast to ideas of normative masculinity for male slaves.

Connell (2005) defines hegemonic masculinity as the range of dynamic practices which lend legitimacy to the patriarchy. In Anglo-European societies, this has been particularly centred on men being dominant and women subordinate, in both public and private spheres (Hooper, 2001). In the Jamaican context, black and white masculinities competed and interacted over material resources and access to women's sexuality (Beckles, 2004). Moreover, black men who were subordinated through slavery developed a specific masculinised identity as a means of survival and independence outside of the control of slave owners (Beckles, 2004). It is also worth noting here that $65 \%$ of those transferred from West Africa were men and this meant that many of the communications with plantation owners were solely between men (Beckles, 2004). The defeat of Western Africans and the loss of control over their land symbolised the white colonist's victory and reinforced European domination - white men represented masculinity through imperialism over enslaved black men (Beckles, 2004).

In this context, many male Afro-Jamaican slaves were made to feel emasculated, not only by their reliance on white colonists, but also through their limited ability to protest against their treatment (King, 2006). A 'black masculinity' emerged which emphasised the same tenets as its European counterpart; both political authority and the subjugation of womanhood were valued by many Afro-Jamaican men (Beckles, 2004). Furthermore, the aspects of this masculinity including power, dominance and authority were familiar to black men who were ritually feminised through their servitude (Beckles, 2004). Subsequently, white men were able to exert masculine power over slaves, as well 
as under the broader spectre of imperialism (Beckles, 2004). However, some slaves also had an opportunity to exercise this power over other slaves and this typically occurred along racial lines, with lighter skinned slaves having a higher status with owners and being given greater positions of power on plantations (Patterson, 1967).

British colonists constructed African sexuality as the 'other', against which European sexual practice could be measured. Simultaneously, Afro-Jamaicans looked upon the colonists as the 'other', particularly due to the prevalent sexual exploitation of slaves by the British elite (Allyn, 2012). The colonial construction of female slaves as 'temptresses' meant that white slave owners were seen as weak or helpless to the clutches of slave women, who were deemed by a historian at the time to be "possessed of no scruples, relentless ambition and amazing sexual skills" (Burnard, 2007:82). In reality, as Burnard (2007) points out, this construction of slave women as willing participants ignores what was undoubtedly sexual violence in the majority of cases. Female slaves were seen as sexually insatiable, and the property of their owners, so their denials meant very little (Burnard, 2007). This also contributed to feelings of emasculation among men; in an environment where white colonists were dominant, the denial of their patriarchal status as 'real men' with complete control over their wives and children served to undermine a male slave's sense of masculinity (Patterson, 1967). Moreover, when slave women were unavailable, settlers often turned to men to meet their sexual needs (LaFont, 2001). The knowledge among Jamaicans that male slaves were raped in front of their partners is thought to be one of the reasons that 'homosexuality' 31 is seen as a colonial imposition (King, 2006).

LaFont (2001) emphasises the behaviour of the elites, as well as the treatment of slaves - both women and men - as one of the driving forces behind the rejection of nonprocreative sex, particularly sodomy. She argues that by rejecting the behaviour of the elites, slaves could construct a moral superiority and this "would have been facilitated by the fact that many elites created and indulged in lives that could be seen as indefensible at the moral level" (LaFont, 2001:para 52). Further, there is evidence to suggest that slaves were victimised not only sexually, but also through torture (Smith \& Kosobucki, 2011). King (2006) notes that Jamaicans adopted homophobic attitudes as a form of resistance to the white elites and the physical and sexual violence that

${ }^{31}$ Of course, as Foucault (1976) points out, the concept of 'homosexuality' as it is thought of today did not actually come into existence until the late- $19^{\text {th }}$ century. 
accompanied slavery. Resistance to slavery in Jamaica was also particularly strong, with uprisings and rebellions occurring at least once every five years until emancipation (Turner, 1998). This formed part of the black liberation struggle, which centred on a rejection of all western phenomena. 'Sodomites' were viewed by Jamaicans as overly influenced by liberal western sexual mores and it was thought "that someone with a homosexual identity could not truly be in tune with the struggle for black liberation because they had accepted a 'western perversion"' (King, 2006:43).

The eventual emancipation of Afro-Jamaican slaves occurred with the decline in the demand for sugar, as well as the abolitionist movement of the $18^{\text {th }}$ century, spearheaded by William Wilberforce (Smith \& Kosobucki, 2011; Turner, 1998). Missionaries also became key figures in the abolitionist movement, particularly Baptists, many of whom were ex-slaves from the United States (Charles, 2011). Slavery was formally abolished for the entire British Empire in $1833^{32}$ and emancipation in Jamaica occurred in 1834, with the eradication of unpaid labour in Jamaica occurring in 1838 (Turner, 1998). After emancipation, missionaries from numerous denominations were involved in spiritually educating the slaves (Charles, 2011) and they encouraged the view of sexual relations as solely procreative (LaFont, 2001). Moreover, biblical verses calling for the death of a "man [who] lie[s] with a man as he lieth with a woman", as well as mandating sex only to "multiply and replenish the earth" cemented these notions (cited in Charles, 2011:910). This had the effect of dichotomising heterosexuality as 'good' and 'sodomy' as 'bad' (Charles, 2011).

The Jamaican Offences Against the Person Act was passed by colonial powers in 1864 (LaFont, 2001). The relevant sections of the Jamaican Act, which remain in place to this day, criminalise sex acts between males only, and read:

\section{Unnatural Offences}

76. Whosoever shall be convicted of the abominable crime of buggery, committed either with mankind or with any animal, shall be liable to be imprisoned and kept to hard labour for a term not exceeding ten years.

77. Whosoever shall attempt to commit the said abominable crime, or shall be guilty of any assault with intent to commit the same, or of any indecent assault upon any male person, shall be guilty of a misdemeanour, and being convicted thereof, shall be liable to be imprisoned for a term not exceeding seven years, with or without hard labour

[...]

32 The trade in slaves was abolished in 1807; emancipation refers to those who were already slaves at the time of abolition (Patterson, 1967). 


\section{Outrages on Decency}

79. Any male person who, in public or private, commits or is a party to the commission of, or procures or attempts to procure the commission by any male person of, any act of gross indecency with another male person, shall be guilty of a misdemeanour, and being convicted thereof shall be liable at the discretion of the court to be imprisoned for a term not exceeding two years, with or without hard labour (Jamaica Offences Against the Person Act, 1864:ss. 76-77, 79).

These laws draw heavily from British antecedents, which criminalised "the detestable and abominable Vice of Buggery committed with mankind or beast" (Sanders, 2008:2). As noted in Chapter Two, the absence of a law criminalising sexual activity between females may be symbolic of their wider invisibility, particularly at the time these laws were passed and consequently adopted by Commonwealth states. The introduction of these laws, along with others from the colonial power, sought to put an end to the perceived liberal sexual mores of the white settlers in the Caribbean (LaFont, 2001). Since the legal codes are in themselves a colonial imposition, this suggests that rather than the practice of homosexuality itself being a colonial imposition, evidence of British imperialism can be more appropriately recognised in the legal codes imposed on Jamaica's citizens. Asal, Sommer and Harwood (2012) contend that Commonwealth states, who inherited the bulk of their law from Britain, are much less likely to decriminalise. Moreover, a number of authors have pointed out that Commonwealth states are more likely to have criminalising laws still on their books (Asal et al., 2012; Baudh, 2008; Sanders, 2008). However, Phillips (2007:145) offers an important caveat in trying to understand imperialism in the context of sexual politics:

continuities between metropolitan and non-metropolitan sexuality politics are sometimes due to western exports and imposition; the transplantation of sexuality politics however [is] not just determined by the centre; identity and politics were appropriated and reinterpreted by people in places cast as margins; [m] etropolitan initiatives were also resisted in these places.

With this in mind, this chapter now moves on to defining sexuality in contemporary Jamaica

\section{Defining sexuality in contemporary Jamaica}

Sexual orientation, in contemporary Western societies, has generally been defined in binary terms: homo/hetero, masculine/feminine, and so on. The exact definitions of these binary terms are constantly in flux, but tend to focus on men as active and women as passive, both in social and sexual life (Hooper, 2001). Foucault (1976) argues that sexuality in modern times is not just a description of who one has sex with, but is something that is linked entirely to that person's identity. This is a product of the 
discursive explosion pertaining to sexuality co-occurring with the shift from a juridical model of power to what is termed 'bio-power' 33 . In Jamaica, non-heterosexual identities are denigrated and undermined. Thus, even though the law only criminalises male same sex relations, lesbian relations are similarly stigmatised, although to a lesser extent (LaFont, 2001). Lesbians are also more likely to be targeted for sexual violence than men who are homosexual, or other women, on the basis of their sexual orientation (HRW, 2004). However, as Silvera (1992) points out, lesbianism in the Caribbean is still relatively invisible and this may be related to the idea that sex between women is just an imitation of heterosexual sex. Moreover, lesbian identity may be seen as less threatening to notions of masculinity. As Hope (2001:6) explains:

...female homosexuality cannot undermine the traditional tenets of Jamaican patriarchy because, based on their lack of a real penis - a significant biological definer of masculinity, none of these actors can be socially elevated to true masculine status by wider society.

Jamaica, as a former colony of Britain, has many common characteristics when compared with contemporary Western sexualities. However, its history outlined above provides further context to the specific ways in which non-hetero sexualities have been shaped and, consequently, demonised in Jamaican society. Drawing upon examples, this section sets out how such sexualities are understood in contemporary Jamaica.

Sexual orientation is linked to the performance of gender in contemporary society (Butler, 1999). Discourses related to gender and sexuality have come to focus on both the act as well as the person engaged in it creating an image, for example, of the psychologically damaged 'homosexual' (Foucault, 1976). In the Jamaican context, social stigma is primarily aimed at those who are thought to be engaging in non-procreative sex - that is, those in non-heterosexual relationships 34 . These sexualities then become easy targets of blame for the decline of morals and the spread of HIV/AIDS (Weeks, 2003). Rubin (1984) sets out a useful 'sex hierarchy' for what societies view as 'good' sex and 'bad' sex, with 'good sex' including married, procreative, heterosexual and missionary and 'bad sex' including unclear gender roles, promiscuous homosexuality, sadomasochism and so on.

33 Discussed in Chapter One, bio-power can be defined as the "numerous and diverse techniques for achieving the subjugation of bodies and the control of populations" (Foucault, 1976:140).

34 There are other issues here such as contraception and abortion which also contravene non-procreative sex. While there is not space to examine these in detail, homosexuality is seen as more visible and it is assured that same sex couples must be engaging in non-procreative sex. 


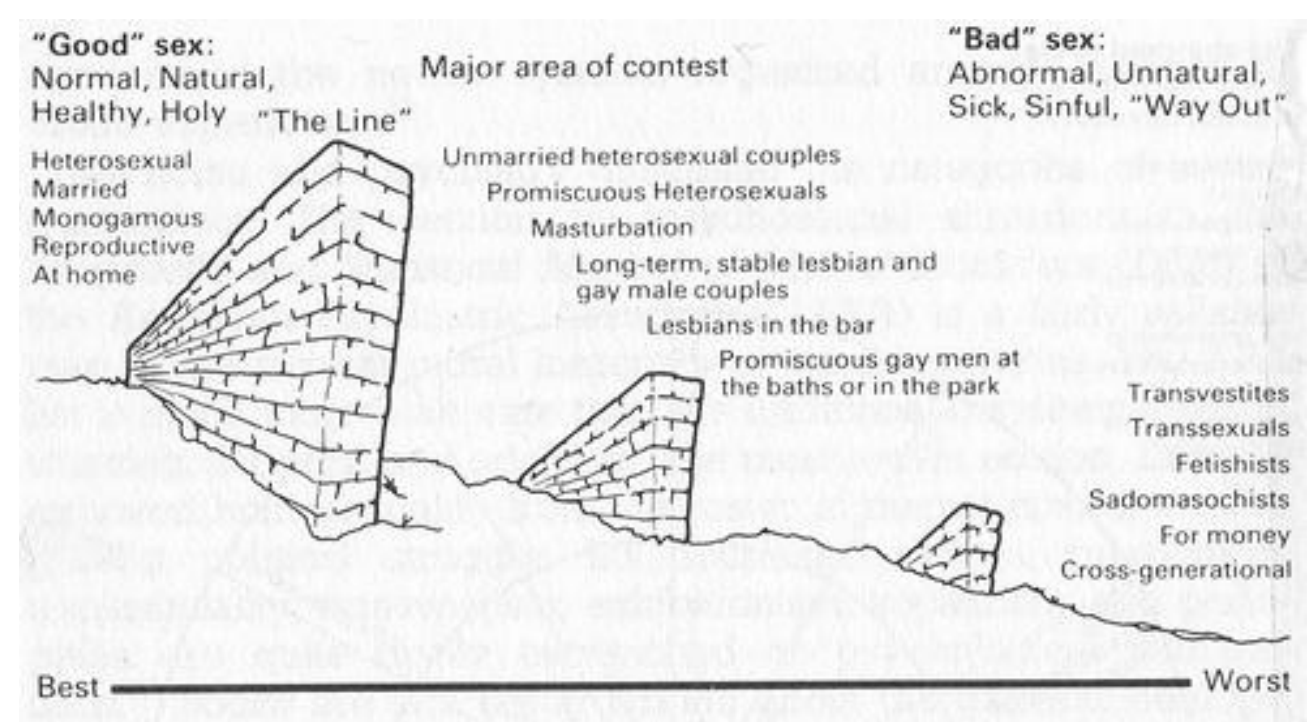

Figure 5.1: Rubin's (1984:161) sex hierarchy

Figure 5.1 sets out Rubin's initial 'sex hierarchy' for Western societies and Figure 5.2 adapts this to a Jamaican context. Any non-heterosexual sex is considered 'bad' sex in Jamaica and has connotations of sin and immorality. For example, there is still a widespread view that non-procreative sexual behaviour between two people of the same sex is immoral and contributes to the "decaying social fabric in society", which has a "net negative effect" on young people (Boxill et al., 2012:18). Moreover, the strong influence of Christianity supports and reinforces the sinfulness of homosexuality. Religion has remained an important driving factor in opinions about homosexuality, with survey data showing that $56.4 \%$ of those surveyed thought that one could not be homosexual and religious at the same time; further, $61 \%$ stated that one could not be Christian and also homosexual (Boxill et al., 2011:20-21). Additionally, homosexuality is still rejected as a cultural imposition and movements for gay rights are viewed as a form of cultural imperialism (Allyn, 2012). Allyn (2012) notes that, while Western societies have come (albeit slowly) to accept the demands of the gay rights, sexual rights and women's rights movements, Jamaican society has claimed a moral superiority by not succumbing to these demands. However, marriage is by no means valued in Jamaica and this most likely has its roots in the fact that marriage between slaves was prohibited. With this in mind, marriage is not required for the 'good sex' category in Jamaica (see Figure 5.2). The area in the middle is referred to as the 'main area of contest', which in Jamaica encompasses heterosexual sex that is non-procreative and other nonprocreative acts such as masturbation. This section will now discuss how masculinity 
and femininity are constructed in Jamaica, using the particular example of the dancehall culture.

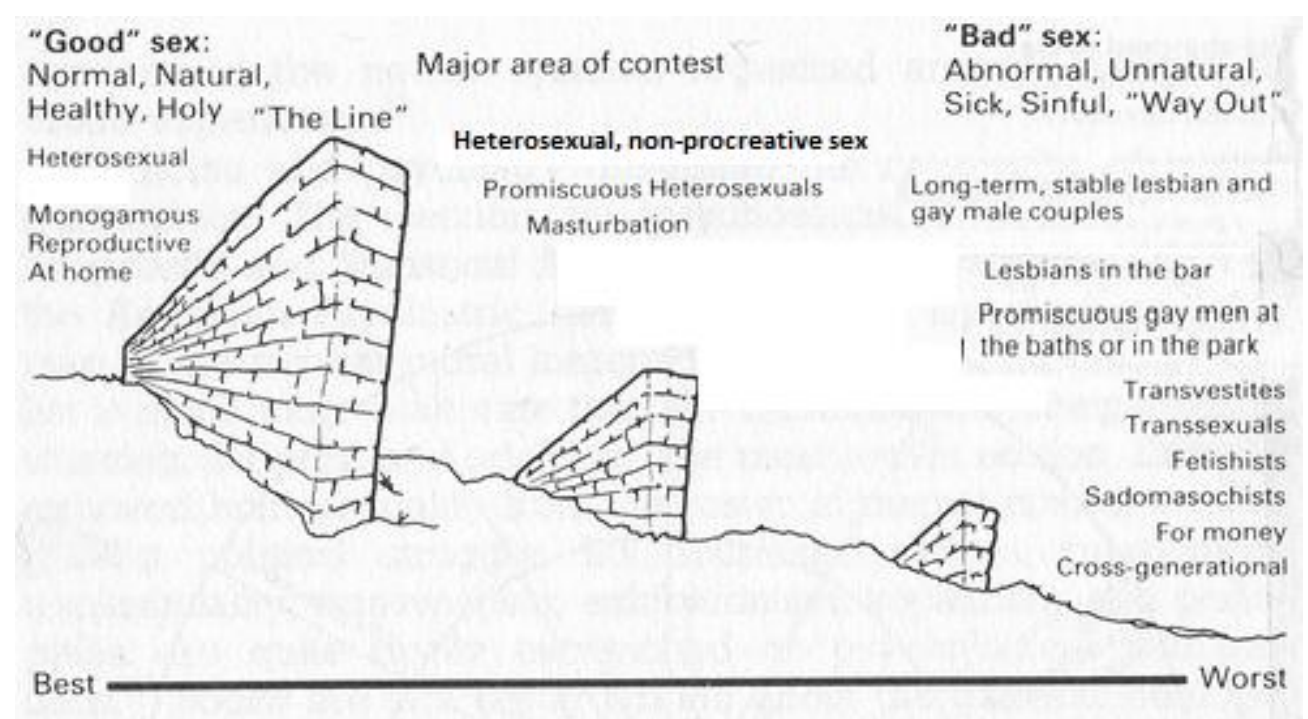

Figure 5.2: Rubin's (1984:161) sex hierarchy adapted for the Jamaican context

Gender socialisation is a significant feature of Jamaican life and one that aligns with contemporary Western gender norms. Gender divisions are entrenched early in a child's life and it is seen as a parent's responsibility to make sure a male child grows up 'tough' - this may account for the high rates of corporal punishment towards boys, which is seen to 'harden them up' for adulthood (Chevannes, 1999). Children are quickly integrated into the gendered activities of adulthood. These roles equate to traditional Western notions of gender: girls are encouraged to become skilled in domestic activities, while boys are encouraged to undertake non-domestic work - typically physically demanding - that supports the household (Chevannes, 1999, 2001). Moreover, survey data shows that Jamaicans are made aware of homosexuality relatively early in their lives, with $51 \%$ indicating that they knew about it before the age of 14 (Boxill et al., 2011). This fits with descriptions of growing up in Jamaica, which include boys as young as 12 being encouraged to become (hetero)sexually active (Allyn, 2012; Chevannes, 2001). Chevannes (2001:94) offers examples of this: "Denzil had to screw a girl, for her, the father, wanted no batty man 35 in the house. Ursi said she sat her big son down, let him know that it is a girl he must screw, no 'batty business"'. Further, male children who display traits which are considered to be feminine are often reprimanded by family

35 ‘Batty man' is a Jamaican Creole slang term for homosexual. 
members, as displaying such behaviour is seen to be a 'sign' of homosexuality. In this context, hegemonic masculinities and femininities become embedded in public discourse.

In Western societies, "hegemonic masculinity is emphatically heterosexual, [while] homosexual masculinities are subordinated" (Connell, 2000:102). Jamaica seems to align with this; contemporary hegemonic masculinity in Jamaica is characterised by heterosexual hypersexuality. In other words, the sexual conquest of many women, rather than relationships with them, is considered most important to the male gender role (Allyn, 2012). On the other hand, hegemonic femininity is thoroughly subordinate and emphasises physical weakness, an inability to successfully exercise violence and acquiescence to men (Schippers, 2007). Moreover, Kempadoo (2003) points out that femininity in Caribbean nations is particularly focused on pathologising female sexuality, where the only normative sexual identity for a woman is a desire for procreation. Women who do not fit with this normative sexual identity are viewed as 'sick'.

Dancehall music is one of the main scenes of gender expression in Jamaican cultural life (Cooper, 2004; Hope, 2006a). In particular, dancehalls have become an avenue to express certain forms of masculinity, while denigrating others (Hope, 2006b). Within this space, hegemonic masculine status closely follows its European counterpart with wealth, education and heterosexual status being the most desired attributes (Hope, 2006a). Hope (2004) argues that the phenomenon of the Jamaican dancehall arose with the rapid social and political changes of the 1980s and the ascendancy of global capitalism. With the opening of the economy to global markets, many Jamaicans struggled to maintain basic necessities, and dancehall music arose as a form of resistance to the socioeconomic order (Hope, 2004). Moreover, the violent lyrics, aimed at a variety of groups, can also be understood as resisting imperialist notions of social decorum (Cooper, 2004). Cooper (2004) points out that this revolutionary attitude originated in the widespread rebellions during the slave era. In contemporary Jamaica, dancehall music has replaced reggae ${ }^{36}$ as the primary form of cultural expression working against the status quo and both forms "share a common concern with

\footnotetext{
${ }_{36}$ Reggae, made most famous by Bob Marley, arose out of the Rastafari movement which became a "language of resistance against the systemic brutalization of African people in Jamaica" (Cooper \& Donnell, 2004:6).
} 
destabilizing the social space of the respectable middle class...[t]he lyrics of both artists articulate an anti-establishment class politics and a gender politics" (Cooper, 2004:81).

Dancehall music is centred on hegemonic masculinities (Hope, 2006a). Although lesbians are also denigrated in Jamaican culture, they are not targeted by these songs as their presence is not threatening to the discourses of masculinity in the same way (Hope, 2001). The dancehall culture in Jamaica is particularly infamous for songs which openly renounce gay men as doers of evil (Hope, 2006a). Songs by a range of dancehall DJs contain homophobic messages including: "[bomb] dem [homosexuals] down", "gunshots for all the faggot[s]" as well as refrains to burn 'sodomites' (lyrics quoted in Gutzmore, 2004:129). These songs have prompted a campaign run by the Jamaican Forum for Lesbians All-Sexuals and Gays (J-FLAG), among others, which accuses these artists of promoting violence against homosexuals. Subsequently, a number of artists have been banned from entering certain countries to perform (Thompson, 2007). While such campaigns have been criticised for acting to curb free speech, the entire cultural economy of dancehalls in Jamaica is shaped by the cultural icons who choose to give such views prominence (Saunders, 2003).

This section has explored how sexuality has come to be defined in contemporary Jamaica, employing frameworks of hegemonic masculinity (in opposition to homosexuality) and the violent discourse of Jamaican dancehall. This demonstrates that sexual orientations other than heterosexuality continue to be demonised both in lay understandings and in wider media practices, such as dancehall music. The next section examines how this heteronormative culture is manifest in state-sanctioned discrimination and violence.

\section{State-sanctioned discrimination and violence}

Using Michalowski's (2010) tripartite framework, this section sets out the criminalisation of same sex relations in Jamaica as a state crime. This section combines juridical, organisational deviance and social harm approaches to offer a more nuanced understanding of the Jamaican context.

\section{Juridical}

As detailed above, the relevant sections of the Jamaican Offences Against the Person Act are discriminatory in themselves. However, Jamaica does have human rights laws which 
affirm rights for all. A Charter of Fundamental Rights and Freedoms (CFRF) was added to the Constitution in 2011 and this contains a number of the rights enshrined in the ICCPR, including the rights of all people to the state's protection and the right to equality before the law. Critically, the addition affirms non-discrimination, but lists specific grounds of discrimination without the all-encompassing "and any other status" present in the ICCPR and the UDHR (Jamaican Constitution, 2011)37.

Jamaica is also signatory to all of the major human rights treaties (although has not ratified the Convention Against Torture), and under international law, is subject to their terms. International and domestic civil society groups continually bring the status of LGBT people in Jamaica to the attention of the UN in the hope of gaining binding statements with which the government can be challenged (for example see J-FLAG et al., 2011). Such attempts by civil society groups garner the attention of the UN in defining actions and inactions by the Jamaican government as 'crimes' under international law. However, these legal advances provide limited protection. As Michalowski (2010) points out, juridical definitions have been problematic, particularly given the structural disadvantage of minority groups attempting to have their rights recognised by the state.

\section{Organisational deviance}

While the juridical framework for criminalisation as state crime is by no means certain, the framework of organisational deviance allows for a more robust analysis of state actions which undoubtedly contribute to harms (Michalowski, 2010). By examining the domestic and international civil society response, it is clear that a significant audience sees such wrongs as equivalent with 'crime'. This section assesses the global and local responses to Jamaican criminalisation laws, which label these laws outside of organisational norms.

In a shadow report produced for the UN, a number of CSOs note that criminalising laws not only contribute to an environment in which state officials are free to harass and discriminate against LGBT individuals, but also encourage discrimination and violence (J-FLAG et al., 2011). Consequently, "the atmosphere of intolerance denies LGBT

\footnotetext{
37 The CFRF prohibits discrimination on the grounds of "race, place of origin, political opinions, colour, creed or sex" (HRComm, 2011: 3), while the UDHR prohibits discrimination "without distinction of any kind, such as race, colour, sex, language, religion, political or other opinion, national or social origin, property, birth or other status" (author's emphasis; UDHR, 1948:Art 2(1))
} 
individuals access to minimum state services, such as health care and police protection" (J-FLAG et al., 2011:4). Along these lines, a number of international CSOs have been involved in submitting reports to UN mechanisms which will be explored further in the next chapter.

There is little domestic opposition to the laws as they are popularly supported (Boxill et al., 2011, 2012). However, J-FLAG formed as the primary domestic opposition group in 1998 seeing the need for advocacy from citizens who were experiencing state and community violence (J-FLAG, 2011a). They have been the sole voice in Jamaica pushing for decriminalisation and also provide crisis services, statistics, education and other support services (J-FLAG, 2011a). More recently J-FLAG has been involved in setting up a legal case challenging the laws to go before the Inter-American Court on Human Rights, who are a body central to the provision of information to the UN (Bowcott \& Wolfe-Robinson, 2012).

A number of prominent international human rights organisations have spoken out against criminalisation in recent years. Amnesty International (2008:5) published a general paper on laws which criminalise sexuality and gender identity and concluded that these "act as an official incitement to or justification for violence against [nonheterosexual identities]". In addition, AI's annual reports regularly comment on the state of human rights of LGBT people (e.g. AI, 2012). Human Rights Watch has also been steadfast in its opposition to criminalisation. In a 2004 in-depth report, HRW documented the scale and nature of abuses by government officials, healthcare workers and the general public, undertaken with impunity. This report calls for the repeal of criminalising legislation (HRW, 2004) ${ }^{38}$. HRW has continued its endeavours, recently sending a letter to the new Prime Minister, Portia Simpson Miller, spelling out the harms caused by the laws, as well as the state's lack of response to the human rights abuses perpetrated by members of the public (Dittrich, 2012).

The response from bystander states to asylum claims also shows international acknowledgement of state-led harms in Jamaica. A number of Jamaicans have successfully sought asylum in other countries due to the persecution they have faced in Jamaica. In 2011, a lesbian won an appeal to stay in the UK on the basis that her life

${ }^{8}$ There is another report on the situation, which will be published by HRW in the next two years (B.O. Dittrich, Personal Communication, 19/11/2012). 
would be in danger in Jamaica, having already been threatened with 'corrective rape' ("Jamaican lesbian wins appeal", 2011). In 2010, 28 Jamaicans were granted asylum in the United States on the basis of sexual orientation, gender identity or HIV/AIDS status (“Jamaicans granted asylum", 2011). In one case, a gay Jamaican man was granted asylum in the United States under the UN Convention Against Torture, with evidence indicating he was likely to face torture if he returned to Jamaica (HRW, 2007). In one case, a prominent campaigner for LGBT rights in Jamaica was forced to flee to Canada in January 2012 after receiving death threats (HRW, 2012). These examples show that bystander states are willing to acknowledge the harm inflicted on sexual minorities through criminalising laws by accepting asylum claims.

The organisational deviance approach offers a useful lens to understand criminalisation in Jamaica. Both domestic and international CSOs advocate for the rights of LGBT people in Jamaica and other states indicate their disapproval of criminalising laws through the UN and the IACHR, as well as by accepting asylum seekers. Both CSOs and other states name criminalisation of same sex relations as in itself criminal through the application of human rights norms that have not yet reached the status of binding law. This chapter next turns to the social harm approach.

\section{Social harm}

As discussed in Chapter Three, a social harm approach is useful in framing state actions and inactions, which may not be designated as 'crimes', but may have outcomes that are undoubtedly injurious to people (Hillyard \& Tombs, 2007). Here, harms will be separated into direct and indirect harms, as in Chapter Three, and will draw primarily from human rights reports and media articles.

\section{Direct harms}

In Jamaica, state officials endorse and act upon the words of criminalising laws. It is unclear how often these laws are enforced by the police and no statistics are available from the Jamaican Constabulary Force (JCF), despite attempts to gain such statistics by human rights organisations (e.g. HRW, 2004).

The powers given to the police under the law allow them to arbitrarily arrest and detain individuals on a routine basis (HRW, 2004). Amnesty International (2001b) reports that gay people in Jamaica are commonly victims of police harassment. These are not 
isolated occurrences. Reports exist of large numbers of JCF officers appearing at people's residences under the guise of enforcing the law (Carr, 2003; HRW, 2004). Moreover, "[b]ecause anal sex is illegal and Jamaican men can and are sometimes arrested only on suspicion they have to live with the fear that their home can be invaded at any time" (Allyn, 2012:7). In one example, in February 2011, the JCF raided a gay bar, kicking in the door and forcibly evicting patrons by whipping them with pistols, all the while shouting anti-gay slurs (J-FLAG et al., 2011).

Gay and lesbian Jamaicans are reluctant to report victimisation to the JCF, as they may open themselves up to arrest by doing so. Those who do report are often told that they have no recourse to the law because of their homosexual status (Charles, 2011). Due to the significant amount of violence perpetrated against lesbian and gay individuals, and the part that the police play in this, most homophobic crimes are not reported "because [the victims of these crimes] did not believe that police would take action to address it, especially in cases where police were the perpetrators" (HRW, 2004:27). The lack of protection for sexual minorities in Jamaica and the lack of treatment as simple subjects of the law means that lesbian and gay Jamaicans routinely experience harm at the hands of state officials.

There is also outspoken political support for the law. The last Prime Minister of Jamaica, in power until late-2011, was emphatic in his disdain for homosexuality, publicly arguing that a gay man would never be allowed to serve on his Cabinet ("Golding talks gays", 2008). Similarly, one MP has continually argued that J-FLAG should be regarded as an illegal organisation and gay men, who he also believes are paedophiles, should be sent to prison for life (Long \& Schleifer, 2009). Any support for the law being changed is usually "carefully couched in terms of the requirement of sound public policy, particularly the fight against HIV/AIDS" (Cowell \& Saunders, 2011: 319). While new Prime Minister Simpson-Miller is said to be more amenable to decriminalisation, condemnation from the public and other Jamaican MPs may have the effect of discouraging such a change (HRW, 2012). In 2012, a survey found that $76.7 \%$ of Jamaican citizens support the laws, many citing fears that homosexuality would become mainstream if the laws were decriminalised (Boxill et al., 2012:2). This makes it unlikely that repeal will occur in the near future. While such discourse cannot be understood as criminal, the marginalisation and public condemnation it encourages has the effect of further harming lesbian and gay individuals by placing them outside of 
social norms and protections.

\section{Indirect harms}

The violence perpetrated on gay and lesbian Jamaicans by other citizens has led to it being described as "the most homophobic Caribbean territory" (Williams, 2000: 106), and even the most homophobic place on Earth (Padgett, 2006). One of the most high profile cases of extreme violence in Jamaica is the 2004 murder of gay rights activist Brian Williamson, a co-founder of J-FLAG. Williamson was found stabbed to death in his home (Padgett, 2006). According to HRW (2004), soon after his body was discovered, a crowd gathered outside the crime scene and began chanting, laughing and calling out the lyrics to "boom bye bye" 39 . In another high profile 2005 case, Steve Harvey, an AIDS worker who worked with gay men and sex workers, was abducted from his home at gunpoint. He was later found miles from home with gunshots to the back of his head; his flatmates reported that the assailants had asked “Are you batty men?". When Harvey refused to answer the question, he was abducted (Younge, 2006).

Such incidents of violence are by no means isolated; gay and lesbian Jamaicans live with the constant fear of violence. In another 2004 incident, a man drove his son to school and encouraged other students to beat him up, having found pictures of naked men in his school bag. The police were eventually called to restore order, and it is likely that the boy only survived because a teacher jumped on top of him to protect him (Walker, 2004). Tatchell (2004) outlines several more occurrences of violence including a machete attack by a homophobic mob, a gay man being chased into a church and shot multiple times, and a man being beaten to death in Montego Bay with police as witnesses. Police were also forced to save three gay men from an angry mob in another incident when they were chased into a pharmacy (Walker, 2007).

Attacks such as these are ongoing: J-FLAG releases statistics on the violence reported to them, which are sure to be an underestimate. The most recent statistics recorded at least 21 instances of violence between January and June 2012 (Lewis, 2012). At the time of writing, the most recent available case was at the University of Technology in Kingston. Two students suspected of being homosexual were chased by an angry mob of students

\footnotetext{
39 "Boom bye bye" is the title of a song by dancehall artist, Buju Banton. Its lyrics translate roughly to "Gunshots in a gay man's head. Rude boys will not promote any nasty men, they have to die" (translation of lyrics in Hope, 2001:4)
} 
in November 2012, until one ran to the Guardhouse, assuming he would be protected. Instead, the guards also attacked him ("UTech to punish students", 2012). These attacks all contribute to the fear of violence as a lived experience, and the tacit acceptance of attacks among public officials. Further, the government contributes to an atmosphere of impunity. In 2007, a public defender warned the gay community to avoid flaunting their sexuality in public, as doing so would incite violence (Laurence \& Campbell, 2007). Most incidents of violence are redefined as isolated incidents, results of a 'lover's tiff' or as a consequence of confrontational behaviour by victims (HRW, 2004). By blaming the gay community for their own victimisation, the government and the police force can neutralise challenges as to the treatment of gay and lesbian citizens - it is 'their problem' and 'they are the troublesome ones'. Criminalisation tacitly endorses homophobia and leads to an environment where attacks are seen as a form of mob justice. This uncovers the "structural and operational harms brought about by state practices" - in this case, criminalisation and the continuing and overt violence directed towards sexual minorities, as well as the lack of protection afforded to them (Michalowski, 2010:21).

Violence against sexual minorities does not just come in the form of physical violence. 'Corrective rape' to 'cure' women of their sexual preference is not uncommon (AI, 2011; Hanson, 2011; HRW, 2004; Silvera, 1992). Many of the women interviewed for HRW's (2004) report had been raped multiple times by assailants who knew they were lesbians. Corrective rape acts as a form of social policing in this context. Thus, even though lesbian sexual identity is not illegal, it is looked upon in a similar manner to male homosexuality, although with much less visibility ${ }^{40}$. Corrective rape is thought to have the effect of 'punishing' women for their sexual identity as well as 'curing' them of their same sex attraction (AI, 2011). The threat of rape, as with any threat of violence, is a consistent one that reinforces the necessity of heterosexuality to lesbian women in Jamaica (cf. Mason, 2002). The practice and threat of corrective rape causes myriad harms and the existence of criminalising laws undoubtedly contributes to its occurrence and the impunity with which it occurs.

As well as physical and sexual violence, the stigma towards gay men, in particular, has become institutionalised through the HIV/AIDS epidemic. Approximately $1.7 \%$ of the

40 For example, two women linking arms or holding hands are not likely to be seen as lesbians, while two men doing the same would be instantly labelled as homosexual. 
population are HIV positive, with higher rates among 'at risk' populations - sex workers, men who have sex with men and homeless people (Ministry of Health, 2012). It is estimated that around 50\% of HIV positive people do not know their status (Ministry of Health, 2012). Additionally, stigma towards those living with HIV/AIDS is so high in Jamaica that many people report becoming suicidal on their diagnosis, not because of the disease itself, but because of the social isolation and discrimination that will result when others find out (White \& Carr, 2005). The HIV/AIDS epidemic in Jamaica is still associated with homosexuality, despite efforts to dispel the belief that gay men are primarily responsible for the spread of HIV (White \& Carr, 2005). One recent letter to the Jamaica Observer (Hope, 11 July, 2011) expounds that

[i]f we stop to examine it, we have a better quality of life by obeying the laws of God. Sexually transmitted infections are physically damaging...The treatments for these diseases are expensive - they are diseases directly resulting from our lifestyle choices.

A number of people interviewed by HRW (2004) reported being refused treatment for HIV or having treatment delayed on the basis of their sexual orientation. This was thought to be because health workers did not want to treat someone they knew had engaged in 'breaking the law'. Gay men who are in hospital being treated for HIV/AIDS are often left without basic adequate care (HRW, 2004) and approximately 10\% of health workers believe that gay men do not deserve the same quality of care (Brown et al., 2012). Additionally, some healthcare workers, on finding out that a patient is gay, will tell the person that they are HIV-positive without testing them (Caceres, 2002). Rights to privacy are also routinely overlooked with gay men reporting that their sexual orientation was 'outed' to other patients, as well as health workers (HRW, 2004). Further, stigma associated with homosexuality can affect recording; for example, health workers may erroneously record transmission as heterosexual to avoid being known as treating gay patients (HRW, 2004). A recent study on health and social services in Jamaica found that medical workers are reluctant to be responsible for the treatment of a gay man (Brown et al., 2012). Efforts to prevent the spread of HIV have also been affected by the stigma associated with its spread. In one particularly notable case, attempts to hand out condoms at a men's prison resulted in a riot where several prisoners were killed due to their assumed homosexuality (HRW, 2004). The failure to adequately address the HIV/AIDS epidemic is intrinsically tied up with criminalisation.

This section has mapped out the existence of criminalisation laws in Jamaica using 
Michalowski's (2010) tripartite framework of state crime. While the juridical framework for understanding criminalisation as a state crime has been difficult to apply to state actions at a domestic level, organisational deviance and social harm approaches can frame criminalisation as a 'state crime'. This framework offers potential in particular for the Jamaican situation, as decriminalisation can be seen as the first step towards acknowledging the human rights of people with non-heterosexual orientations.

\section{Conclusion}

This chapter has argued that the historical context and the contemporary environment in Jamaica have both led to the continued support of criminalising laws, and contributed to the ongoing stigma and discrimination towards those suspected of homosexuality. The historical antecedents of the homophobia that exists until this day have their roots in the era of slavery and the physical and sexual violence that accompanied it, as well as in religious teachings. Despite the passing of criminalising laws in the late- $18^{\text {th }}$ century by colonial powers, contemporary cultural supports have embedded the view of homosexuality as a Western imposition and this is emphasised in the example of dancehall music. In this context, the Jamaican government, through its refusal to repeal criminalising laws, is seen to condone and encourage violence and harms within its institutions and within Jamaican social and cultural practices. 


\section{Chapter Six: Resisting criminalisation - the role of civil society and the UN}

\section{Introduction}

Following on from previous chapters, Jamaica's history, as well as its contemporary social and cultural climate, have led to it becoming renowned as a place where it is not safe to be openly gay. This chapter will expand on how civil society organisations (CSOs) have played a part in challenging the continued existence of criminalising laws. Further, it will examine UN mechanisms that have been used to confront Jamaica about these laws, as well as the ongoing violence and discrimination, both state and civil, which accompanies them. Despite the danger that is faced daily by those in Jamaica who do not fit with heteronorms, CSOs within Jamaica continue to resist and challenge criminalisation laws, as well as high rates of homophobic violence and discrimination. Moreover, transnational and domestic CSOs have joined together to confront Jamaica on human rights breaches. With this in mind, the first section of this chapter outlines CSOs' efforts to challenge Jamaica on criminalisation through the use of reports, public letters and on occasion, legal mechanisms. Following this, the way in which the Jamaican government is able to neutralise and deny human rights claims by these groups is examined. This chapter argues that while CSOs have limited power in terms of being able to effectively challenge states regarding serious breaches of human rights, they remain a vital component of resistance to illegitimate state actions by raising awareness and providing information the UN, among others.

Subsequently, this chapter examines the extent to which Jamaica is challenged on criminalisation-related phenomena within the UN, a body which often relies on the evidence of CSOs. The ways in which criminalisation is raised by various UN bodies is analysed; in addition, bodies which could challenge Jamaica on criminalisation, but do not, are discussed. Further, the extent to which Jamaica has been able to neutralise, deny or simply ignore challenges on criminalisation, violence and discrimination is expanded upon using Cohen's (2001) model of denial and drawing upon the model used in Chapter Four, consisting of categories of response including: invisibility, not our culture/religion, lack of a mandate, no discrimination and partial acknowledgement (cases of discrimination are being investigated). This part of the chapter demonstrates how the UN relies on CSOs to provide up-to-date information, as well as the varied ways 
in which the Jamaican government is still able to deny, ignore or neutralise challenges through UN bodies. The chapter concludes by considering the ways in which change both in the form of decriminalisation and further steps towards equality ${ }^{41}$ - could be envisaged. The role of continued resistance by CSOs in Jamaica and the key role to be played by transnational CSOs connecting with domestic actors to put pressure on the government are emphasised.

\section{The role of civil society in challenging Jamaica on human rights}

In Chapter Four, the work of CSOs in challenging state crime was highlighted. This section explores the role of civil society in challenging state actions and inactions in Jamaica, related to the criminalisation of same sex relations, and violence and discrimination from state and non-state actors towards those assumed to be homosexual. While there has been little in the way of major research, the efforts, particularly by J-FLAG and HRW have raised awareness about the situation in Jamaica.

As covered in Chapter Five, HRW's 2004 report is the first and only in-depth one by a major human rights organisation that successfully documents and explains the homophobic environment in Jamaica and the effect that this has on fighting the HIV/AIDS epidemic there. As Cohen (1996) outlines, human rights reports serve as a form of bearing witness to events taking place. Reports such as this one single out issues that are acknowledged by many grassroots groups in Jamaica, but that have enjoyed little international public scrutiny due to the primary focus in domestic groups on engagement with, and protection of, the community they represent (cf. Foley \& Edwards, 1996). In this context, human rights reports which 'out' state malpractice can help to contribute "to the knowledge base upon which civil society can build resistance and change" (Green \& Ward, 2012:32). In-depth reports can also create an impetus for other forms of resistance to take place.

CSOs can further inspire resistance to state crime by making episodes of violence, and the damaging atmosphere in which they occur, visible. This "moral consciousnessraising" plays an important role in inspiring change from both above (through international law and transnational bodies) and below (through grassroots actions)

\footnotetext{
${ }_{41}$ These could include, for example 1) decriminalisation; 2) equalisation of ages of consent; 3) the introduction of anti-discrimination laws; and 4) legal partnerships such as marriage or civil union (Waaldijk, 1994:51-52).
} 
(Risse \& Sikkink, 1999:5). For example, HRW exerts continuous pressure on the Jamaican government to acknowledge the damage inflicted by laws criminalising consensual same sex behaviour. Moreover, they publicise incidents of violence that occur on the basis of sexual orientation which may, for one reason or another, not be reported in the mainstream press. In this way they challenge the Jamaican government and support domestic opposition from groups such as J-FLAG (Risse \& Sikkink, 1999). HRW has issued press releases, for example, one which called on Jamaica to "Investigate [the] murder of alleged lesbians" (HRW, 2006), and another which challenged the government to "Repeal [the] anti-buggery law; Protect LGBT people" (HRW, 2012). Alongside these, HRW send letters to government officials (e.g. Dittrich, 2012; Long \& Schleifer, 2009; Schleifer \& Long, 2008). In one of these, it is stated that "Jamaica does not comply with international human rights standards to which it has agreed" and goes on to outline international standards that apply to sexual orientation (Dittrich, 2012:3). By publicising the discriminatory violence in Jamaica and the base of international human rights which Jamaica is considered to be in breach of, CSOs frame state actions as breaches of human rights - and thus international crimes - lending credence to the claims of domestic groups by publicly shaming governments (Risse \& Sikkink, 1999).

Transnational CSOs have also played a major role in legally challenging the Jamaican government over criminalising laws. Both AFW and a British-based group called the Human Dignity Trust (HDT) have recently taken cases to the Inter-American Court on Human Rights42 (AFW, 2011; Bowcott \& Wolfe-Robinson, 2012). Whether or not these actions lead to legal change, the labelling of the Jamaican state as criminal for retaining the relevant sections of the OAPA challenges the legitimacy of the government and, in doing so, may put their reputation as 'global citizens' with respect for human rights on the line (Ward \& Green, 2000). AFW's case, for example, relies on the American Convention of Human Rights (the IACHR's equivalent of the UDHR), as well as international law. It argues that the criminalising laws encourage and condone abuses against homosexuals by those acting on behalf of the state, as well as encouraging a form of 'vigilante justice' from the public (AFW, 2011).

\footnotetext{
42 The Inter-American Court on Human Rights is part of the Inter-American Commission on Human Rights. The court is modelled on the European Court of Human Rights and hears cases from the Americas. In this case the decision would not be binding on Jamaica, as it is not a full member (Bowcott \& Wolfe-Robinson, 2012).
} 


\section{State neutralisation and denial}

While transnational CSOs play an important role in challenging breaches of human rights, there are a number of ways in which the Jamaican government has been able to neutralise these accusations and demands. It should be noted that while states are under no obligation to respond to CSO critiques, they often do so as a way of 'saving face' (Cohen, 1996). Cohen $(1996,2001)$ discusses a number of strategies which states use to both challenge and neutralise allegations of human rights breaches. One which is evident in Jamaica is what is deemed a 'counteroffensive', where a government does not necessarily deny allegations, but instead goes on the attack (Cohen, 1996). In response to the 2004 HRW report, a Jamaican Minister responded saying that its contents had been "unacceptably insensitive" in dictating to Jamaica how to deal with its own laws, adding that Jamaica would not respond to external organisations' critiques of their policies (Rose, 2004). In this way, CSOs pointing out breaches are labelled as interfering outsiders pushing Western ideologies onto unwilling states. Another form of denial is 'spatial isolation', which typically relates to challenges on specific incidents. Here, there is agreement that a specific incident has happened, but no acknowledgement that such violence is systemic or related to the state (Cohen, 2001). For example, one letter from HRW to the then Prime Minister, Bruce Golding (Schleifer \& Long, 2008), called on the Jamaican government to publicly condemn a recent episode of homophobic violence, and to actively investigate such incidents, as well as to ensure rights for all, regardless of sexual orientation or gender identity. Golding responded that the matter was being investigated by the police with no response to any of the other recommendations in the letter (Golding, 2008).

The use of modern media has also been increasingly instrumental in exposing states for criminal actions against their citizens (e.g. Stanley, 2012). One way in which transnational CSOs have been able to combat the denial of a wider problem is with the use of modern media, which Cohen (2001:186) notes is a way of "telling truth to power". For example, HRW sent a detailed letter to the new Prime Minister, Portia SimpsonMiller, in 2012, which outlined several episodes of violence and critically, also included a number of links to YouTube videos of violent incidents taking place (Dittrich, 2012). With evidence like this, states such as Jamaica use interpretive denial to respond to allegations from CSOs. Here, states can admit that something happened, that it may have looked a certain way, but that it was something other than what it is alleged to be (Cohen, 2001). One way in which the Jamaican government and the JCF have been able 
to downplay incidents of violence, particularly by state officials, is to reframe them as gay-on-gay violence, usually insinuating a 'lover's tiff' even where there is clear evidence to the contrary (HRW, 2004; J-FLAG et al., 2011). This fits with what Cohen (2001:109) describes as moves to "attribute responsibility to forces - named or unknown - that supposedly have nothing to do with the government”. Moreover, in many cases violence occurs from those not acting on behalf of the state. In Jamaica, although violence from government forces is also widespread, violence from private citizens is more common (J-FLAG, 2011b). In this way, Jamaica can distance itself from violence - it was an isolated event, we had no control over it, and so on. By ignoring the systemic discrimination which condones and even encourages acts of violence, the state can claim innocence (Cohen, 2001).

In what Cohen (2001) deems 'condemnation of the condemners', states attempt to divert attention away from their own wrongdoing to the questionable character of their victims. Along these lines, the Jamaican government and other CSOs in opposition to decriminalisation (such as the Jamaican Coalition for a Healthy Society [JCHS]) have responded to J-FLAG by casting them as dangerous and criminal. Generally, members of the legislature are, at best, unsupportive of J-FLAG (Cowell \& Saunders, 2011). In one example, an MP stated that he was concerned about gay Jamaicans forming into groups because they were abusive and violent citizens who were more likely to hold firearms (Cowell \& Saunders, 2011). Similarly, members of the public seem to subscribe to these notions of dangerousness; one letter to the editor argues that the "Dark Ages may once again be on the horizon" if the 'gay agenda' gets its way (Lyon, 7 May, 2012) Another letter appears to blame homosexuality entirely for the spread of sexually transmitted infections (Hope, 11 July, 2012). The JCHS argues that the LGBT 'agenda' threatens fundamental human rights, such as freedom of religion and speech and warns that if this 'agenda' takes further action then it risks breaching these rights (Brown, 2012). The government encourages such views by denying that violence is widespread and blaming groups such as J-FLAG for promoting 'Western values'.

The Jamaican government also engages in literal denial, by arguing that there is no violence or discrimination, and that the organisation reporting it is exaggerating the truth for its own ends. For example, Les Green, the then Assistant Commissioner of the $\mathrm{JCF}$, denied claims that the gay community were regularly victimised. Additionally, as discussed above, he argued that most murders of gay men were committed by other gay 
men (Walker, 2012). Through such actions, victims of discriminatory violence based on sexual orientation are denied the status of being a 'victim' of homophobic violence. Their victimisation is classed as occurring within the community, rather than against it, and the Jamaican government is then able to deny any responsibility towards preventing it (Cohen, 2001). This feeds into the stereotypes around gay men which insinuate that they are unusually violent or that their relationships are less likely to be successful due their innate sinfulness (Charles, 2011). The attitude of victim-blaming is connected to the denial of the victim status where the "victim is transformed into a wrong-doer" (Sykes \& Matza, 1957:668).

The government has used a range of techniques to attack the credibility of CSOs, argue the content of their allegations and deny the wider environment attached to occurrences of heterosexist violence. This section has contextualised those responses using Cohen's (1996, 2001) varieties of denial. The next section examines how UN mechanisms, with the aid of CSO evidence, have challenged Jamaica on criminalisation and related phenomena.

\section{Jamaica and the UN on criminalisation and related phenomena}

This chapter has shown that CSOs play a key role in exposing state wrongdoing and bringing it to the attention of international bodies. However, given state and public strategies of denial and neutralisation, the effect CSOs can have is limited. This section examines the response of the UN and looks at how their varying mechanisms, many of which include an element of CSO input, have challenged Jamaica on human rights breaches related to criminalisation. Further, the failure by the UN, in particular, to shed light on the issue will be discussed. Responses are examined using the categories drawn on in Chapter Four: invisibility, not our culture/religion, lack of a mandate, no evidence of discrimination, and partial agreement.

Before examining how the UN have responded to criminalisation in Jamaica, it is necessary to understand how various UN mechanisms can be used, and to what effect. The only mechanism which mandates regular and cyclic reporting within the UN is the UPR, discussed in Chapter Four. Committees attached to covenants such as the HRComm and the Committee on Economic Social and Cultural Rights (IESCR) request annual reporting in their covenants, but states often do not submit reports or submit 
them several years late, and Jamaica is no exception to this43. Finally, Special Procedures (SPs) are comprised of independent experts (Special Rapporteurs [SRs]) appointed by the UN to focus on either states 44 or issues relating to a particular set of human rights (thematic mandates); they produce annual reports, country reports and seek responses from states (UNOHCHR, 2013). These procedures are again limited in what they can achieve. For example, country reports can only be produced by thematic Special Procedures if the SR receives an invitation from the state's government (UNOHCHR, 2013). Similarly, although SRs produce annual reports detailing information requested to, and received from, all states, there is no way to force states to respond and questions often go unanswered (UNOHCHR, 2008).

While the UN holds an important role - being able to legally challenge states for wrongdoing - much of the evidence they rely on is gleaned from CSOs. Representatives from CSOs are typically the ones pushing for particular changes or highlighting particular abuses to the UN. Information gathering by CSOs is vital in getting human rights violations onto the international agenda, and more pertinently onto the UN agenda (Green \& Ward, 2012). CSOs, even those without consultative status, contribute to all of the mechanisms that will be explored here. Under the UPR process, CSOs (both domestic and transnational) are invited to make contributions. Committees also welcome information from CSOs, primarily to glean as much information about the situation as possible. For this reason, CSOs will feature heavily in this section.

\section{Invisibility}

Invisibility is the most prominent response to criminalisation, not just from the Jamaican government, but also enshrined through a number of UN bodies who have failed to challenge Jamaica on its criminalising laws, and discriminatory homophobic violence. For example, while there is much evidence of violence against lesbian women, in the form of 'corrective rape', the Committee on the Elimination of Discrimination Against Women (CommEDAW) has never raised the issue of sexual orientation in dialogue with Jamaica. This could be due to the fact that female-female sexual relations are not criminalised, but the laws criminalising men still contribute towards an

\footnotetext{
43 For example, according to the 2010 UNOHCHR report for the UPR, all monitoring committee reports were overdue (HRCoun, 2010e).

44 These are usually states with gross human rights issues, or which are plagued by civil conflict. Some examples of states with Special Procedures include: the Palestinian Territories, Sudan, Myanmar (Burma) and Iran (UNOHCHR, 2013).
} 
environment where any non-heterosexual relationship is demonised, as discussed in the previous chapter. The failure to mention sexual orientation is likely due to other issues taking precedence. Jamaica has very high rates of violence against women, as well as ongoing problems with equal education and employment (CommEDAW, 2006). In an environment where states often do not submit reports, or submit them several years late, UN committees often fail to challenge states on what are considered to be secondary issues. The Committee on the Rights of the Child (CommRC) has also never raised the issue, despite considerable international evidence that recognition of sexual orientation is something which occurs primarily in adolescence (Chan, 2006). Again, other issues such as child abuse, poverty and low rates of child literacy appear to be major concerns (CommRC, 2003). Jamaica has not ratified the Convention Against Torture; this means that the Committee Against Torture is unable to raise human rights breaches based on sexual orientation. Given information about arbitrary detention and maltreatment of subjects in Jamaica, at times amounting to torture (HRW, 2004), challenging Jamaica on these issues could be well within its scope.

These issues expose a major weakness of the UN in challenging breaches of human rights. UN mechanisms primarily rely on states' willingness to implement international human rights into domestic legislation. Cohen (2001:167) notes that in modern societies, "immediate knowing has become democrati[s]ed and globali[s]ed" international monitoring organisations purportedly standing up for human rights only do so in certain situations. When atrocities are condoned by states, it is notoriously difficult (except in the most extreme of cases) to acknowledge and challenge such states (Cohen, 2001). In the case of Jamaica, the 'international community' is able to turn a blind eye to state-condoned discrimination and violence. Further, bodies like the UN rely on cascades of norms (cf. Risse \& Sikkink, 1999), believing that sexual orientation rights will eventuate once other rights have been enshrined; this further cements the silencing of marginalised groups in the international legal sphere.

Another way in which challenges to Jamaica are made invisible is through the lack of a government response to challenges when they do occur45. Special Rapporteurs send 'letters of allegation' annually to states all over the world, challenging them on various human rights allegations. For example, the Special Rapporteur on the Rights to Freedom of Opinion and Expression (SRRFOE) sent two letters of allegation to the

45 Of note, Jamaica had responded to just 6 of 23 questions sent by SRs (HRCoun, 2010e). 
Jamaican government regarding limits on these rights for human rights defenders within Jamaica. Despite ongoing appeals sent by the SRRFOE, it is stated that "no replies to [the SR's] communication of 11 March and 6 December 2004 were received at the time this report was finalised" (ECOSOC, 2005a:204). Similarly, a letter of allegation was sent by the Special Rapporteur on the Situation of Human Rights Defenders (SRSHRD) in 2005 about the murder of Lenford Harvey and follow-up requests for a response were sent in 2006 and 2007; none of these received a response (ECOSOC, 2006; HRCoun, 2007a). Finally, the Special Rapporteur on Extrajudicial, Summary and Arbitrary Executions sent an allegation of impunity related to both Lenford Harvey, and the case of Victor Jarrett, who was stoned to death by a mob, including police officers, in 2005 and a follow-up request in 2007, neither of which was replied to (ECOSOC, 2005b; HRCoun, 2007b). One reason for the lack of response could be the lack of public knowledge about SR processes - governments may only respond if an allegation is broadcast widely and thus, if there is a risk that mainstream media and public shaming may become involved (Cohen, 1996). If such allegations are not publicised, then the government's lack of response remains hidden, and there can be no public debate or recognition that this 'official silence' is taking place occurs (Mathiesen, 2004). In this situation, the silence and the ignoring of letters of allegation can be understood as "the most radical form of denial possible" (Cohen, 1996:521). Likewise, the very nature of SRs is that they respond to isolated events rather than broader social conditions. In all of the allegations, the general homophobic environment is touched upon very briefly, but the primary focus is understandably on one event - in this case, primarily the murder of Lenford Harvey, which garnered significant international media attention (ECOSOC, 2005a, 2006; HRCoun, 2007a). The divorcing of such events from the context in which they take place means they are easier to label as isolated occurrences that are not indicative of a wider problem (Cohen, 2001).

Another way that challenges can be rendered invisible in UN processes is that states can neutralise them by offering a response that does not address the challenge. In Jamaica's latest report for the Committee on Civil and Political Rights (held within the HRComm), they were asked how non-discrimination would be guaranteed on all grounds, including sexual orientation (as in Article Two of the ICCPR) ${ }^{46}$. Jamaica responded by restating the text of the Constitution, with the limited grounds of: "race, place of origin, political opinions, colour, creed or sex" (HRComm, 2011:3). This constitutes what can be deemed

\footnotetext{
${ }^{46}$ See Footnote 37, Chapter Five.
} 
a dismissal; while a response is still offered, it is clearly not an answer to the question posed. They followed this up by giving examples of Jamaican laws with clauses covering discrimination on the grounds mentioned in the Constitution.

Similarly, three stakeholder reports (AI, 2011b; Hear the Children's Cry et al., 2011; JFLAG et al., 2011) note that the CFRF (the recent addition to the Jamaican Constitution) is inadequate, as it does not protect from discrimination on the basis of sexual orientation or gender identity. Amnesty International argue that the CFRF has entrenched further discrimination, by including a clause that no existing law could be held as inconsistent with the CFRF, thus the discriminatory sections of the OAPA cannot be reviewed using this law (AI, 2011b). The questions asked by the HRComm, as well as the recommendations from stakeholders, clearly challenge Jamaica on the lack of laws regarding discrimination based on 'any other status', which would encompass sexual orientation. However as outlined above, they are not strictly denying anything. Rather, they offer an account relevant to discrimination, but ignore the central component of the question.

\section{Not our culture/religion}

The Jamaican government is reluctant to accept recommendations based on what are perceived to be cultural and religious norms and moral standards of citizens (HRCoun, 2011j). Jamaica stated several times during the working group stage of the UPR process that the issue of sexual orientation was "sensitive" (see: HRCoun, 2011j:6, 9, 2011k:6). Further, survey data suggests that almost half of Jamaicans believe it is not possible to be a practising Christian and also homosexual (Boxill et al., 2011). Of note, one stakeholder report states that attitudes towards homosexuality are strongly influenced by religion, and that more extreme religious beliefs are the ones which are publicised ( $\mathrm{J}-$ FLAG et al., 2011). Moreover, as detailed in the previous chapter, homosexuality is often understood within Jamaica as a Western imposition. In this vein, UN challenges to other states are viewed as unjustified outside interference with cultural norms and domestic policies (Cohen, 2001). Moreover, because homosexuality is openly denigrated in Jamaican society, those who become victims of discrimination and violence are denied their status as victims. In this way, challenges are neutralised through the denial of the victim, and attacks are instead viewed as a "rightful retaliation or punishment" (Sykes \& Matza, 1957:668). 
The idea that 'homosexuality' did not exist in Jamaica (or in Africa) prior to European colonisation is an erroneous one (King, 2006). However, by asserting that the government is put in a difficult position because of the opinions of the majority of Jamaicans, steps towards decriminalisation are stated to be impossible, due to the overarching necessity of democracy (Mathiesen, 2004). Further, the government can exonerate itself of any responsibility to change policies which condone and/or encourage homophobic violence by stating that they cannot change laws without the will of the people, a sentiment that the UN finds difficult to argue with (Cohen, 2001). This assumption ignores the fact that the laws are supported by statements from politicians and civil servants at the highest level; moreover, the lack of a robust discrimination law has been entrenched in the CFRF, which has been pointed out by civil society actors within Jamaica (J-FLAG et al., 2011). The Jamaican government, however, continue to offer denials on the basis of culture, a form of implicatory denial through righteousness (Cohen, 2001). In this way, Jamaica can claim a moral superiority over Western nations - your country may accept these actions, but ours will not (Cohen, 2001). Challenges are then neutralised through condemning those who criticise Jamaica by shifting the focus to their perceived immorality through what Sykes and Matza (1957) call 'condemnation of the condemners'. Ideas about the culture of citizens are also linked heavily with the perceived necessity of a democratic mandate to decriminalise.

\section{'But democracy' - Lack of a mandate}

Not having a mandate to decriminalise consensual same sex relations is an excuse given by a large number of states (see Chapter Four). Moreover, it typically relates to changes in law and policy - in this example, the continuing criminalisation of same sex relations and the lack of enshrined discrimination law related to sexual orientation. This sort of challenge is typically employed in UN forums such as the UPR, which offers a number of opportunities for questions and claims by states and CSOs. For example, during the stakeholder report - which is circulated prior to the advance questions from other states - Jamaica was challenged on a number of grounds including the criminalisation in the OAPA and the lack of sexual orientation or gender identity as grounds for nondiscrimination, particularly in the CFRF (HRCoun, 2010f). The UK, the Czech Republic, the Netherlands, Sweden and Norway then submitted advance questions regarding criminalisation and discrimination (HRCoun, 2010g, 2010h, 2010i, 2010j). In response to these questions, Jamaica stated that "[c]ultural norms, values, religious and moral standards underlay a rejection of male homosexual behaviour by a majority of 
Jamaicans" (HRCoun, 2011j:6). There is considerable evidence that suggests that the majority of the population (75-85\%) are in opposition to decriminalisation (Boxill et al., 2011:24, 2012:2) and the appeal by the Jamaican government to the 'higher' human right of democracy means that their response goes unchallenged (Cohen, 2001; Sykes \& Matza, 1957). Similarly, in response to advance questions submitted by states for the HRComm, Jamaica responded that there was no evidence that the Parliament of Jamaica would consider revising the definition of discrimination in the near future (HRComm, 2011). The Jamaican delegation appears here to separate itself from the Jamaican Parliament and paints it as an unchangeable force bound to the voice of its citizens. In this way, any potential change of attitudes is put in doubt and "the change which is demanded is proposed as impossible" (Mathiesen, 2004:30).

Of note is the fact that many stakeholder reports go deeper than simply raising issues. For example, in J-FLAG et al.'s (2011) shadow report, the intolerance promoted by government officials, as well as the impunity which supports the painting of nonheterosexual people as sub-human, is emphasised as supporting an atmosphere where over three-quarters of the population support criminalisation. The rejection of LGBT populations by Jamaicans can be directly linked to official discourses, legal frameworks and the lack of protection afforded to these minorities. This is something which is severely limited in state challenges and dialogues within the UN (primarily due to limited time) and emphasises why civil society groups play such an important role in terms of raising awareness. However, since states are not obligated to respond to stakeholder reports (and in Jamaica's case have not done so in the UN context), there is a need for states to further emphasise the atmosphere of intolerance which perpetuates such attitudes within Jamaica. Furthermore, Jamaica is able to neutralise challenges about discrimination by focusing on their lack of a mandate, rather than the connection between discriminatory laws and violence, in effect denying any responsibility for violence perpetrated by private citizens (Sykes \& Matza, 1957).

\section{No evidence of discrimination}

Jamaica has repeatedly denied challenges through claiming that there is no discrimination and there have been no reported cases of it. For example, in response to a question about discrimination and ill-treatment of homosexuals, Jamaica responded by stating that "there is no legal or other discrimination" thus even though consensual sex is prohibited by law "[t]he government is opposed to discrimination and violence 
against homosexuals" (HRComm, 2011:9). Such statements are made in spite of all the evidence produced by civil society groups and included as part of the UN process. This is a form of Cohen's (2001:108) interpretive denial, which he calls 'magical legalism' - "a method to 'prove' that an allegation could not possibly be correct because the action is illegal". These counterclaims are useful to states precisely because they use the legal language of human rights and do not deny the legitimacy of these rights (Cohen, 2001).

Similarly, in responding to advance questions during the UPR progress, Jamaica argues that there were no 'credible' cases of arbitrary detention or harassment by government forces and no evidence of mob-related killings of LGBT persons (HRCoun, 2011j). Numerous reports of police-perpetrated and encouraged harassment exist and are reported regularly by J-FLAG (e.g. J-FLAG, 2011b, n.d.). From this, it is clear that Jamaica does not consider this group to be 'credible' fitting with the notion of a counteroffensive, where a state labels an domestic human rights organisation untrustworthy (Cohen, 2001). One recommendation given during the working group to ensure the protection of LGBT human rights defenders - was listed as unsupported. In its response, Jamaica explained that "it is based on false or erroneous premises", indicating that the danger human rights defenders allegedly face is false (HRCoun, 2011:22). This is despite the highly publicised murders of both Brian Williamson and Lenford Harvey and through this statement, the word of CSOs, which challenge Jamaica on such events and provide information to UN bodies, is rendered obsolete. CSOs are devalued here and their complaints are considered untrustworthy. The lack of an onus to respond to CSO reports submitted to the UN means the process is severely limited in terms of challenging state perceptions of these groups.

\section{Cases of discrimination are being investigated}

On occasion, Jamaica has responded to specific allegations with comments that issues are being investigated. During the 2011 HRComm report, a question was asked about measures taken to protect human rights defenders, and what action had been taken in regard to the murders of Brian Williamson and Lenford Harvey. Jamaica responded by giving details of the prosecutions of both cases, but did not respond to the allegation of measures taken to protect human rights defenders more generally (HRComm, 2011). Since both of these cases were taken up and publicised by CSOs such as HRW and AI, and investigated by SRs, they are more difficult to deny. Thus, in only addressing a single part of the question, these incidents are isolated from the greater atmosphere of 
homophobic violence in Jamaica. Homophobic threats of violence, injury and murder, which many would argue occur on a daily basis (e.g. HRW, 2004) are in this way painted as "unique or at least...unusual and abnormal; associations of something which deviates from the pattern and is not causally integrated into it" (Mathiesen, 2004:26).

This section has drawn on Cohen's (2001) framework of denial to explore the ways in which Jamaica has been able to neutralise, deny and ignore challenges by UN mechanisms. While the UN has a number of mechanisms which offer pathways to seriously challenge states on human rights breaches, the lack of weight given to CSO reports in the process, as well as the lack of onus on states to respond to allegations, becomes an exercise in political manipulation.

\section{Conclusion: Pathways to change}

The UN has played a part in attempting to effect lasting change to the homophobic environment in Jamaica and the laws which support and condone it. Further, transnational and domestic CSOs continue to play an important role in pushing for effective action. As Risse and Sikkink (1999) outline, the institutionalisation of human rights norms relies on the existence of strong civil society groups who act from below in a variety of ways. CSOs engage in a range of techniques to both raise consciousness about human rights violations and to attempt to get issues on the UN agenda (Risse \& Sikkink, 1999). Moreover, by working to expose state wrongdoing out of the intricate network of day-to-day state actions, CSOs cooperate and collaborate to embed human rights norms in the legal discourse of a state (Green \& Ward, 2012).

CSOs have also played a part in broadcasting state actions and inactions as 'crimes' in the juridical sense by looking to international and regional legal systems - the UN and the IACHR - with an aim of legally challenging the OAPA. In this sense, the UN serves as a useful guiding force in constructing the idea of criminalisation as a crime. More pertinently, UN conventions offer an important base to documents such as the Yogyakarta Principles (covered in Chapter Three). These serve as guidelines of 'conduct norms' in a state context and provide a wider framework to address wrongful state actions (Michalowski, 2010). Finally, the work of, in particular, transnational CSOs exposes the harms that Jamaicans are subject to on a daily basis. However, as Cohen (2001) notes, in an increasingly globalised world, images and accounts of state wrongdoing are everywhere and publics become desensitised to them. Yet, as he also 
states, demands for social justice "do not demand extraordinary heroism, but they do discourage ordinary silence" (Cohen, 2001:277). 


\section{Chapter Seven: Conclusion}

This thesis has examined the criminalisation of same sex relations and the myriad harms experienced by individuals who do not adhere to state-mandated heteronorms. It argues that, while homophobic violence takes place all over the world, states which criminalise non-hetero identities cement the view of LGBT people as unnatural, criminal and, in many cases, as sick. Moreover, criminalisation can be understood as a crime against citizens, a point that is established in Chapters Three and Five, using Michalowski's (2010) tripartite framework of state crime. By defining certain sexual acts as criminal, states normalise the view that those who engage in them are people to be vilified, and as a consequence, discriminatory violence against them is often met with impunity.

Civil society organisations have been at the forefront of trying to obtain recognition for sexual minorities in criminalising states, despite intense opposition. This thesis has emphasised the ways in which CSOs help to institutionalise human rights norms within the discourse of state governments, and the UN. Thus, while there is no binding international human rights law which pertains specifically to sexual orientation, CSOs have applied existing human rights law to sexual orientation rights through documents like the Declaration of Montreal, the Yogyakarta Principles and the Declaration on Sexual Orientation and Gender Identity. Moreover, they continue to push for recognition through specific and binding human rights laws regarding sexual orientation.

This thesis has demonstrated that decriminalisation is one step that states can take towards providing full rights to those who do not fit heterosexual norms. Further, given the critical framework that underlies this research, it is argued that states have a responsibility to protect citizens (in this case sexual minorities) from violence, whether perpetrated by state officials or private individuals. Drawing on the case study of Jamaica, it is shown that criminalisation does not continue to exist in isolation from historical and cultural contexts; rather, criminalisation continues because it is supported and condoned at all levels of society.

To conclude this thesis, this chapter will now expand on the four primary arguments of this research: the hegemonic force of law, the idea of criminalisation as state crime, the techniques used to deny, neutralise and minimise the harms inflicted on sexual 
minorities in criminalising states, and the importance of civil society in resisting this form of state crime.

\section{The hegemonic force of law}

Laws which criminalise same sex relations have been shown to condone and legitimise violence against sexual minorities. It is unquestionable that, because of the way sexuality as a concept has been constructed, such laws criminalise not only sexual acts, but also identities. As argued in Chapter Two, law can provide meaning to violence, leading citizens to see themselves as acting for the law. Laws which criminalise identities further propagate a heterosexual hegemony, diminishing, alienating and othering any who do not fit this narrowly defined norm. Further, the existence of criminalising laws lends credence to practices of arbitrary arrest of those assumed to be homosexual. The Jamaican case study in Chapters Five and Six shows that these laws are used as justification for the arrest and harassment of men who are assumed to be gay, as well as condoning the violence committed against them.

Most states with criminalising laws inherited these from colonisers, particularly the UK, Portugal and Spain. Despite this, many states who are challenged on their laws argue that homosexuality is simply not acceptable in their culture and (as discussed in Chapters Two, Four and Six), that same sex relations are a Western perversion. As shown in Jamaica, the Atlantic slave trade and the inhumanities perpetrated by British settlers during that time, offer an explanation for the current levels of homophobia. The case study of Jamaica emphasises the way in which state officials and members of the public are able to reject and deny the existence of homosexuality in their state. They view the UN, as well as transnational CSOs (such as Amnesty International, Human Rights Watch and many others) as interfering in domestic matters.

As detailed above, these laws do not exist in isolation from the wider environment; rather, in states with criminalisation, the laws are often publicly supported by religious leaders, government ministers and citizens. Subsequently, victims of heterosexist violence are, in many states, placed outside the protection of the law. In this environment, as is evident in Jamaica, these individuals are not seen as worthy of protection and are targeted with vigilante action. As detailed above, homosexuality is viewed as a Western perversion, and public comments from high-ranking government officials denigrate non-heterosexual identities as 'sick' and 'criminal', aligning them with 
bestiality and paedophilia.

In sum, law, in interaction with culture, acts as a hegemonic force. It presents the denigration of, and discrimination against, homosexual people as 'common-sense' and 'normal'. Laws do not dictate social behaviour; rather, they set the boundaries of state acceptability for private actions. States hold a monopoly on what characterises legitimate violence and the criminalisation of consensual same sex relations lends credence to the practice of arbitrary arrest and detention from state officials, as well as violence from the public.

\section{Criminalisation as state crime}

Drawing upon critical criminology, this thesis further argues that criminalisation can be understood as a crime by states. Michalowski's (2010) tripartite framework has been applied in this thesis to explain how states can be considered criminal on three different levels. At a juridical level, recent international legal progress has meant that states with criminalisation laws can be labelled as criminal because they breach a number of international human rights standards emanating from documents like the UDHR, the ICCPR and the IESCR. This is evident in Chapters Four and Six, that explore the role of the UPR in restraining state violations; within the UN, many challenges are based around breaches of human rights law and CSO reports to the UPR outline an almost inexhaustible list of human rights breaches. The juridical understanding of crime is useful precisely because it is taken seriously by states and is understood as crime by most people.

However, as is outlined throughout the thesis, and in much of the state crime literature, a juridical approach ignores many breaches of human rights that, for one reason or another, do not fit under the rubric of existing laws. The organisational deviance approach (developed by Green and Ward, 2004) examines acts which would be seen as having similar outcomes to crimes, and would be labelled as outside legal norms by an audience. Since sexual orientation still has a tenuous place in international human rights law, this approach offers a route to recognition for sexual minorities, which could potentially also lead to more binding human rights law. As shown in Chapter Three, a number of CSOs and some interested states within the UN have created non-binding statements which outline the problems and harms inflicted by criminalisation in no uncertain terms. Much of the action taken by domestic and international CSOs has been 
along these lines, with the most recent case being taken to the Inter-American Court of Human Rights. While not legally binding if successful, this case would demonstrate the damage done by criminalising laws, including homophobic attacks and murders.

Both juridical and organisational deviance approaches cast criminalisation as undoubtedly a 'state crime'. However, there are still many practices which inflict harm on people that are obscured by these definitions. This is particularly obvious when looking at discriminatory laws, as in many cases people who are harmed by them do not experience one simple incident of extreme harm, but experience a number of harms throughout their lives. In the context of criminalising laws, those who live with the daily fear of arrest and violence are harmed through the very existence of such laws. A social harm approach, then, is most helpful in recognising long term and structural harms that are embedded in everyday life, as shown in Chapters Three and Five. Harms inflicted on populations from arbitrary arrest and detention to violent attacks and instances of sexual violence can also be considered as 'state crimes'.

This thesis demonstrates that all of these approaches are useful in cementing the view that the criminalisation of same sex relations is criminal and harmful to populations. Moreover, it is evident that research needs to incorporate all three levels of state crime analysis in order to be attentive to the continuation of violations against those cast as 'others' by states. In this vein, some acts related to criminalisation are made illegal through domestic and international law, while others go against widely held legal values. Finally there are other acts which are hidden, but still intensely harmful.

\section{Denial, minimisation and neutralisation}

This thesis has shown that, even where states have been challenged on criminalisation in the UN, there are many ways that these states are able to deny wrongdoing, or neutralise claims by challenging states or CSOs. Stanley Cohen's (1993, 1996, 2001) work on denial has been useful to examine how and why states, along with media, religious and social discourses, do this. However, it is important to note that denial is not just an issue in regard to criminalising states, but also one which affects the UN, in particular in its reluctance to effect lasting change.

Chapters Four and Six used an original model to expand on and contextualise responses to both CSOs and various UN processes. 'Invisibility' was used to refer to the lack of a 
response, or in many cases the lack of any challenge to the state concerned. Further, 'not our culture/religion' tied into ideas, described earlier in this chapter, of states claiming that homosexuality is simply not acceptable in their country. Closely related to this is 'the lack of a mandate', where states are able to draw on survey data from the public to argue that decriminalisation would go against the tenets of democracy. A further response given is that there is 'no evidence' of discrimination; this can occur even where there is very clear evidence documented by CSOs. Finally 'partial agreement' is where states admit that cases of discrimination are being investigated, but they still deny the wider context of homophobic violence and impunity. This shows the way in which denial operates alongside overt acceptance.

Using this model, this thesis argues that, while there is increasing recognition of violence against sexual minorities and its relationship with criminalising laws, states are still able to use a number of techniques to deny and neutralise claims. Moreover, it indicates that to pursue thinking on state crimes, one needs to be attentive to techniques of denial. Yet, as is outlined above, in some instances, state do not deny; rather, they actively and openly denigrate LGBT populations and encourage violence. In this way, denial operates alongside overt acceptance, and states argue that homosexuality is simply not acceptable and must be stamped out. In many cases, the only evidence presented within the UN is that gathered by CSOs, and states are often able to go 'on the attack' in these instances, claiming that these organisations are in some way biased or cannot be trusted for other reasons. Because of the lack of power that CSOs have in the UN process, it can be very difficult to force discussion on these issues, a point that ties in well to the last major argument of this thesis.

\section{The importance of civil society in resisting state crime}

While this thesis has highlighted many shortcomings and impossibilities in the international legal arena in relation to sexual orientation rights, it is important to note that CSOs continue to be the main bodies pushing for change. In particular, this thesis argues that these organisations continue to produce evidence that allows states to be challenged in the first place. In Jamaica, for example, J-FLAG is one organisation that has been particularly active in standing up for the rights of citizens, with a number of recent campaigns that publicly criticise the defiant stance of the government.

It is argued throughout this thesis that transnational and domestic CSOs often work in 
combination to effect change at the domestic and international levels. Stakeholder reports submitted during UN processes are often co-authored by several CSOs who combine their slightly different areas of focus into a single document. This allows information to emerge in the international arena that would otherwise go unnoticed and unaddressed. Such actions are not taken lightly and in many of the states discussed in this thesis, members of these organisations live in constant danger. For example, at least two human rights defenders in Jamaica have been murdered due to their work with CSOs which have pushed for decriminalisation. While there are many barriers to both gaining binding human rights law on sexual orientation and getting states to decriminalise, CSOs stand at the forefront of this struggle. However, their impact is lessened because of the limits within the UN and within states where their very existence can be criminal.

With the above in mind, this thesis argues that civil society takes on the biggest responsibility in responding to state crime, and taking action to prevent it. This is true both on the international level, as described above, and on the domestic level, where organisations such as J-FLAG in Jamaica have been responsible for gathering and disseminating information about human rights breaches which are related to decriminalisation.

\section{Looking to the future}

The research on sexual orientation rights is still relatively scant, albeit slowly increasing. State crime studies offer a useful framework to focus on how states can be criminal towards their own citizens. This thesis adds to the criminological work that deals with homophobic violence (Berril \& Herek, 1992; Herek, 1992; Mason, 2002, 2008; Tomsen, 2009), as well as the more expansive recent literature dealing with sexual orientation and human rights (Baudh, 2008; Brown, 2010; Chan, 2006; Corrêa et al., 2008; Dittrich, 2008; Kollman \& Waites, 2009; Narayan, 2006; O'Flaherty \& Fisher, 2008; Reddy et al., 2007; Sheill, 2009; Swiebel, 2008; Tahmindjis, 2005; Waites, 2009) by examining the responsibility that states have in protecting their citizens. The critical approach taken in this research has highlighted the ongoing human rights violations against those not fitting with heteronorms, and the key way in which states could exercise their power to protect all of their citizens - to engage in decriminalisation practices. Such a move would ensure that lesbians and gay men are placed on an equal footing with other citizens, being able to enjoy lives of non-discrimination and legal 
protection, in which they are free to live without the fear of violence. 


\section{Appendix One: Criminalisation of same sex relations around the world}

This is an original collation of data, compiled by analysing UN documents (particularly UPR documents and UNOHCHR, 2012), CSO reports (in particular AI, 2008; HRW, 2008, 2013) academic work on criminalising states (Asal, Sommer \& Harwood, 2012; Baudh, 2008; Ottosson, 2010; Sanders, 2008) and legislation. As explained in Chapter Two, this list only includes states with explicitly criminalising laws. It also includes extra information, not available in other analyses, of the range of enforcement and reasoning behind the laws.

Status

- Illegal

- Illegal for (only) men

Penalty

- Death penalty as an option (dark red)

- Lengthy prison sentence or other serious penalty (including hard labour, chemical castration and corporal punishment) (orange)

- Other less serious or uncertain penalty (grey)

Enforcement

- 'Enforced often' - There is evidence that the state in question has enforced their laws throughout the criminal justice system.

- 'Unclear enforcement' - There is no information about any prosecutions, but there is little information to go on.

- 'Rarely enforced' - There is some information that suggests the laws are rarely enforced throughout the criminal justice system, although arrests have taken place.

- 'Sporadically enforced' - Laws sometimes enforced, but usually only through arrest, creating a climate of fear and uncertainty.

- 'No enforcement' - There is considerable evidence to suggest that no arrests have been made in recent years, and that no prosecutions have taken place. 


\section{Reasoning}

- Religious - This means that the laws, partially or fully, are based in religious belief. States in this category often have elements of Shari'a law.

- Cultural (colonial legacy) - This means the law remains on the books primarily as a colonial legacy (and a lack of action to repeal it) and that there is little to no institutionalised homophobia.

- Cultural - This means that the law exists or remains in place primarily because of a culture of homophobia. There may be elements of religion connected to this, but they are not central to criminalisation (i.e. they are not imposed through the legal system).

- Cultural and religious - The law exists or remains in place because of a culture of homophobia, and religion (either Christianity or Islam) is a central factor in criminalisation.

Legal system

- Islamic law - Can be either elements of this or full Shari'a law which draws precedents directly from the Qur'an.

- Common law - Based on the British legal system. Typically taken to mean law established through case law precedents.

- Civil law - Law system evident throughout the rest of Europe; law is usually based on legal codes.

- Customary - based on tribal law or customs.

- Combination - A combination of two or more of the above.

\section{Declaration stance}

- Signed opposing statement - Did not sign the DSOGI and also signed the Syrianled opposing statement.

- Did not sign - did not sign either statement.

- $\quad$ Signed - Signed up to DSOGI.

- N/A - i.e. Gaza, Somaliland cannot become signatory to UN documents. South Sudan did not yet exist as an independent state in 2008. 


\begin{tabular}{|c|c|c|c|c|c|c|}
\hline Country & Status & Penalty & Enforced? & $\begin{array}{l}\text { Reason(s } \\
\text { ) }\end{array}$ & $\begin{array}{l}\text { Legal } \\
\text { system }\end{array}$ & $\begin{array}{l}\text { DSOGI } \\
\text { stance }\end{array}$ \\
\hline Afghanistan & Illegal & $\begin{array}{l}\text { 'Long' } \\
\text { imprisonment } \\
\text { or death. }\end{array}$ & $\begin{array}{l}\text { Enforced } \\
\text { regularly }\end{array}$ & $\begin{array}{l}\text { Religious } \\
\text { (Islam) }\end{array}$ & $\begin{array}{l}\text { Islamic and } \\
\text { US-UK law } \\
\text { post-2001 } \\
\text { invasion. }\end{array}$ & $\begin{array}{l}\text { Signed } \\
\text { opposing } \\
\text { statement }\end{array}$ \\
\hline Algeria & Illegal & $\begin{array}{l}\text { Up to } 2 \text { years } \\
\text { in prison. }\end{array}$ & $\begin{array}{l}\text { Enforced } \\
\text { regularly }\end{array}$ & $\begin{array}{l}\text { Religious } \\
\text { (Islam) }\end{array}$ & $\begin{array}{l}\text { Civil and } \\
\text { religious } \\
\text { law. }\end{array}$ & $\begin{array}{l}\text { Signed } \\
\text { opposing } \\
\text { statement }\end{array}$ \\
\hline $\begin{array}{l}\text { Antigua \& } \\
\text { Barbuda }\end{array}$ & Illegal & $\begin{array}{l}\text { Up to } 15 \text { years } \\
\text { in prison. }\end{array}$ & $\begin{array}{l}\text { Unclear } \\
\text { enforcement }\end{array}$ & $\begin{array}{l}\text { Cultural } \\
\text { (colonial } \\
\text { legacy) }\end{array}$ & $\begin{array}{l}\text { Common } \\
\text { law. }\end{array}$ & $\begin{array}{l}\text { Did not } \\
\text { sign }\end{array}$ \\
\hline Bangladesh & Illegal & $\begin{array}{l}\text { Up to } 10 \text { years } \\
\text { in prison } \\
\text { and/or fine. }\end{array}$ & $\begin{array}{l}\text { Enforced } \\
\text { regularly }\end{array}$ & Cultural & $\begin{array}{l}\text { Common } \\
\text { law and } \\
\text { religious. }\end{array}$ & $\begin{array}{l}\text { Signed } \\
\text { opposing } \\
\text { statement }\end{array}$ \\
\hline Barbados & Illegal & $\begin{array}{l}\text { Up to life } \\
\text { sentence in } \\
\text { prison. }\end{array}$ & $\begin{array}{l}\text { Sporadically } \\
\text { enforced }\end{array}$ & $\begin{array}{l}\text { Cultural } \\
\text { (colonial } \\
\text { legacy) }\end{array}$ & $\begin{array}{l}\text { Common } \\
\text { law. }\end{array}$ & $\begin{array}{l}\text { Did not } \\
\text { sign }\end{array}$ \\
\hline Belize & $\begin{array}{l}\text { Illegal } \\
\text { for } \\
\text { men }\end{array}$ & $\begin{array}{l}10 \text { years in } \\
\text { prison. }\end{array}$ & $\begin{array}{l}\text { Unclear } \\
\text { enforcement }\end{array}$ & Cultural & $\begin{array}{l}\text { Common } \\
\text { law. }\end{array}$ & $\begin{array}{l}\text { Did not } \\
\text { sign }\end{array}$ \\
\hline Bhutan & Illegal & $\begin{array}{l}\text { Up to } 1 \text { year in } \\
\text { prison. }\end{array}$ & $\begin{array}{l}\text { Unclear } \\
\text { enforcement }\end{array}$ & Cultural & $\begin{array}{l}\text { Common } \\
\text { law. }\end{array}$ & $\begin{array}{l}\text { Did not } \\
\text { sign }\end{array}$ \\
\hline Botswana & Illegal & $\begin{array}{l}-7 \text { years in } \\
\text { prison. }\end{array}$ & $\begin{array}{l}\text { Sporadically } \\
\text { enforced }\end{array}$ & Cultural & $\begin{array}{l}\text { South } \\
\text { African law. }\end{array}$ & $\begin{array}{l}\text { Did not } \\
\text { sign }\end{array}$ \\
\hline Brunei & Illegal & $\begin{array}{l}\text { Fine and/or up } \\
\text { to } 10 \text { years in } \\
\text { prison. }\end{array}$ & $\begin{array}{l}\text { Unclear } \\
\text { enforcement }\end{array}$ & $\begin{array}{l}\text { Religious } \\
\text { (Islam) }\end{array}$ & $\begin{array}{l}\text { Common } \\
\text { law and } \\
\text { religious } \\
\text { law. }\end{array}$ & $\begin{array}{l}\text { Signed } \\
\text { opposing } \\
\text { statement }\end{array}$ \\
\hline Burma & Illegal & $\begin{array}{l}\text { Up to life } \\
\text { sentence in } \\
\text { prison. }\end{array}$ & $\begin{array}{l}\text { Unclear } \\
\text { enforcement }\end{array}$ & Cultural & $\begin{array}{l}\text { Common } \\
\text { law. }\end{array}$ & $\begin{array}{l}\text { Did not } \\
\text { sign }\end{array}$ \\
\hline Burundi & Illegal & $\begin{array}{l}3 \text { months-2 } \\
\text { years in prison } \\
\text { and/or fine. }\end{array}$ & $\begin{array}{l}\text { Sporadically } \\
\text { enforced }\end{array}$ & Cultural & Civil law. & $\begin{array}{l}\text { Did not } \\
\text { sign }\end{array}$ \\
\hline Cameroon & Illegal & $\begin{array}{l}\text { Fine and/or } 5 \\
\text { years in } \\
\text { prison. }\end{array}$ & $\begin{array}{l}\text { Enforced } \\
\text { regularly }\end{array}$ & Cultural & $\begin{array}{l}\text { Civil and } \\
\text { common } \\
\text { law. }\end{array}$ & $\begin{array}{l}\text { Signed } \\
\text { opposing } \\
\text { statement }\end{array}$ \\
\hline Comoros & Illegal & $\begin{array}{l}\text { 1-5 years in } \\
\text { prison and/or } \\
\text { fine. }\end{array}$ & $\begin{array}{l}\text { Unclear } \\
\text { enforcement }\end{array}$ & $\begin{array}{l}\text { Info not } \\
\text { available }\end{array}$ & $\begin{array}{l}\text { Civil and } \\
\text { Religious } \\
\text { law. }\end{array}$ & $\begin{array}{l}\text { Signed } \\
\text { opposing } \\
\text { statement }\end{array}$ \\
\hline Cook Islands & $\begin{array}{l}\text { Illegal } \\
\text { for } \\
\text { men }\end{array}$ & $\begin{array}{l}\text { Up to } 7 \text { years } \\
\text { in prison. }\end{array}$ & $\begin{array}{l}\text { Unclear } \\
\text { enforcement }\end{array}$ & $\begin{array}{l}\text { Cultural } \\
\text { and } \\
\text { religious } \\
\text { (Christian) } \\
\end{array}$ & $\begin{array}{l}\text { Civil and } \\
\text { common } \\
\text { law. }\end{array}$ & $\begin{array}{l}\text { Did not } \\
\text { sign }\end{array}$ \\
\hline Dominica & Illegal & $\begin{array}{l}\text { Up to } 10 \text { years } \\
\text { in prison. }\end{array}$ & $\begin{array}{l}\text { Sporadically } \\
\text { enforced }\end{array}$ & $\begin{array}{l}\text { Cultural } \\
\text { (colonial } \\
\text { legacy) }\end{array}$ & $\begin{array}{l}\text { Common } \\
\text { law. }\end{array}$ & For \\
\hline Eritrea & Illegal & $\begin{array}{l}\text { Prison (length } \\
\text { of sentence } \\
\text { unclear). }\end{array}$ & $\begin{array}{l}\text { Sporadically } \\
\text { enforced }\end{array}$ & $\begin{array}{l}\text { Cultural } \\
\text { (colonial } \\
\text { legacy) } \\
\end{array}$ & $\begin{array}{l}\text { Civil and } \\
\text { religious } \\
\text { law. }\end{array}$ & $\begin{array}{l}\text { Signed } \\
\text { opposing } \\
\text { statement }\end{array}$ \\
\hline Ethiopia & Illegal & $\begin{array}{l}1-10 \text { years in } \\
\text { prison. }\end{array}$ & $\begin{array}{l}\text { Unclear } \\
\text { enforcement }\end{array}$ & Cultural & Civil law. & $\begin{array}{l}\text { Signed } \\
\text { opposing } \\
\text { statement }\end{array}$ \\
\hline
\end{tabular}




\begin{tabular}{|c|c|c|c|c|c|c|}
\hline Gambia & Illegal & $\begin{array}{l}\text { Up to } 14 \text { years } \\
\text { in prison. }\end{array}$ & $\begin{array}{l}\text { Enforced } \\
\text { regularly }\end{array}$ & $\begin{array}{l}\text { Religious } \\
\text { (Islam) } \\
\text { and } \\
\text { cultural }\end{array}$ & $\begin{array}{l}\text { Common } \\
\text { law, Islamic } \\
\text { and } \\
\text { customary } \\
\text { law. }\end{array}$ & $\begin{array}{l}\text { Signed } \\
\text { opposing } \\
\text { statement }\end{array}$ \\
\hline Gaza & $\begin{array}{l}\text { Illegal } \\
\text { for } \\
\text { men }\end{array}$ & $\begin{array}{l}\text { Up to } 10 \text { years } \\
\text { in prison. }\end{array}$ & $\begin{array}{l}\text { Enforced } \\
\text { regularly }\end{array}$ & $\begin{array}{l}\text { Info not } \\
\text { available }\end{array}$ & $\begin{array}{l}\text { Elements of } \\
\text { Shari'a, } \\
\text { civil and } \\
\text { common } \\
\text { law. }\end{array}$ & N/A \\
\hline Ghana & $\begin{array}{l}\text { Illegal } \\
\text { for } \\
\text { men }\end{array}$ & $\begin{array}{l}\text { Misdemeanour } \\
\text { - unclear on } \\
\text { sentence. }\end{array}$ & $\begin{array}{l}\text { Enforced } \\
\text { regularly }\end{array}$ & Cultural & $\begin{array}{l}\text { Common } \\
\text { law. }\end{array}$ & $\begin{array}{l}\text { Did not } \\
\text { sign }\end{array}$ \\
\hline Grenada & $\begin{array}{l}\text { Illegal } \\
\text { for } \\
\text { men }\end{array}$ & $\begin{array}{l}\text { Up to } 10 \text { years } \\
\text { in prison. }\end{array}$ & $\begin{array}{l}\text { Unclear } \\
\text { enforcement }\end{array}$ & Cultural & $\begin{array}{l}\text { Common } \\
\text { law. }\end{array}$ & $\begin{array}{l}\text { Did not } \\
\text { sign }\end{array}$ \\
\hline Guinea & Illegal & $\begin{array}{l}6 \text { months to } 3 \\
\text { years in } \\
\text { prison. }\end{array}$ & $\begin{array}{l}\text { Sporadically } \\
\text { enforced }\end{array}$ & $\begin{array}{l}\text { Religious } \\
\text { (Islam) } \\
\text { and } \\
\text { cultural }\end{array}$ & $\begin{array}{l}\text { Civil law } \\
\text { and } \\
\text { customary } \\
\text { law. }\end{array}$ & $\begin{array}{l}\text { Signed } \\
\text { opposing } \\
\text { statement }\end{array}$ \\
\hline Guyana & $\begin{array}{l}\text { Illegal } \\
\text { for } \\
\text { men }\end{array}$ & $\begin{array}{l}\text { Up to life } \\
\text { sentence in } \\
\text { prison. }\end{array}$ & $\begin{array}{l}\text { Unclear } \\
\text { enforcement }\end{array}$ & Cultural & $\begin{array}{l}\text { Civil and } \\
\text { common } \\
\text { law. }\end{array}$ & $\begin{array}{l}\text { Did not } \\
\text { sign }\end{array}$ \\
\hline Iran & Illegal & $\begin{array}{l}\text { Death or } \\
\text { corporal } \\
\text { punishment. }\end{array}$ & $\begin{array}{l}\text { Enforced } \\
\text { regularly }\end{array}$ & $\begin{array}{l}\text { Religious } \\
\text { (Islam) }\end{array}$ & $\begin{array}{l}\text { Shia Islam } \\
\text { law. }\end{array}$ & $\begin{array}{l}\text { Signed } \\
\text { opposing } \\
\text { statement }\end{array}$ \\
\hline Jamaica & $\begin{array}{l}\text { Illegal } \\
\text { for } \\
\text { men }\end{array}$ & $\begin{array}{l}\text { Up to } 10 \text { years } \\
\text { in prison with } \\
\text { or without } \\
\text { hard labour. }\end{array}$ & $\begin{array}{l}\text { Enforced } \\
\text { regularly }\end{array}$ & Cultural & $\begin{array}{l}\text { Common } \\
\text { law. }\end{array}$ & $\begin{array}{l}\text { Did not } \\
\text { sign }\end{array}$ \\
\hline Kenya & $\begin{array}{l}\text { Illegal } \\
\text { for } \\
\text { men }\end{array}$ & $\begin{array}{l}\text { Up to } 14 \text { years } \\
\text { in prison. }\end{array}$ & $\begin{array}{l}\text { Sporadically } \\
\text { enforced }\end{array}$ & Cultural & $\begin{array}{l}\text { Common, } \\
\text { Islamic and } \\
\text { customary } \\
\text { law. }\end{array}$ & $\begin{array}{l}\text { Signed } \\
\text { opposing } \\
\text { statement }\end{array}$ \\
\hline Kiribati & $\begin{array}{l}\text { Illegal } \\
\text { for } \\
\text { men }\end{array}$ & $\begin{array}{l}\text { Up to } 14 \text { years } \\
\text { in prison. }\end{array}$ & $\begin{array}{l}\text { Unclear } \\
\text { enforcement }\end{array}$ & Cultural & $\begin{array}{l}\text { Common } \\
\text { law. }\end{array}$ & $\begin{array}{l}\text { Did not } \\
\text { sign }\end{array}$ \\
\hline Kuwait & Illegal & $\begin{array}{l}\text { 7-10 years in } \\
\text { prison. }\end{array}$ & $\begin{array}{l}\text { Enforced } \\
\text { regularly }\end{array}$ & $\begin{array}{l}\text { Religious } \\
\text { (Islam) }\end{array}$ & $\begin{array}{l}\text { Civil and } \\
\text { Islamic law. }\end{array}$ & $\begin{array}{l}\text { Signed } \\
\text { opposing } \\
\text { statement }\end{array}$ \\
\hline Lebanon & Illegal & $\begin{array}{l}\text { Minimal } \\
\text { penalty. }\end{array}$ & $\begin{array}{l}\text { Enforced } \\
\text { regularly }\end{array}$ & Cultural & Civil law. & $\begin{array}{l}\text { Signed } \\
\text { opposing } \\
\text { statement }\end{array}$ \\
\hline Lesotho & $\begin{array}{l}\text { Illegal } \\
\text { for } \\
\text { men } \\
\end{array}$ & $\begin{array}{l}\text { Information } \\
\text { unavailable. }\end{array}$ & $\begin{array}{l}\text { Unclear } \\
\text { enforcement }\end{array}$ & Cultural & $\begin{array}{l}\text { South } \\
\text { African law. }\end{array}$ & $\begin{array}{l}\text { Did not } \\
\text { sign }\end{array}$ \\
\hline Liberia & Illegal & Fine. & $\begin{array}{l}\text { Enforced } \\
\text { regularly }\end{array}$ & $\begin{array}{l}\text { Religious } \\
\text { (Christian) } \\
\text { and } \\
\text { cultural }\end{array}$ & $\begin{array}{l}\text { Common } \\
\text { and } \\
\text { customary } \\
\text { law. }\end{array}$ & $\begin{array}{l}\text { Did not } \\
\text { sign }\end{array}$ \\
\hline Libya & Illegal & $\begin{array}{l}\text { Up to } 5 \text { years } \\
\text { in prison. }\end{array}$ & $\begin{array}{l}\text { Enforced } \\
\text { regularly }\end{array}$ & $\begin{array}{l}\text { Religious } \\
\text { (Islam) }\end{array}$ & Islamic law. & $\begin{array}{l}\text { Signed } \\
\text { opposing } \\
\text { statement }\end{array}$ \\
\hline
\end{tabular}




\begin{tabular}{|c|c|c|c|c|c|c|}
\hline Malawi & $\begin{array}{l}\text { Illegal } \\
\text { for } \\
\text { men }\end{array}$ & $\begin{array}{l}\text { Up to } 14 \text { years } \\
\text { in prison } \\
\text { and/or } \\
\text { corporal } \\
\text { punishment. }\end{array}$ & $\begin{array}{l}\text { Enforced } \\
\text { regularly }\end{array}$ & Cultural & $\begin{array}{l}\text { Common } \\
\text { and } \\
\text { customary } \\
\text { law. }\end{array}$ & $\begin{array}{l}\text { Signed } \\
\text { opposing } \\
\text { statement }\end{array}$ \\
\hline Malaysia & Illegal & $\begin{array}{l}2-20 \text { years in } \\
\text { prison and/or } \\
\text { whipping. }\end{array}$ & $\begin{array}{l}\text { Enforced } \\
\text { regularly }\end{array}$ & $\begin{array}{l}\text { Religious } \\
\text { (Islam) }\end{array}$ & $\begin{array}{l}\text { Common } \\
\text { and Islamic } \\
\text { law. }\end{array}$ & $\begin{array}{l}\text { Signed } \\
\text { opposing } \\
\text { statement }\end{array}$ \\
\hline Mauritania & Illegal & $\begin{array}{l}\text { Death penalty } \\
\text { or ‘long' prison } \\
\text { term. }\end{array}$ & $\begin{array}{l}\text { Unclear } \\
\text { enforcement }\end{array}$ & $\begin{array}{l}\text { Religious } \\
\text { (Islam) }\end{array}$ & $\begin{array}{l}\text { Islamic and } \\
\text { civil law. }\end{array}$ & $\begin{array}{l}\text { Signed } \\
\text { opposing } \\
\text { statement }\end{array}$ \\
\hline Mauritius & $\begin{array}{l}\text { Illegal } \\
\text { for } \\
\text { men }\end{array}$ & $\begin{array}{l}\text { Up to } 5 \text { years } \\
\text { in prison. }\end{array}$ & $\begin{array}{l}\text { Unclear } \\
\text { enforcement }\end{array}$ & Cultural & $\begin{array}{l}\text { Civil and } \\
\text { common } \\
\text { law. }\end{array}$ & $\begin{array}{l}\text { Signed in } \\
2008 \text { only }\end{array}$ \\
\hline $\begin{array}{l}\text { Morocco } \\
\text { (incl. Western } \\
\text { Sahara) }\end{array}$ & Illegal & $\begin{array}{l}\text { Up to } 3 \text { years } \\
\text { in prison. }\end{array}$ & $\begin{array}{l}\text { Sporadically } \\
\text { enforced }\end{array}$ & $\begin{array}{l}\text { Cultural } \\
\text { and } \\
\text { religious } \\
\text { (Islam) } \\
\end{array}$ & $\begin{array}{l}\text { Islamic and } \\
\text { civil law. }\end{array}$ & $\begin{array}{l}\text { Signed } \\
\text { opposing } \\
\text { statement }\end{array}$ \\
\hline Namibia & Illegal & $\begin{array}{l}\text { Information } \\
\text { unavailable. }\end{array}$ & $\begin{array}{l}\text { Sporadically } \\
\text { enforced }\end{array}$ & Cultural & $\begin{array}{l}\text { South } \\
\text { African law. }\end{array}$ & $\begin{array}{l}\text { Did not } \\
\text { sign }\end{array}$ \\
\hline Nauru & $\begin{array}{l}\text { Illegal } \\
\text { for } \\
\text { men }\end{array}$ & $\begin{array}{l}\text { Up to } 14 \text { years } \\
\text { in prison with } \\
\text { or without } \\
\text { hard labour. }\end{array}$ & $\begin{array}{l}\text { Unclear } \\
\text { enforcement }\end{array}$ & Cultural & $\begin{array}{l}\text { Common } \\
\text { law. }\end{array}$ & Signed \\
\hline Nigeria & $\begin{array}{l}\text { Illegal } \\
\text { for } \\
\text { men } \\
\text { (also } \\
\text { for } \\
\text { women } \\
\text { in } \\
\text { some } \\
\text { areas) } \\
\end{array}$ & $\begin{array}{l}\text { Up to } 14 \text { years } \\
\text { in prison. }\end{array}$ & $\begin{array}{l}\text { Sporadically } \\
\text { enforced }\end{array}$ & $\begin{array}{l}\text { Religious } \\
\text { (Islam) }\end{array}$ & $\begin{array}{l}\text { Shari'a law } \\
\text { in certain } \\
\text { parts. } \\
\text { Otherwise, } \\
\text { common } \\
\text { and civil } \\
\text { law. }\end{array}$ & $\begin{array}{l}\text { Signed } \\
\text { opposing } \\
\text { statement }\end{array}$ \\
\hline Oman & Illegal & $\begin{array}{l}\text { Fines or up to } \\
3 \text { years in } \\
\text { prison. }\end{array}$ & $\begin{array}{l}\text { Enforced } \\
\text { but not } \\
\text { prosecuted }\end{array}$ & $\begin{array}{l}\text { Religious } \\
\text { (Islam) }\end{array}$ & $\begin{array}{l}\text { Shari'a and } \\
\text { customary } \\
\text { law. }\end{array}$ & $\begin{array}{l}\text { Signed } \\
\text { opposing } \\
\text { statement }\end{array}$ \\
\hline Pakistan & Illegal & $\begin{array}{l}2 \text { years up to a } \\
\text { life sentence in } \\
\text { prison. }\end{array}$ & $\begin{array}{l}\text { Enforced } \\
\text { regularly }\end{array}$ & $\begin{array}{l}\text { Religious } \\
\text { (Islam) }\end{array}$ & $\begin{array}{l}\text { Common } \\
\text { law with } \\
\text { provisions } \\
\text { of Shari'a. }\end{array}$ & $\begin{array}{l}\text { Signed } \\
\text { opposing } \\
\text { statement }\end{array}$ \\
\hline Palau & $\begin{array}{l}\text { Illegal } \\
\text { for } \\
\text { men } \\
\end{array}$ & $\begin{array}{l}\text { Up to } 10 \text { years } \\
\text { in prison. }\end{array}$ & $\begin{array}{l}\text { Unclear } \\
\text { enforcement }\end{array}$ & Cultural & US law. & Signed \\
\hline $\begin{array}{l}\text { Papua New } \\
\text { Guinea }\end{array}$ & Illegal & $\begin{array}{l}\text { Up to } 14 \text { years } \\
\text { in prison. }\end{array}$ & $\begin{array}{l}\text { Unclear } \\
\text { enforcement }\end{array}$ & Cultural & $\begin{array}{l}\text { Common } \\
\text { and } \\
\text { customary } \\
\text { law. }\end{array}$ & $\begin{array}{l}\text { Did not } \\
\text { sign }\end{array}$ \\
\hline Qatar & Illegal & $\begin{array}{l}\text { Fines or up to } \\
5 \text { years in } \\
\text { prison. }\end{array}$ & $\begin{array}{l}\text { Enforced } \\
\text { regularly }\end{array}$ & $\begin{array}{l}\text { Religious } \\
\text { (Islam) }\end{array}$ & $\begin{array}{l}\text { Islamic and } \\
\text { civil law. }\end{array}$ & $\begin{array}{l}\text { Signed } \\
\text { opposing } \\
\text { statement }\end{array}$ \\
\hline Samoa & Illegal & $\begin{array}{l}\text { Up to } 7 \text { years } \\
\text { in prison. }\end{array}$ & $\begin{array}{l}\text { Unclear } \\
\text { enforcement }\end{array}$ & Cultural & $\begin{array}{l}\text { Common } \\
\text { law. }\end{array}$ & Signed \\
\hline Saudi Arabia & Illegal & $\begin{array}{l}\text { Death penalty } \\
\text { or long prison } \\
\text { term. }\end{array}$ & $\begin{array}{l}\text { Enforced } \\
\text { regularly }\end{array}$ & $\begin{array}{l}\text { Religious } \\
\text { (Islam) }\end{array}$ & Islamic. & $\begin{array}{l}\text { Signed } \\
\text { opposing } \\
\text { statement }\end{array}$ \\
\hline
\end{tabular}




\begin{tabular}{|c|c|c|c|c|c|c|}
\hline Senegal & Illegal & $\begin{array}{l}1 \text { month-5 } \\
\text { years in } \\
\text { prison. }\end{array}$ & $\begin{array}{l}\text { Enforced } \\
\text { regularly }\end{array}$ & $\begin{array}{l}\text { Religious } \\
\text { (Islam) } \\
\text { and } \\
\text { cultural } \\
\end{array}$ & $\begin{array}{l}\text { French } \\
\text { civil law. }\end{array}$ & $\begin{array}{l}\text { Signed } \\
\text { opposing } \\
\text { statement }\end{array}$ \\
\hline Seychelles & $\begin{array}{l}\text { Illegal } \\
\text { for } \\
\text { men }\end{array}$ & $\begin{array}{l}\text { Up to } 14 \text { years } \\
\text { in prison. }\end{array}$ & $\begin{array}{l}\text { Unclear } \\
\text { enforcement }\end{array}$ & $\begin{array}{l}\text { Cultural } \\
\text { (colonial } \\
\text { legacy) }\end{array}$ & $\begin{array}{l}\text { Civil and } \\
\text { common } \\
\text { law. }\end{array}$ & Signed \\
\hline Sierra Leone & $\begin{array}{l}\text { Illegal } \\
\text { for } \\
\text { men }\end{array}$ & $\begin{array}{l}\text { Life } \\
\text { imprisonment. }\end{array}$ & $\begin{array}{l}\text { Sporadically } \\
\text { enforced }\end{array}$ & $\begin{array}{l}\text { Religious } \\
\text { (Christian } \\
\text { and Islam) }\end{array}$ & $\begin{array}{l}\text { Civil and } \\
\text { customary } \\
\text { law. }\end{array}$ & Signed \\
\hline Singapore & $\begin{array}{l}\text { Illegal } \\
\text { for } \\
\text { men }\end{array}$ & $\begin{array}{l}\text { Up to } 2 \text { years } \\
\text { in prison. }\end{array}$ & $\begin{array}{l}\text { Unclear } \\
\text { enforcement }\end{array}$ & $\begin{array}{l}\text { Info not } \\
\text { available }\end{array}$ & $\begin{array}{l}\text { English } \\
\text { common } \\
\text { law. } \\
\text { Muslims } \\
\text { subject to } \\
\text { Shari'a law. }\end{array}$ & $\begin{array}{l}\text { Did not } \\
\text { sign }\end{array}$ \\
\hline $\begin{array}{l}\text { Solomon } \\
\text { Islands }\end{array}$ & Illegal & $\begin{array}{l}\text { Up to } 14 \text { years } \\
\text { in prison. }\end{array}$ & $\begin{array}{l}\text { Unclear } \\
\text { enforcement }\end{array}$ & Cultural & $\begin{array}{l}\text { Common } \\
\text { and } \\
\text { customary } \\
\text { law. }\end{array}$ & $\begin{array}{l}\text { Signed } \\
\text { opposing } \\
\text { statement }\end{array}$ \\
\hline Somalia & Illegal & $\begin{array}{l}\text { Flogging } \\
\text { and/or prison. } \\
\text { Death for } \\
\text { repeat } \\
\text { offending. }\end{array}$ & $\begin{array}{l}\text { Unclear } \\
\text { enforcement }\end{array}$ & $\begin{array}{l}\text { Religious } \\
\text { (Islam) }\end{array}$ & $\begin{array}{l}\text { Civil, } \\
\text { Islamic and } \\
\text { customary } \\
\text { law }\end{array}$ & $\begin{array}{l}\text { Signed } \\
\text { opposing } \\
\text { statement }\end{array}$ \\
\hline Somaliland & Illegal & $\begin{array}{l}\text { Death penalty } \\
\text { or prison. }\end{array}$ & $\begin{array}{l}\text { Unclear } \\
\text { enforcement }\end{array}$ & $\begin{array}{l}\text { Religious } \\
\text { (Islam) }\end{array}$ & Shari'a law. & N/A \\
\hline South Sudan & Illegal & $\begin{array}{l}\text { Up to } 10 \text { years } \\
\text { in prison. }\end{array}$ & $\begin{array}{l}\text { Unclear } \\
\text { enforcement }\end{array}$ & $\begin{array}{l}\text { Cultural } \\
\text { and } \\
\text { religious } \\
\text { (Christian } \\
\text { and Islam) } \\
\end{array}$ & $\begin{array}{l}\text { Civil and } \\
\text { customary } \\
\text { law. }\end{array}$ & N/A \\
\hline $\begin{array}{l}\text { St Kitts \& } \\
\text { Nevis }\end{array}$ & $\begin{array}{l}\text { Illegal } \\
\text { for } \\
\text { men }\end{array}$ & $\begin{array}{l}\text { Up to } 10 \text { years } \\
\text { in prison. }\end{array}$ & $\begin{array}{l}\text { Enforced } \\
\text { but not } \\
\text { prosecuted }\end{array}$ & Cultural & $\begin{array}{l}\text { Common } \\
\text { law. }\end{array}$ & $\begin{array}{l}\text { Did not } \\
\text { sign }\end{array}$ \\
\hline St Lucia & $\begin{array}{l}\text { Illegal } \\
\text { for } \\
\text { men }\end{array}$ & $\begin{array}{l}\text { Fine and/or up } \\
\text { to } 10 \text { years in } \\
\text { prison. }\end{array}$ & $\begin{array}{l}\text { Enforced } \\
\text { but not } \\
\text { prosecuted }\end{array}$ & Cultural & $\begin{array}{l}\text { Civil and } \\
\text { common } \\
\text { law. }\end{array}$ & $\begin{array}{l}\text { Signed } \\
\text { opposing } \\
\text { statement }\end{array}$ \\
\hline $\begin{array}{l}\text { St Vincent \& } \\
\text { the } \\
\text { Grenadines }\end{array}$ & Illegal & $\begin{array}{l}\text { Fine and/or up } \\
\text { to } 10 \text { years in } \\
\text { prison. }\end{array}$ & $\begin{array}{l}\text { No open } \\
\text { enforcement }\end{array}$ & Cultural & $\begin{array}{l}\text { Common } \\
\text { law. }\end{array}$ & $\begin{array}{l}\text { Did not } \\
\text { sign }\end{array}$ \\
\hline Sudan & Illegal & $\begin{array}{l}\text { Minimum } 5 \\
\text { years in prison } \\
\text { or the death } \\
\text { penalty. }\end{array}$ & $\begin{array}{l}\text { Unclear } \\
\text { enforcement }\end{array}$ & $\begin{array}{l}\text { Religious } \\
\text { (Islam) }\end{array}$ & Islamic law. & $\begin{array}{l}\text { Signed } \\
\text { opposing } \\
\text { statement }\end{array}$ \\
\hline Swaziland & $\begin{array}{l}\text { Illegal } \\
\text { for } \\
\text { men }\end{array}$ & $\begin{array}{l}\text { Minimum } 2 \\
\text { years in prison } \\
\text { and fine. }\end{array}$ & $\begin{array}{l}\text { Unclear } \\
\text { enforcement }\end{array}$ & Cultural & $\begin{array}{l}\text { South } \\
\text { African law. }\end{array}$ & $\begin{array}{l}\text { Signed } \\
\text { opposing } \\
\text { statement }\end{array}$ \\
\hline Syria & Illegal & $\begin{array}{l}\text { Up to } 3 \text { years } \\
\text { in prison. }\end{array}$ & $\begin{array}{l}\text { Enforced } \\
\text { regularly }\end{array}$ & $\begin{array}{l}\text { Religious } \\
\text { (Islam) }\end{array}$ & $\begin{array}{l}\text { Islamic and } \\
\text { civil law. }\end{array}$ & $\begin{array}{l}\text { Initiative of } \\
\text { opposing } \\
\text { statement }\end{array}$ \\
\hline
\end{tabular}




\begin{tabular}{|c|c|c|c|c|c|c|}
\hline Tanzania & Illegal & $\begin{array}{l}\text { Up to life } \\
\text { sentence in } \\
\text { prison. }\end{array}$ & $\begin{array}{l}\text { Enforced } \\
\text { regularly }\end{array}$ & Cultural & $\begin{array}{l}\text { Common } \\
\text { law. }\end{array}$ & $\begin{array}{l}\text { Signed } \\
\text { opposing } \\
\text { statement }\end{array}$ \\
\hline Togo & Illegal & $\begin{array}{l}3 \text { years in } \\
\text { prison and } \\
\text { fine. }\end{array}$ & $\begin{array}{l}\text { Unclear } \\
\text { enforcement }\end{array}$ & $\begin{array}{l}\text { Info not } \\
\text { available }\end{array}$ & $\begin{array}{l}\text { Civil and } \\
\text { customary } \\
\text { law. }\end{array}$ & $\begin{array}{l}\text { Signed } \\
\text { opposing } \\
\text { statement }\end{array}$ \\
\hline Tonga & $\begin{array}{l}\text { Illegal } \\
\text { for } \\
\text { men } \\
\end{array}$ & $\begin{array}{l}\text { Up to } 10 \text { years } \\
\text { in prison. }\end{array}$ & $\begin{array}{l}\text { Unclear } \\
\text { enforcement }\end{array}$ & Cultural & $\begin{array}{l}\text { Common } \\
\text { law. }\end{array}$ & $\begin{array}{l}\text { Did not } \\
\text { sign }\end{array}$ \\
\hline $\begin{array}{l}\text { Trinidad \& } \\
\text { Tobago }\end{array}$ & Illegal & $\begin{array}{l}25 \text { years in } \\
\text { prison. }\end{array}$ & $\begin{array}{l}\text { Sporadically } \\
\text { enforced }\end{array}$ & Cultural & $\begin{array}{l}\text { Common } \\
\text { law. }\end{array}$ & $\begin{array}{l}\text { Did not } \\
\text { sign }\end{array}$ \\
\hline Tunisia & Illegal & $\begin{array}{l}\text { Fine or up to } 3 \\
\text { years in } \\
\text { prison. }\end{array}$ & $\begin{array}{l}\text { Sporadically } \\
\text { enforced }\end{array}$ & $\begin{array}{l}\text { Religious } \\
\text { (Islam) } \\
\text { and } \\
\text { cultural }\end{array}$ & $\begin{array}{l}\text { Islamic and } \\
\text { civil law. }\end{array}$ & $\begin{array}{l}\text { Signed } \\
\text { opposing } \\
\text { statement }\end{array}$ \\
\hline Turkmenistan & $\begin{array}{l}\text { Illegal } \\
\text { for } \\
\text { men }\end{array}$ & $\begin{array}{l}\text { Up to } 2 \text { years } \\
\text { in prison. }\end{array}$ & $\begin{array}{l}\text { Unclear } \\
\text { enforcement }\end{array}$ & $\begin{array}{l}\text { Religious } \\
\text { (Islam) }\end{array}$ & $\begin{array}{l}\text { Islamic and } \\
\text { civil law. }\end{array}$ & $\begin{array}{l}\text { Signed } \\
\text { opposing } \\
\text { statement }\end{array}$ \\
\hline Tuvalu & $\begin{array}{l}\text { Illegal } \\
\text { for } \\
\text { men }\end{array}$ & $\begin{array}{l}\text { Up to } 14 \text { years } \\
\text { in prison. }\end{array}$ & $\begin{array}{l}\text { Unclear } \\
\text { enforcement }\end{array}$ & $\begin{array}{l}\text { Cultural } \\
\text { (colonial } \\
\text { legacy) }\end{array}$ & $\begin{array}{l}\text { Common } \\
\text { law. }\end{array}$ & Signed \\
\hline UAE & Illegal & $\begin{array}{l}\text { Fines, } \\
\text { deportation, } \\
\text { prison, } \\
\text { chemical } \\
\text { castration or } \\
\text { death. }\end{array}$ & $\begin{array}{l}\text { Enforced } \\
\text { regularly }\end{array}$ & $\begin{array}{l}\text { Religious } \\
\text { (Islam) }\end{array}$ & $\begin{array}{l}\text { Islamic and } \\
\text { civil law. }\end{array}$ & $\begin{array}{l}\text { Signed } \\
\text { opposing } \\
\text { statement }\end{array}$ \\
\hline Uganda & Illegal & $\begin{array}{l}\text { Up to } 7 \text { years } \\
\text { in prison. }\end{array}$ & $\begin{array}{l}\text { Sporadically } \\
\text { enforced }\end{array}$ & Cultural & $\begin{array}{l}\text { Common } \\
\text { law. }\end{array}$ & $\begin{array}{l}\text { Signed } \\
\text { opposing } \\
\text { statement }\end{array}$ \\
\hline Uzbekistan & $\begin{array}{l}\text { Illegal } \\
\text { for } \\
\text { men }\end{array}$ & $\begin{array}{l}\text { Up to } 3 \text { years } \\
\text { in prison. }\end{array}$ & $\begin{array}{l}\text { Enforced } \\
\text { regularly }\end{array}$ & $\begin{array}{l}\text { Cultural } \\
\text { legacy from } \\
\text { Russia }\end{array}$ & $\begin{array}{l}\text { Soviet civil } \\
\text { law. }\end{array}$ & $\begin{array}{l}\text { Did not } \\
\text { sign }\end{array}$ \\
\hline Yemen & Illegal & $\begin{array}{l}\text { Flogging } \\
\text { and/or death } \\
\text { penalty. }\end{array}$ & $\begin{array}{l}\text { Enforced } \\
\text { regularly }\end{array}$ & $\begin{array}{l}\text { Religious } \\
\text { (Islam) }\end{array}$ & Islamic law. & $\begin{array}{l}\text { Signed } \\
\text { opposing } \\
\text { statement }\end{array}$ \\
\hline Zambia & $\begin{array}{l}\text { Illegal } \\
\text { for } \\
\text { men }\end{array}$ & $\begin{array}{l}\text { Up to } 14 \text { years } \\
\text { in prison. }\end{array}$ & $\begin{array}{l}\text { Sporadically } \\
\text { enforced }\end{array}$ & $\begin{array}{l}\text { Religious } \\
\text { (Christian) } \\
\text { and } \\
\text { cultural }\end{array}$ & $\begin{array}{l}\text { Common } \\
\text { and } \\
\text { customary } \\
\text { law. }\end{array}$ & $\begin{array}{l}\text { Did not } \\
\text { sign }\end{array}$ \\
\hline Zimbabwe & $\begin{array}{l}\text { Illegal } \\
\text { for } \\
\text { men }\end{array}$ & $\begin{array}{l}\text { Information } \\
\text { unavailable. }\end{array}$ & $\begin{array}{l}\text { Enforced } \\
\text { regularly }\end{array}$ & Cultural & $\begin{array}{l}\text { South } \\
\text { African law. }\end{array}$ & $\begin{array}{l}\text { Signed } \\
\text { opposing } \\
\text { statement }\end{array}$ \\
\hline
\end{tabular}




\section{References}

Abrahams, R. (1996). Vigilantism: Order and disorder on the frontiers of the state. In O. Harris (Ed.), Inside and outside the law: Anthropological studies of authority and ambiguity (pp. 41-55). London: Routledge.

AFW. (2011). Maurice Tomlinson's Countdown to Tolerance: Setting the stage. Retrieved from: $\quad$ http://www.aidsfreeworld.org/PublicationsMultimedia/Countdown-to-Tolerance/2011/November/Setting-the-Stage.aspx. 18 March, 2013.

Allyn, A. R. (2012). Homophobia in Jamaica: A study of cultural heterosexism in praxis. Retrieved from: http://papers.ssrn.com/sol3/papers.cfm?abstract id=2097180. 22 November, 2012.

AI. (2001a). Crimes of hate, conspiracy of silence: Torture and ill-treatment based on sexual identity. London: Amnesty International Publications.

AI. (2001b). Jamaica: Killings and violence by Police: How many more victims. London: Amnesty International Publications.

AI. (2008). Love, hate and the law: Decriminalizing homosexuality. London: Amnesty International Publications.

AI. (2011a). Annual Report 2011: The state of the world's human rights: Jamaica. London: Amnesty International Publications.

AI. (2011b). Jamaica: Submission to the UN Human Rights Committee for the $103^{\text {rd }}$ Session. London: Amnesty International Publications.

AI. (2012). Annual Report 2012: The state of the world's human rights: Jamaica. London: Amnesty International Publications.

Asal, V., Sommer, U. \& Harwood, P. G. (2012). Original sin: A cross-national study of the legality of homosexual acts. Comparative Political Studies. Advance Online Publication. doi: 10.1177/0010414012453693.

Atkinson, P., \& Hammersley, M. (2007). Ethnography: Principles in practice. New York: Routledge.

Baudh, S. (2006). Sodomy in India: Sex crime or human right? IDS Bulletin, 37(5), 5863. doi: 10.1111/j.1759-5436.2006.tboo303.x. 
Baudh, S. (2008). Human rights and the criminalisation of consensual same-sex sexual acts in the Commonwealth, South and Southeast Asia. New Delhi, India: The South and Southeast Asia Resource Centre on Sexuality.

Beckles, H. (2004). Black masculinity in Caribbean slavery. In R. E. Reddock (Ed.), Interrogating Caribbean Masculinities: Theoretical and empirical analyses (pp. 225-243). Kingston: University of the West Indies Press.

Beckmann, A. (2009). The social construction of sexuality and perversion: Deconstructing sadomasochism. Basingstoke, Hampshire: Palgrave Macmillan.

Berrill, K. T. \& Herek, G.M. (1992). Primary and secondary victimization in anti-gay hate crimes: Official response and public policy. In G. M. Herek \& K. T. Berrill (Eds.), Hate crimes: Confronting violence against lesbians and gay men (pp. 89-104). London: SAGE.

Bibbings, L. (2004). Heterosexuality as harm: Fitting in. In P. Hillyard, C. Pantazis, S. Tombs \& D. Gordon (Eds.), Beyond criminology: Taking harm seriously (pp. 217-235). London: Pluto Press.

Bibbings, L. (2009). The heterostate: Hegemonic heterosexuality and state power. In R. Coleman, J. Sim, S. Tombs \& D. Whyte (Eds.), State, Power and Crime (pp. 3548). London: SAGE.

Black, D. (1984). Crime as social control. In D. Black (Ed.), Toward a general theory of social control: Volume 2 - selected problems (pp. 1-27). New York: Academic Press.

Boroumand Foundation. (2013). Omid: A memorial in defence of human rights in Iran. Retrieved from: http://www.iranrights.org/english/memorial.php. 22 February, 2013.

Bourdieu, P. (2000). Pascalian Meditations (R. Nice, Trans.). New York: Stanford University Press.

Bowcott, O. \& Wolfe-Robinson, M. (2012, October 26). Gay Jamaicans launch legal action over island's homophobic laws. The Guardian. Retrieved from: http://www.guardian.co.uk/world/2012/oct/26/jamaica-gay-rightshomophobic-laws. 27 October, 2012.

Bowen, G. A. (2009). Document analysis as a qualitative research method. Qualitative Research Journal, 9(2), 27-40. doi: 10.3316/QRJo902027. 
Boxill, I., Galbraith, E., Mitchell, R., Russell, R., Johnson, S. \& Waller, L. (2012). National Survey of Attitudes and Perceptions of Jamaicans towards Same Sex Relationships: A follow-up study. Kingston, Jamaica: Department of Psychology and Social Work, University of the West Indies.

Boxill, I., Martin, J., Russell, R., Waller, L., Meikle, T. \& Mitchell, R. (2011). National Survey of Attitudes and Perceptions of Jamaicans towards Same Sex Relationships. Kingston, Jamaica: Department of Psychology and Social Work, University of the West Indies.

Brown, A., Bailey, A., Palmer, Q., Tureski, K., Rogers, S. J., Cushni, A. \& Adelaja, A. (2012). Layered stigma among health facility and social services staff towards most at-risk populations in Jamaica. Washington DC: C-Change.

Brown, C. Does the Gleaner have a gay agenda? [Letter to the Editor]. The Gleaner. Retrieved from: http://jamaicagleaner.com/gleaner/20120608/cleisure/cleisure4.html. 20 December, 2012.

Brown, D. (2010). Making room for sexual orientation and gender identity in international human rights law: An introduction to the Yogyakarta Principles. Michigan Journal of International Law, 31(4), 821-879.

Burnard, T. (2007). Evaluating gender in early Jamaica 1674-1784. The History of the Family, 12(2), 81-91. doi: 10.1016/j.hisfam.2007.08.001.

Butler, J. (1993). Bodies that matter: On the discursive limits of 'sex'. London: Routledge.

Butler, J. (1999). Gender trouble: Feminism and the subversion of identity. London: Routledge.

Butler, J. (2004). Undoing gender. London: Routledge.

Caceres, C. (2002). HIV among gay and other men who have sex with men in Latin America and the Caribbean: A hidden epidemic? AIDS, 16(3), 23-33. doi: 10.1097/00002030-200212003-00005.

Carr, R. (2003). On “judgements”: Poverty, sexuality-based violence and social justice in $21^{\text {st }}$ century Jamaica. Caribbean Journal of Social Work, 2, 71-87.

Cerna, C. M. (1994). Universality of human rights and cultural diversity: Implementation of human rights in different socio-cultural contexts. Human Rights Quarterly, 16(4), 740-752. 
Chan, P. C. W. (2006). No, it's not just a phase: An adolescent's right to sexual minority identity under the United Nations Convention on the rights of the child. The International Journal on Human Rights, 10 (2). doi: 10.1080/13642980600608590.

Chand, S. (2010, February 26). Same sex law decriminalised. Fiji Times Online. Retrieved from: http://www.fijitimes.com/story.aspx?id=140812. 18 July, 2012.

Charles, C. A. D. (2011). Representations of homosexuality in Jamaica. Social and Economic Studies, 6o(1), 3-29.

Charlesworth, H., Chinkin, C. \& Wright, S. (1991). Feminist approaches to international law. American Journal of International Law, 85, 613-645.

Chevannes, B. (1999). What you sow is what you reap: Violence and the construction of male identity in Jamaica. Current Issues in Comparative Education, 2(1), 51-61.

Chevannes, B. (2001). Learning to be a man: Culture, socialization and gender identity in five Caribbean communities. Kingston, Jamaica: University of the West Indies Press.

Chouliaraki, L., \& Fairclough, N. (1999). Discourse in late modernity: Rethinking critical discourse analysis. Edinburgh: Edinburgh University Press.

Cohen, S. (1993). Human rights and crimes of the state: The culture of denial. Australian and New Zealand Journal of Criminology, 26(2), 97-115. Doi: 10.1177/000486589302600201.

Cohen, S. (1996). Government responses to human rights reports: Claims, denials and counterclaims. Human Rights Quarterly, 18(3), 517-543.

Cohen, S. (2001). States of denial: Knowing about atrocities and suffering. Cambridge: Polity Press.

CommEDAW. (2006). Concluding comments of the Committee on the Elimination of Discrimination against Women: Jamaica. UN doc, CEDAW/C/JAM/CO/5, 25 August, 2006.

CommRC. (2003). Consideration of reports submitted by states parties under Article 44 of the Convention: Concluding Observations: Jamaica. UN doc, CRC/C/15/Add.210, 4 July, 2003.

Connell, R. (2000). The men and the boys. Cambridge: Polity Press. 
Coombe, R. J. (1995). The cultural life of things: Anthropological approaches to law and society in conditions of globalization. American University International Law Review, 1O(2), 791-835.

Cooper, C. (2004). Sound clash: Jamaican dancehall culture at large. New York: Palgrave Macmillan.

Cooper, C. \& Donnell, A. (2004). Jamaican Popular Culture: Introduction. Interventions: International Journal of Postcolonial Studies, 6(1), 1-17. doi: 10.1080/1369801042000185633.

Cooper, D. (1995). Power in struggle: Feminism, sexuality and the state. Buckingham: Open University Press.

Corrêa, S. Petchesky, R., \& Parker, R. (2008). Sexuality, health and human rights. London: Routledge.

Cowell, F. \& Milon, A. (2012). Decriminalisation of sexual orientation through the Universal Periodic Review. Human Rights Law Review, 12(2), 341-352. doi.: 10.1093/hrlr/ngsoo9.

Cowell, N. M. \& Saunders, T. S. (2011). Exploring heteronormativity in the public discourse of Jamaican legislators. Sexuality and Culture, 15, 315-331. doi: 10.1007/s12119-011-9105-2.

Crotty, M. (1998). The foundations of social research: Meaning and perspective in the research process. Crow's Nest, NSW: Allen and Unwin.

Declaration of Montreal. (2006). From the International Conference on LGBT Human Rights.

Retrieved

from:

http://www.declarationofmontreal.org/declaration/DeclarationofMontreal.pdf. 26 September, 2012.

Dicklitch, S., Yost, B. \& Dougan, B. M. (2012). Building a Barometer of Gay Rights (BGR): A case study of Uganda and the persecution of homosexuals. Human Rights Quarterly, 34(2), 448-471.

Dittrich, B. O. (2008). The Yogyakarta Principles. In I. Dubel \& A. Hielkema (Eds.), Urgency Required: Gay and lesbian rights are human rights (pp. 241-248). The Hague: Humanist Institute for Cooperation with Developing Countries (Hivos).

Dittrich, B. O. (2012, July 16). Jamaica: Letter to Prime Minister Simpson-Miller on behalf of Human Rights Watch. Retrieved from: 
http://www.hrw.org/news/2012/o7/16/jamaica-letter-prime-minister-simpsonmiller. 21 September, 2012.

Donnelly, J. (1999). Non-discrimination and sexual orientation: Making a place for sexual minorities in the global human rights regime. In P. Baehr, C. Flinterman \& M. Senders (Eds.), Innovation and inspiration: Fifty years of the Universal Declaration of Human Rights (pp. 93-110). Amsterdam: Royal Netherlands Academy of Arts and Sciences.

ECOSOC. (2011, 23 May). Committee on Non-Governmental Organizations denies status to International Gay and Lesbian Association, closing door on applicant after ten years. Retrieved from: http://www.un.org/News/Press/docs/2011/ecosoc6482.doc.htm. 26 September, 2012.

ECOSOC. (2005a). The right to freedom of opinion and expression: Addendum: Summary of cases transmitted to governments and replies received. UN doc, E/CN.4/2005/64/Add.1, 29 March, 2005.

ECOSOC. (2005b). Extrajudicial, summary or arbitrary executions: Report of the Special Rapporteur, Philip Alston: Summary of cases transmitted to governments and replies received. UN doc, E/CN.4/2005/7/Add.1, 17 March, 2005 .

ECOSOC. (2006). Promotion and protection of human rights defenders: Report of the Special Representative of the Secretary General: Addendum: Summary of cases transmitted to governments and replies received. UN doc, E/CN.4/2006/95/Add.1, 22 March, 2006.

EqualityJA. (2013). We are Jamaicans Ad campaign [Youtube channel]. Retrieved from: http://www.youtube.com/user/EqualityJA. 20 January, 2013.

Evans, T. (2005). International human rights law as power/knowledge. Human Rights Quarterly, 27(3), 1046-1068.

Fairclough, N. (1989). Language and power. Essex: Longman Press.

Fairclough, N. (1995). Critical discourse analysis: The critical study of language. Essex: Pearson Education.

Finnemore, M. \& Sikkink, K. (1999). International norm dynamics and political change. In P. J. Katzenstein, R. O. Keohane \& S. D. Krasner (Eds.), Exploration and 
contestation in the study of world politics. Cambridge, MA: MIT Press.

Foley, M. W. \& Edwards, B. (1996). The paradox of civil society. Journal of Democracy, $7(3), 38-52$.

Foucault, M. (1976/78). The history of sexuality: Volume One (R. Hurley, Trans). London: Penguin Books.

Fradella, H. F. (2002). Legal, moral, and social reasons for decriminalizing sodomy. Journal of Contemporary Criminal Justice, 18(3), 279-301. doi: 10.1177/1043986202018003005.

Gays and Lesbians of Zimbabwe [GALZ]. (2011). Report of discrimination against women in Zimbabwe based on sexual orientation and gender identity. Harare, Zimbabwe: GALZ. Submitted for consideration at the $5^{1^{\text {st }}}$ Session of the Committee on the Elimination of Discrimination Against Women.

Golding, B. (2008, February 29). Letter from Bruce Golding via Prime Minister of Jamaica [via Human Rights Watch]. Retrieved from: http://www.hrw.org/news/2008/o2/28/letter-bruce-golding-prime-ministerjamaica. 13 January, 2013.

Golding talks about policing, gays on BBC. (2008, May 21). Jamaica Gleaner. Retrieved from: $\quad$ http://jamaica-gleaner.com/gleaner/20080521/lead/lead3.html. $\quad 8$ December, 2012.

Goodman, R. (2001). Beyond the enforcement principle: Sodomy laws, social norms and social panoptics. California Law Review, 89(3), 643-739.

Grenada Chapter of the Caribbean HIV/AIDS Partnership, Hope Pals Foundations, Grenada Human Rights Desk, Caribbean Forum for Lesbians All-sexuals \& Gays, Caribbean Vulnerable Communities Coalition, Caribbean Coalition of National Aids Programme Coordinators, Global Rights, and the IGLHRC. (2007). Sexuality, gender, HIV vulnerability and human rights in Grenada. New York: IGLHRC.

Green, P. \& Ward, T. (2000). State crime, human rights and the limits of criminology. Social Justice, 27(1), 101-115.

Green, P. \& Ward, T. (2004). State crime: Governments, violence and corruption. London: Pluto Press.

Green, P. \& Ward, T. (2012). Civil society, resistance and state crime. In E. Stanley \& J. 
McCulloch (Eds.), State Crime and Resistance (pp. 28-40). London: Routledge.

Grover, A. (2010). Report of the Special Rapporteur on the right of everyone to the enjoyment of the highest attainable standard of physical and mental health. Geneva: United Nations Office of the High Commissioner for Human Rights.

Gubrium, J. F. \& Holstein, J. A. (2003). Analyzing interpretive practice. In N. K. Denzin \& Y. S. Lincoln (Eds.), Strategies of qualitative inquiry: Second edition (pp. 214248). Thousand Oaks, California: SAGE.

Gutzmore, C. (2004). Casting the first stone! Policing of homo/sexuality in Jamaican popular culture. Interventions: International Journal of Postcolonial Studies, 6(1), 118-134. doi: 10.1080/1369801042000185697.

Guyana Rainbow Foundation [GRF], IGLHRC \& Society Against Sexual Orientation Discrimination. (2012). Human rights violations of lesbian, bisexual and transgender (LBT) people in Guyana: A shadow report. New York: IGLHRC. Submitted for consideration at the $5^{2^{\text {nd }}}$ Session of the Committee on the Elimination of Discrimination Against Women.

Hanson, V. (2011). Correcting 'corrective rape'. Paper presented at the Caribbean HIV Conference: Strengthening evidence to achieve sustainable action, The Bahamas (18-21 November, 2011).

Hear the Children's Cry, Independent Jamaican Council of Human Rights, J-FLAG, Jamaican Community of HIV-positive women, Jamaicans for Justice, Mensana, Stand up for Jamaica \& Women's Resource and Outreach Centre. (2011). Jamaica: Civil society report on the implementation of the ICCPR. Geneva: Centre for Civil and Political Rights.

Herek, G. M. (1992). Hate crimes: Confronting violence against lesbians and gay men. In G. M. Herek \& K. T. Berrill (Eds.), Hate crimes: Confronting violence against lesbians and gay men (pp. 89-104). London: SAGE.

Hidayatullah, A. (2003). Islamic conceptions of sexuality. In D. W. Machacek \& M. M. Wilcox (Eds.), Sexuality and the world's religions (pp. 255-). Santa Barbara, California: ABC-CLIO.

Hillyard, P., \& Tombs, S. (2007). From 'crime' to social harm? . Crime, Law and Social Change, 48(1-2), 9-25. doi: 10.1007/s10611-007-9079-z. 
Hooper, C. (2001). Manly states: Masculinities, international relations and gender politics. New York: Columbia University Press.

Hope, D. (2001). Of 'Chi-chi' men: The threat of male homosexuality to Afro-Jamaican masculine identity. Paper presented at the $26^{\text {th }}$ Annual Caribbean Studies Association Conference, Maho Bay, St Maarten (27 May-2 June, 2001).

Hope, D. (2004). The British link-up crew: Consumption masquerading as masculinity in the dancehall. International Journal of Postcolonial Studies, 6(1), 101-117. doi: 10.1080/136980104200185688.

Hope, D. (2006a). 'Passa passa': Interrogating cultural hybridities in Jamaican dancehall. Small Axe, 21, 119-133.

Hope, D. (2006b). 'Dons' and 'Shottas': Performing violent masculinity in dancehall culture. Social and Economic Studies, 55(1/2), 115-131.

Hope, E. (2011, July 11). Homosexual lifestyle is wrong [Letter to the Editor]. Jamaica Observer. Retrieved from: http://www.jamaicaobserver.com/results/Homosexual-lifestyle-iswrong 11930237\#ixzz2CL9l7Qnq. 10 November, 2012.

HRComm. (2011). Consideration of reports submitted by states under Article 40 of the Covenant: Jamaica: Addendum: Replies from the Government of Jamaica. UN doc, CCPR/C/JAM/Q/3/Add.1, 11 July, 2011.

HRCoun. (2007a). Report of the Special Representative of the Secretary General: Addendum: Summary of cases transmitted to governments and replies received. UN doc, A/HRC/4/37/Add.1, 27 March, 2007.

HRCoun. (2007b). Report of the Special Rapporteur on Extrajudicial, Summary and Arbitrary Executions, Philip Alston: Summary of cases transmitted to governments and replies received. UN doc, A/HRC/4/20/Add.1, 12 March, 2007.

HRCoun. (2008). Report of the Working Group on the Universal Periodic Review: Pakistan. UN doc, A/HRC/8/42, 4 June, 2008.

HRCoun. (2009a). Report of the Working Group on the Universal Periodic Review. Saudi Arabia. UN doc, A/HRC/11/23, 4 March, 2009.

HRCoun. (2009b). Report of the Working Group on the Universal Periodic Review: Afghanistan. UN doc, A/HRC/12/9, 7 May, 2009. 
HRCoun. (2009c). Report of the Working Group on the Universal Periodic Review: Barbados: Addendum. UN doc, A/HRC/10/73/Add.1, 16 March, 2009.

HRCoun. (2009d). Report of the Working Group on the Universal Periodic Review: Tuvalu. UN doc, A/HRC/10/84, 9 January, 2009.

HRCoun. (2009e). Report of the Working Group on the Universal Periodic Review: Bangladesh: Addendum. UN doc, A/HRC/11/18/Add.1, 9 June, 2009.

HRCoun. (2009f). Report of the Working Group on the Universal Periodic Review: Malaysia. UN doc, A/HRC/11/30, 5 October, 2009.

HRCoun. (2009g). Report of the Human Rights Council on its Tenth Session. UN doc, A/HRC/10/29, 9 November, 2009.

HRCoun. (2010a). Report of the Working Group on the Universal Periodic Review: Kiribati. UN doc, A/HRC/15/3, 17 June, 2010.

HRCoun. (2010b). Report of the Working Group on the Universal Periodic Review: Kenya. UN doc, A/HRC/15/8, 17 June, 2010.

HRCoun. (2010c). Report of the Working Group on the Universal Periodic Review: Grenada. UN doc, A/HRC/15/12, 16 June, 2010.

HRCoun. (2010d). Report of the Working Group on the Universal Periodic Review: Guyana. UN doc, A/HRC/15/14, 21 June, 2010.

HRCoun. (2010e). Summary prepared by the OHCHR in accordance with Paragraph 15(b) of the annex to the HRCoun resolution 5/1: Jamaica. UN doc, A/HRC/WG.6/9/JAM/2, 12 August, 2010.

HRCoun. (2010f). Summary prepared by the OHCHR in accordance with Paragraph 15(c) of the annex to the HRCoun resolution 5/1: Jamaica. UN doc, A/HRC/WG.6/9/JAM/3, 10 August, 2010.

HRCoun. (2010g). Advance questions to Jamaica. Retrieved from: http://lib.ohchr.org/HRBodies/UPR/Documents/session9/JM/Jamaica.pdf. 20 January, 2013.

HRCoun. (2010h). Advance questions to Jamaica: Addendum 1. Retrieved from: http://lib.ohchr.org/HRBodies/UPR/Documents/session9/JM/Jamaica_Add1.p df. 20 January, 2013.

HRCoun. (2010i). Advance questions to Jamaica: Addendum 2. Retrieved from: 
http://lib.ohchr.org/HRBodies/UPR/Documents/session9/JM/Jamaica_Add2.p df. 20 January, 2013.

HRCoun. (2010j). Advance questions to Jamaica: Addendum 4. Retrieved from: http://lib.ohchr.org/HRBodies/UPR/Documents/sessiong/JM/Jamaica Add4.p df. 20 January, 2013.

HRCoun. (2011a). Report of the Working Group on the Universal Periodic Review: Nauru. UN doc, A/HRC/17/3, 8 March, 2011.

HRCoun. (2011b). Report of the Working Group on the Universal Periodic Review: Seychelles. UN doc, A/HRC/18/7, 11 July, 2011.

HRCoun. (2011c). Council establishes mandate on Cote d'Ivoire, adopts protocol to child rights treat, requests study on discrimination and sexual orientation. Geneva: UNOHCHR. Retrieved from: http://www.ohchr.org/en/NewsEvents/Pages/DisplayNews.aspx?NewsID=11167 \&LangID=E. 10 August 2012.

HRCoun. (2011d). Discriminatory laws and practices and acts of violence against individuals based on their sexual orientation or gender identity. UN doc, A/HRC/19/41, 17 November, 2011.

HRCoun. (2011e). Report of the Working Group on the Universal Periodic Review: Togo. UN doc, A/HRC/19/10, 14 December, 2011.

HRCoun. (2011f). Report of the Working Group on the Universal Periodic Review: Namibia. UN doc, A/HRC/17/14, 24 March, 2011.

HRCoun. (2011g). Report of the Working Group on the Universal Periodic Review: Saint Kitts and Nevis. UN doc, A/HRC/17/12. 15 March, 2011.

HRCoun. (2011h). Report of the Working Group on the Universal Periodic Review: Swaziland. UN doc, A/HRC/19/6, 12 December, 2011.

HRCoun. (2011i). Report of the Working Group on the Universal Periodic Review: Trinidad and Tobago. UN doc, A/HRC/19/7, 14 December, 2011.

HRCoun. (2011j). Report of the Working Group on the Universal Periodic Review: Jamaica. UN doc, A/HRC/16/14, 4 January, 2011.

HRCoun. (2011k). Report of the Working Group on the Universal Periodic Review: Jamaica: Addendum. UN doc, A/HRC/16/14/Add.1, 11 March, 2011. 
HRW. (2004). Hated to death: Homophobia, violence and Jamaica's HIV/AIDS epidemic. New York: HRW.

HRW. (2007, October 1). Convention Against Torture claim approved for gay Jamaican. Retrieved from: http://www.hrw.org/news/2007/10/01/convention-againsttorture-claim-approved-gay-jamaican. November 6, 2012.

HRW. (2008). This Alien Legacy: The origin of 'sodomy' laws in British colonialism. New York: HRW.

HRW. (2010). Criminalizing identities: Rights abuses in Cameroon based on sexual orientation and gender identity. New York: HRW.

HRW. (2009, February 19). Jamaica: Condemn homophobic remarks. Retrieved from: http://www.hrw.org/news/2009/02/19/jamaica-condemn-homophobicremarks. November 6, 2012.

HRW. (2012b, July 18). Jamaica: Combat homophobia. Repeal buggery law; Protect LGBT people. Retrieved from: http://www.hrw.org/news/2012/07/18/jamaicacombat-homophobia. November 20, 2012.

HRW. (2013). World Report 2013: Events of 2012. New York: HRW.

Hunt, A. (1993). Explorations in law and society: Towards a constitutive theory of law. New York: Routledge.

Hurwitz, S. J. \& Hurwitz, E. F. (1971). Jamaica: A historical portrait. New York: Praeger Publishers.

International Council on Human Rights Policy [ICHRP]. (2009). Sexuality and human rights discussion paper. Versoix, Switzerland: ICHRP.

International Gay and Lesbian Human Rights Commission \& IRQO. (2011). Human rights violations on the basis of sexual orientation, gender identity and homosexuality in the Islamic Republic of Iran. New York: IGLHRC. Submitted for consideration at the $103^{\text {rd }}$ Session of the Human Rights Committee.

Jamaican Constitution Amendment (2011). Retrieved from: http://www2.ohchr.org/english/bodies/hrc/docs/ngos/JJSR Jamaica HRC103 Annex1.pdf. 8 January 2013

J-FLAG. (n.d.). Comments on the interim report by the Government of Jamaica pursuant to Paragraph 27 of the concluding observations of the HRComm in 
respect of Jamaica's Third Periodic Report to the ICCPR. Kingston: J-FLAG

J-FLAG. (2011a). History. Retrieved from: http://www.jflag.org/about/history/. 6 July, 2012.

J-FLAG. (2011b). Homophobic discrimination and violent incidents as reported to JFLAG (January-June 2011). Retrieved from: http://www.jflag.org/wpcontent/uploads/2011/o7/JFLAG-Homophobic-Violence-Summary-Jan-June2011-Sheet1.pdf. 2 November, 2012.

J-FLAG, Women for Women, Heartland Alliance for Human Rights and Human Dignity, IGLHRC, AIDS-Free World \& The George Washington University Law School International Human Rights Clinic. (2011). Human rights violations of lesbian, gay, bisexual and transgender (LGBT) people in Jamaica: A shadow report. New York: IGLHRC. Submitted for consideration at the $103^{\text {rd }}$ Session of the Human Rights Committee.

Jamaican lesbian wins appeal to stay in UK (2011, July 8). Jamaica Observer. Retrieved from: http://www.jamaicaobserver.com/news/Jamaican-lesbian-wins-appealto-stay-in-UK 9162502. 13 November, 2012.

Jamaicans granted asylum. (2011, February 12). Jamaica Observer. Retrieved from: http://www.jamaicaobserver.com/news/28-gay-jamaicans-granted-asylum-inus-last-year. 13 November, 2012.

Jamieson, R. \& McEvoy, K. (2005). State crime by proxy and juridical othering. British Journal of Criminology, 45, 504-527. Doi: 10.1093/bjc/azio35.

Kaldor, M. (2003). The idea of global civil society. International Affairs, 79(3), 583-593. Kempadoo, K. (2003). Sexuality in the Caribbean: Theory and research (with an emphasis on the Anglophone Caribbean). Social and Economic Studies, 52(3), $59-88$.

King, J. (2006). Outing the centre: Homophobia in Jamaica. Independent Study Project Collection. Brattleboro, Vermont.

Kogan, T. S. (1994). Legislative violence against lesbians and gay men. Utah Law Review, 1994(1), 209-245.

Kohler, M. H. (1986). History, homosexuals and homophobia: The judicial intolerance of Bowers v Hardwick. Connecticut Law Review, 19, 129-142.

Kollman, K. \& Waites, M. (2009). The global politics of lesbian, gay, bisexual and 
transgender human rights: An introduction. Contemporary Politics, 15(1), 1-17. doi.: 10.1080/13569770802674188.

Kugle, S. S. a.-H. (2003). Homosexuality in Islam: Critical reflection on gay, lesbian and transgender Muslims. Oxford: OneWorld Publications.

LaFont, S. (2001). Very straight sex: The development of sexual mores in Jamaica. Journal of Colonialism and Colonial History, 2(3), 1-25. doi: 10.1353/cch.2001.0051.

Laurence, A. \& Campbell, E. (2007, April 25). Witter warns gays: "Flaunting sexual preference may incite violence." Jamaica Gleaner. Retrieved from: http://jamaica-gleaner.com/gleaner/20070425/lead/lead1.html. 11 November, 2012.

Leslie, C. R. (2000). Creating criminals: The injuries inflicted by "unenforced" sodomy laws. Harvard Civil Rights-Civil Liberties Law Review, 35(1), 103-181.

Lewis, D. (2012, July 12). Is Jamaica a more tolerant society? Retrieved from: http://www.jflag.org/2012/07/. 20 November, 2012.

Long, S. \& Schleifer, R. (2009, February 19). Letter to Prime Minister Golding. Retrieved from: http://www.hrw.org/news/2009/02/19/letter-prime-ministergolding. 22 December, 2012.

Lyon, I. (2012, May 7). Gays should stop burning fire on freedom of speech [Letter to the Editor]. The Gleaner. Retrieved from: http://jamaicagleaner.com/gleaner/20120507/letters/letters2.html. 19 November, 2012.

Marks, S. \& Clapham, A. (2005). Sexuality. In their, International Human Rights Lexicon (pp. 327-344). Oxford: Oxford University Press.

Madsen, M., \& Dezalay, Y. (2002). The power of the legal field: Pierre Bourdieu and the law. In R. Banakar \& M. Travers (Eds.), An introduction to law and social theory (pp. 189-204). Oxford: Hart Publishing.

Mason, G. (2002). The spectacle of violence: Homophobia, gender and knowledge. London: Routledge.

Mason, G. (2008). Hate crime. In T. Anthony \& C. Cunneen (Eds.), The Critical Criminology Companion (pp. 180-190). Annandale, NSW: Hawkins Press.

Mathiesen, T. (2004). Silently silenced: Essays on the creation of acquiescence in modern society. Winchester: Waterside Press. 
McVeigh, S., Rush, P., \& Young, A. (2001). A judgment dwelling in law: Violence and the relations of legal thought. In A. Sarat (Ed.), Law, violence and the possibility of justice (pp. 101-141). Princeton: Princeton University Press.

Merry, S. E. (2006). Human rights and gender violence: Translating international law into local justice. Chicago: University of Chicago Press.

Mezey, N. (2001). Law as culture. The Yale Journal of Law and the Humanities, 13(1), $35-67$.

Michalowski, R. (2010). In search of 'state and crime' in state crime studies. In W. J. Chambliss, R. Michalowski \& R. C. Kramer (Eds.), State Crime in the Global Age (pp. 13-30). Devon: Willan Publishing.

Ministry of Health. (2012). Country progress report: Jamaica. Official report submitted to the UNAIDS Secretariat. Kingston: Ministry of Health.

Mittelstaedt, E. (2008). Safeguarding the rights of sexual minorities: The incremental and legal approaches to enforcing international human rights obligations. Chicago Journal of International Law, 9(1), 353-386.

Moore, S. F. (1978). Law as process: An anthropological approach. London: Routledge and Kegan Paul.

Msibi, T. (2009). Not crossing the line: Masculinities and homophobic violence in South Africa. Agenda, 23(80), 50-54. doi: 10.1080/10130950.2009.9676240.

Murray, R., \& Viljoen, F. (2007). Towards non-discrimination on the basis of sexual orientation: The normative basis and procedural possibilities before the African Commission on Human and People's Rights and the African Union. Human Rights Quarterly, 29(1), 86-111. doi: 10.1353/hrq.2007.0010.

Narayan, P. (2006). Somewhere over the rainbow...International human rights protections for sexual minorities in the new millennium. Boston University International Law Journal, 24(2), 313-348.

Narrain, A. (2004). Queer: Despised sexuality, law and social change. Bangalore, India: Books for Change.

Nussbaum, M. C. (1999). Sex and Social Justice. Oxford: Oxford University Press.

O’Flaherty, M. \& Fisher, J. (2008). Sexual orientation, gender identity and international human rights law: Contextualising the Yogyakarta Principles. Human Rights Law Review, 8(2), 207-248. doi.: 10.1093/hrlr/ngnoo9. 
Offences Against the Person Act (1864/2005). Retrieved from: http://www.moj.gov.jm/laws/statutes/Offences\%20Against\%20the\%20Person\% 20Act.pdf. 17 May, 2011.

Ottosson, D. (2010). State-sponsored homophobia: A world survey of laws prohibiting same sex activity between consenting adults. Brussels, Belgium: ILGA.

Padgett, T. (2006). The most homophobic place on Earth? Time Magazine. Retrieved from: http://www.time.com/time/world/article/o,8599,1182991,00.html. 20 September, 2012.

Patterson, O. (1967). The sociology of slavery: An analysis of origins, development and structure of Negro slave society in Jamaica. London: MacGibbon \& Kee.

Pemberton, S. (2007). Social harm future(s): Exploring the potential of the social harm approach. Crime, Law and Social Change, 48(1-2), 27-41. doi: 10.1007/s10611007-9078-0.

Phillips, O. (2009). Blackmail in Zimbabwe: Troubling narratives of sexuality and human rights. The International Journal of Human Rights, 13(2-3), 345-364. Doi: $10.1080 / 13642980902758192$.

Phillips, R. (2007). Histories of sexuality and imperialism: What's the use? History Workshop Journal, 63(1), 136-153. doi: 10.1093/hwj/dbmo04.

Prior, L. (2003). Using documents in social research. London: SAGE.

Rathgeber, T. (2008). The HRC Universal Periodic Review: A preliminary assessment. FES Briefing Paper 6. Retrieved from: http://library.fes.de/pdffiles/bueros/genf/05479.pdf. 18 January, 2013.

Reddy, V. (2006). Decriminalisation of homosexuality in post-apartheid South Africa: A brief legal case history review from sodomy to marriage. Agenda: Empowering Women for Gender Equity, 20, 146-157. Doi: 10.1080/10130950.2006.9674708.

Reddy, V., Potgieter, C. \& Mkhize, N. (2007). Cloud over the rainbow nation. HSRC Review, 5(1), 10-11.

Rich, A. (1996). Compulsory heterosexuality and lesbian existence. In S. Jackson \& S. Scott (Eds.), Feminism and sexuality: A reader (pp. 130-143). Washington DC: Columbia University Press.

Richardson, D. (1998). Sexuality and citizenship. Sociology, 32(1), 83-100. Doi: 
$10.1177 / 0038038598032001006$.

Riles, A. (2009). Cultural conflicts. In M. Freeman \& D. Napier (Eds.), Law and anthropology (pp. 89-125). Oxford: Oxford University Press.

Risse, T. \& Sikkink, K. (1999). The socialization of international human rights norms into domestic practices: Introduction. In T. Risse, S. C. Ropp \& K. Sikkink (Eds.), The Power of Human Rights: International norms and domestic change (pp. 138). Cambridge: Cambridge University Press.

Romany, C. (1994). State responsibility goes private: A feminist critique of the public/private distinction in international human rights law. In R. J. Cook (Ed.), Human rights of women: National and international perspectives (pp. 85-115). Philadelphia: University of Pennsylvania Press.

Rose, D. (2004, November 18). 'We won't be bullied': Gov't says it has no plans to repeal buggery laws; denies anti-gay allegations. Jamaica Gleaner. Retrieved from: http://jamaica-gleaner.com/gleaner/20041118/lead/lead1.html. 26 January, 2013.

Roth, K. (1994). Domestic violence as an International Human Rights issue. In R. J. Cook (Ed.), Human rights of women: National and international perspectives (pp. 326-339). Philadelphia: University of Pennsylvania Press.

Rubin, G. (1984). Thinking sex: Notes for a radical theory of the politics of sexuality. In C. Vance (Ed.), Pleasure and danger: Exploring female sexuality (pp. 267-293). London: Routledge \& Kegan Paul.

Saiz, I. (2004). Bracketing sexuality: Human rights and sexual orientation: A decade of development and denial at the UN. Health and Human Rights, 7(2), 48-80.

Samoa Law Reform Commission. (2011, 20 December). Samoa Government accepts abolishing Criminal Libel but rejects Sodomy and Adultery. Retrieved from: http://www.samoalawreform.gov.ws/News/Media/SamoaGovernmentacceptsab olishingCriminalLibel/tabid/6912/language/en-US/Default.aspx. 21 June, 2012.

Sanders, D. (1996). Getting lesbian and gay issues on the international human rights agenda. Human Rights Quarterly, 18(1), 67-106. Doi: 10.1353/hrq.1996.0010.

Sanders, D. (2008). 377 and the unnatural afterlife of British colonialism. Paper presented at the $5^{\text {th }}$ Asian Law Institute Conference, National University of Singapore (22-23 May, 2008). 
Saunders, P. J. (2003). Is not everything good to eat, good to talk: Sexual economy and dancehall music in the global marketplace. Small Axe, 13, 95-115. doi: 10.1215/-71-95.

Schippers, M. (2007). Recovering the feminine other: Masculinity, femininity and gender hegemony. Theory and Society, 36(1), 85-102. doi: 10.1007/s11186-0079022-4.

Schleifer, R. \& Long, S. (2008, February 26). Letter to Bruce Golding, Prime Minister of Jamaica on behalf of HRW. Retrieved from: http://www.hrw.org/news/2008/02/26/letter-bruce-golding-prime-ministerjamaica. 28 December, 2012.

Scraton, P. (2007). Power, conflict and criminalisation. Abingdon, Oxon: Routledge.

Sheill, K. (2009). Human rights, sexual orientation, and gender identity at the UN General Assembly. Journal of Human Rights Practice, 1(2), 315-319. doi.: 10.1093/jhuman/hupoo8.

Silvera, M. (1992). Man royals and sodomites: Some thoughts on the invisibility of AfroCaribbean lesbians. Feminist Studies, 18(3), 521-532.

Smith, C. \& Kosobucki, R. (2011). Homophobia in the Caribbean: Jamaica. Unpublished manuscript, Nova Southeastern University, Fort Lauderdale, Florida.

Stanley, E. (2007). Towards a criminology for human rights. In A. Barton, K. Corteen, D. Scott \& D, Whyte (Eds.), Expanding the criminological imagination: Critical readings in criminology (pp. 168-197). Devon: Willan Publishing.

Stanley, E. (2012). Reisistance to state-corporate crimes in West Papua. In E. Stanley \& J. McCulloch (Eds.), State Crime and Resistance (pp. 84-98). London: Routledge.

Sunstein, C. R. (1996). On the expressive function of law. University of Pennsylvania Law Review, 144(5), 2021-2053.

Sunstein, C. (1997). Free markets and social justice. New York: Oxford University Press.

Swiebel, J. (2008). The Montreal Declaration of Human LGBT Rights. In I. Dubel \& A. Hielkema (Eds.), Urgency Required: Gay and lesbian rights are human rights (pp. 235-240). The Hague: Hivos. 
Sykes, G. \& Matza, D. (1957). Techniques of neutralization: A theory of delinquency. American Sociological Review, 664-670.

Tahmindjis, P. (2005). Sexuality and international human rights law. In H. Graupner \& P. Tahmindjis (Eds.), Sexuality and human rights: A global overview (pp. 9-30). Binghamton, New York: Harrington Park Press.

Tatchell, P. (2004, October 4). Black and gay and hunted. New Statesman. Retrieved from: http://www.newstatesman.com/node/148995. 24 October, 2012.

Thomas, K. (1992). Beyond the privacy principle. Columbia Law Review, 92(6), 14311516.

Thompson, C. (2007, August 7). Curbing homophobia in reggae. TIME Magazine. Retrieved from: http://www.time.com/time/arts/article/o,8599,1650585,00.html. 8 January, 2013.

Thoreson, R. \& Cook, S. (2011). Nowhere to turn: Blackmail and extortion of LGBT people in Sub-Saharan Africa. New York: IGLHRC.

Tomsen, S. (2009). Violence, prejudice and sexuality. London: Routledge.

Tonkiss, F. (1998). Analysing discourse. In C. Seale (Ed.), Researching society and culture (pp. 245-260). London: SAGE.

Turner, M. (1998). Slaves and missionaries: The disintegration of Jamaican slave society 1787-1834. Kingston: The University of West Indies Press.

UN. (2012). Democracy. Retrieved from:

http://www.un.org/en/globalissues/democracy/. 20 September, 2009.

UNGA. (1948, December 10). Universal Declaration of Human Rights. New York: UNOHCHR.

UNGA. (1966, December 16). International Covenant on Civil and Political Rights. New York: UNOHCHR.

UNGA. (1969, May 23). Vienna Convention on the Law of Treaties. New York: UNOHCHR.

UNGA. (2008a). Letter dated 18 December 2008 from the Permanent Representatives of Argentina, Brazil, Croatia, France, Gabon, Japan, the Netherlands and Norway to the United Nations addressed to the President of the General Assembly. New 
York: United Nations General Assembly.

UNGA. (2008b). General Assembly adopts 52 resolutions, 6 decisions recommended by Third Committee on wide range of human rights, social, humanitarian issues. UN doc, GA/10801, 18 December, 2008.

UNGA. (2010). Confront prejudice, speak out against violence, Secretary-General says at event on ending sanctions based on sexual orientation, gender identity. UN doc, HR/5043, 10 December, 2010.

UNOHCHR. (2008). Working with the United Nations human rights programme: A handbook for Civil Society. New York: UNOHCHR.

UNOHCHR. (2012). Born free and equal: Sexual orientation and gender identity in international human rights law. New York: UNOHCHR.

UNOHCHR. (2013). Special procedures of the Human Rights Council. Retrieved from: http://www.ohchr.org/EN/HRBodies/SP/Pages/Welcomepage.aspx. 20 March, 2013.

Utech to punish students involved in chase of 'gay' colleagues. (2012, November 7). Jamaica Observer. Retrieved from: http://www.jamaicaobserver.com/news/UTech-to-punish-students-involved-inchase-of---gay-colleagues\#ixzz2CL8swtMV. 15 November, 2012

Waaldijk, K. (1994). Standard sequences in the legal recognition of homosexuality: Europe's past, present and future. Australasian Gay and Lesbian Law Journal, $4(1), 50-74$.

Waites, M. (2009). Critique of 'sexual orientation' and 'gender identity' in human rights discourse: Global queer politics beyond the Yogyakarta Principles. Contemporary Politics, 15(1), 137-156. doi.: 10.1080/13569770802709604.

Walker, K. (2004, February 19). Father encourages students to maul 'gay' son at Dunoon Tech. The Jamaica Observer. Retrieved from: http://www.jamaicaobserver.com/news/55968 Father-encourages-students-tomaul--gay--son-at-Dunoon-Tech\#ixzz2CL5YCBRM. 15 November, 2012

Walker, K. (2007, February 15). Cops save three alleged homosexuals from angry crowd. The Jamaica Observer. Retrieved from: http://www.jamaicaobserver.com/new/119155 Cops-save-three-allegedhomosexuals-from-angry-crowd\#xzz2CL7LI7A1. 15 November, 2012. 
Walker, K. (2012, July 8). Gay lobby claims not true, says Green. The Jamaica Observer. Retrieved from: http://www.jamaicaobserver.com/news/Gay-lobbyclaims-not-true--says-Green. 22 January, 2013.

Ward, T. (2007). State harms. In P. Hillyard, C. Pantazis, S. Tombs \& D. Gordon (Eds.), Beyond criminology: Taking harm seriously (pp. 84-100). London: Pluto Press.

Ward, T., \& Green, P. (2000). Legitimacy, civil society and state crime. Social Justice, 27(4), 76-93.

Weeks, J. (2003). Sexuality (2 ${ }^{\text {nd }} E d$ ). London: Routledge.

Weisberg, R. (1992). Private violence as moral action: The law as inspiration and example. In A. Sarat \& T. R. Kearns (Eds.), Law's Violence (pp. 175-210). Ann Arbor, Michigan: University of Michigan Press.

White, R. \& Carr, R. (2005). Homosexuality and HIV/AIDS stigma in Jamaica. Culture, Health and Sexuality, 7(4), 347-359. doi: 10.1080/13691050500100799.

Wilets, J. D. (1997). Conceptualizing private violence against sexual minorities as gendered violence: An international and comparative law perspective. Albany Law Review, 6o(3), 989-1050.

Williams, L. (2000). Homophobia and gay rights activism in Jamaica. Small Axe, 7, 106111.

Wodak, R. (2004). Critical discourse analysis. In C. Seale, G. Gobo, J. Gubrium \& D. Silverman (Eds.), Qualitative Research Practice (pp. 197-213). London: Sage Publications.

Younge, G. (2006, April 27). Troubled Island. The Guardian, p. 6. 